\title{
Efficacy of Behavioral Interventions for Young Children with Autism Spectrum Disorders: Public Policy, the Evidence Base, and Implementation Parameters
}

\author{
Raymond G. Romanczyk • Emily H. Callahan • \\ Laura B. Turner • Rachel N. S. Cavalari
}

Received: 22 May 2014 / Accepted: 23 May 2014 / Published online: 27 June 2014

(C) Springer Science+Business Media New York 2014

\begin{abstract}
The complex and extensive deficits associated with Autism Spectrum Disorders, in concert with the substantial increase in prevalence over the last three decades, combine to present a challenge to individuals, families, communities, and government that has few parallels. This challenge is complicated by debate among service providers concerning appropriate treatment approaches and the evidence for efficacy. Within this backdrop, numerous healthcare reform initiatives have included coverage for Autism Spectrum Disorders, both enhancing and complicating the role of public education in the mix of provision of appropriate services. Basic principles of limited resources and expenditure accountability require that standards of care and evidence-based procedures be established and agreed upon. While this approach is common in health insurance policies and procedures, it is less so in public
\end{abstract}

R. G. Romanczyk $(\bowtie) \cdot$ L. B. Turner

Department of Psychology, State University of N.Y. at Binghamton,

Binghamton, NY 13902-6000, USA

e-mail: rromanc@binghamton.edu

L. B. Turner

e-mail: lbturner@usj.edu

E. H. Callahan

Virginia Institute of Autism, 1414 Westwood Rd., Charlottesville,

VA 22903, USA

e-mail: ECallahan@viaschool.org

R. N. S. Cavalari

Institute for Child Development, State University of N.Y.

at Binghamton, Binghamton, NY 13902-6000, USA

e-mail: rstraub1@binghamton.edu

Present Address:

L. B. Turner

University of Saint Joseph, West Hartford, CT 06117, USA education. The purpose of this review is to provide impetus toward guidelines for comprehensive treatment services, as well as individual skill/behavior interventions, with respect to required service provider characteristics, setting, and "dosage" (number of hours per week for a designated time period). Quantitative analysis will permit progress in review panel deliberation for both insurance reimbursement and public services allocation by having appropriate comparisons with which to evaluate progress reported versus progress expected given the specific intervention program being provided.

Keywords Autism spectrum disorder - ASD - Intervention · Evidence based · Efficacy · Dosage · Public policy · School . Insurance

The increasing prevalence of Autism Spectrum Disorders (ASD) over the last few decades has presented both a complex problem with respect to the contributing factors for this increase and a significant and growing challenge for currently inadequate service delivery systems. Beginning in 1980 with the adoption of DSM-III (Diagnostic and Statistical Manual of the American Psychiatric Association) criteria for autism, with an estimated prevalence 4.5 per 10,000 , to the present with estimates of 1 in 68 for children (Centers for Disease Control and Prevention [CDC] 2014), the magnitude of the increase has eluded definitive explanation. Public awareness and demand for information and services has also increased. As one index, the coverage of ASD in the popular press, in this example Time Magazine, has increased from three articles in the 1980s, to 11 in the 1990s, to 73 in the 2000s up to 2008. Such increased awareness has been paralleled by attention from professional groups to detect and treat ASD as early as possible. For example, the American Academy of Pediatrics recommends that children be screened for ASD twice by age three (Myers and Johnson 2007). 
The goal of diagnosis and early identification, aside from needed basic research, is to permit the delivery of effective treatment and services. The timing of treatment and services can be a significant variable, but the most important variable is delivering intervention that has been established as effective through well-conducted, replicated outcome research. It is the evidence base that permits decision-making that reflects the needs of individuals and families, as well as broader society, while balancing the harsh reality of fiscal constraints and service accessibility restrictions.

\section{Establishing the Evidence Base}

The need for a systematized and objective process for establishing treatment effectiveness has a long history (Romanczyk and Gillis 2004; 2008) and only comparatively recently has a tenuous consensus emerged as to the specific process. NoyesGrosser et al. 2005 have outlined the specific methodology appropriate to conducting reviews of the literature in order to establish guidelines for clinical practice. This methodology derives from the Agency for Health Care Policy and Research (AHCPR), established in 1997, and currently designated as the Agency for Healthcare Research and Quality (AHRQ). The AHRQ is part of the US Department of Health and Human Services. In turn, Evidence-based Practice Centers (EPCs) were established. These Centers “ ... develop evidence reports and technology assessments on topics relevant to clinical, social science/behavioral, economic, and other health care organization and delivery issues - specifically those that are common, expensive, and/or significant." (http://www. ahrq.gov/clinic/epc/)

The AHRQ clinical practice guideline methodology uses principles for developing practice guidelines recommended by the US Institute of Medicine (Field and Lohr 1992) and is considered to be the standard for developing evidence-based clinical practice guidelines (Eddy and Hasselblad 1994; Holland 1995; Schriger 1995; Woolf 1991; 1994). This methodology has only comparatively recently been applied to ASD, with the New York State Department of Health (NYSDOH) Early Intervention Program (EIP) the first to use this methodology to develop a series of evidence-based clinical practice guidelines.

When examining review projects that use this type of methodology and are inclusive of the full range of published research using established research methodologies, the outcomes have been remarkably consistent: approaches within the broad family of behaviorally oriented interventions yield significant and consistent results. Examples of such largescale reviews include:

- New York State Department of Health, Early Intervention Program (1999a, b). Clinical Practice Guideline: Guideline Technical Report. Autism/Pervasive
Developmental Disorders, Assessment and Intervention for Young Children (Ages 0-3 Years), no. 4217, NYS Department of Health, Albany, NY.

- National Research Council (2001a, b). Educating Children with Autism. Washington DC: National Academy Press.

- National Autism Center. (2009). National Standards Report: National Standards Project-Addressing the need for evidence-based practice guidelines for autism spectrum disorders. Randolph, MA: National Autism Center, Inc.

- Missouri Department of Mental Health (2012). Autism Spectrum Disorders: Guide to Evidence-based Interventions. http://www.autismguidelines.dmh.mo.gov/

Despite the extensive literature base and available guidelines, there remains general disarray concerning intervention recommendations and preferences in the broad field of ASD. Some of this disarray is attributable to changing diagnostic criteria, poor diagnostic reliability, and the range of expression of autism spectrum disorders, (Lord et al. 2011; Lord and Jones 2012; Romanczyk and Callahan 2012), but is secondary to the treatment literature base. Clearly, the presence of wellconducted research studies, academic literature reviews, and practice guidelines has been insufficient to promote adoption, as hundreds of non-empirically based treatments continue to be popular and widely used (Romanczyk et al. 2014). Romanczyk and Gillis (2008) present an analysis of over 400 purported treatments culled from a sample of web sites, and indicate that less than $2 \%$ have strong outcome research evidence.

The first practice guidelines specific to behavioral intervention for ASD in the context of health insurance coverage were recently published (Behavior Analyst Certification Board [BACB] 2012). These guidelines provide an unprecedented level of specificity regarding treatment program characteristics and clinical service delivery, but primarily constitute a consensus document that makes reference to a selected bibliography and does not address specific issues of procedure and "dosage" (number of hours per week for a designated time period).

The purpose of our review is to tie the published research literature to functional practice guidelines that address the relationship of specific clinical problems in individuals with ASD to procedure, dosage, and outcome probabilities, all within the context of existing service delivery systems that engage in resource allocation. This is done in two parts. The first addresses service delivery system issues and the second the evidence base and analysis of cost-benefit.

\section{Part 1-The Service Delivery System}

Educational Requirement vs. Medically Necessary Treatment

In the context of providing federally mandated education services (FAPE—Free appropriate education) for all children, 
and needed intervention for ASD as a specific disorder in the perspective of an evolving set of diagnostic criteria [DSM 5] (2013, Diagnostic and Statistical Manual of the American Psychiatric Association, Fifth Edition), confusion can result with respect to separating broad child education needs from the characteristics of this heterogeneous disorder. The current diverse process by which educational and medical services are "divided" among parties, such as caregivers, school district, and an insurance carrier, adds inconsistency to the provision of services.

From the educational perspective, federal mandate for FAPE is of course within an education rather than clinical context. Statements such as: "The Section 504 regulation requires a school district to provide a "free appropriate public education" (FAPE) to each qualified person with a disability who is in the school district's jurisdiction, regardless of the nature or severity of the person's disability." makes it clear that severity is not a delimiting characteristic. However, statements such as: "An appropriate education may comprise education in regular classes, education in regular classes with the use of related aids and services, or special education and related services in separate classrooms for all or portions of the school day. Special education may include specially designed instruction in classrooms, at home, or in private or public institutions, and may be accompanied by related services such as speech therapy, occupational and physical therapy, psychological counseling, and medical diagnostic services necessary to the child's education..." are complex and less clear (http://www2. ed.gov/about/offices/list/ocr/docs/edlite-FAPE504.html). While implying the role of medical services and specifying service providers who often fall under the umbrella term of medical provider with respect to insurance coverage, by not explicitly including the generally accepted term "medically necessary" services, room for substantial interpretation exists.

It is important to note that in this context, "medically necessary" does not necessarily imply services delivered solely by a physician, but rather may include services from a range of professionals, including behavior analysts, psychologists, speech-language pathologists, etc. The complexity increases when discussing the needs of an individual with a pervasive developmental disorder that affects many areas of functioning. Some of the arguably needed services, such as intervention for debilitating stereotyped behavior, or learning play skills with a sibling, or reducing excessive fear responses to environmental stimuli, do not fall cleanly in some definitions of educational necessity vs. medical necessity. In some ways, what is considered appropriate educational services and appropriate medical services has expanded, but gaps nevertheless remain. It is also important to note that these distinctions are independent of the particular type of service provider. As an example, a clinical psychologist may provide services under the auspices of a particular school district for a child's "educational program" as defined in the Individualized Education Plan, but as likely could provide the same services in a private practice setting under the child's health insurance coverage, depending on the specific policies of the insurance carrier.

Thus, the distinction between educational needs and medical needs can blur in the case of ASD. Some examples are clear, such as a child with adequate eyesight who needs to be taught to read compared to a child with a severe vision problem that requires medical intervention. One perspective that also can cause confusion is the philosophical position that education is provided to all children independent of whatever disorder they may experience and the position that given the presence of a medical disorder (as defined as being a recognized DSM disorder), all services needed to address the disorder's impact are medically necessary. Such "absolute" positions do little to advance solutions to the complex problem of resource allocation and coordination of services.

We would argue that disorders do not define people and also that choosing not to acknowledge the influence of a disorder does not diminish its impact on the individual. The allocation of resources to address a need should be based on objective criteria rather than fluctuating positions grounded in changing philosophy or rigid, arbitrary definitions. However, a central problem is that resource allocation is often tied to specific bureaucratic structures that have at times arbitrary and/or poorly defined distinctions imposed such as "medical" versus "educational". Ideally, the focus should be on what is therapeutic and skill/knowledge enhancing for the individual. But given the entrenched structures that provide services, the requirement for such distinction between what are educational services and medical services will persist.

Within this context of existing structures and existing federal law concerning the right to FAPE for all children, a broadly accepted definition of what are "educational services" and what are "medical services" for individuals with ASD is needed. Adding to the complexity, individual state education departments adopt regulatory definitions of educational classifications, while the diagnostic process currently predominantly uses the criteria in the DSM. Thus, a given state education department may have a definition of autism as an educational classification which differs from the current DSM, and may or may not require a formal DSM diagnosis. These state definitions are not consistent across states and states also vary as to what classifications they utilize (http://ectacenter. org/partc/statepolicies.asp). For instance, New York utilizes 13 educational classifications, Massachusetts 10, and Colorado 14.

As examples, in New York the educational classification of autism is defined as:

(1) Autism means a developmental disability significantly affecting verbal and nonverbal communication and social interaction, generally evident before age 3 , that adversely affects a student's educational 
performance. Other characteristics often associated with autism are engagement in repetitive activities and stereotyped movements, resistance to environmental change or change in daily routines, and unusual responses to sensory experiences. The term does not apply if a student's educational performance is adversely affected primarily because the student has an emotional disturbance as defined in paragraph (4) of this subdivision. A student who manifests the characteristics of autism after age 3 could be diagnosed as having autism if the criteria in this paragraph are otherwise satisfied. (REGULATIONS OF THE COMMISSIONER OF EDUCATION, Pursuant to Sections 207, 3214, 4403, 4404 and 4410 of the Education Law, PART 200 Students with Disabilities).

Whereas in California, the educational classification for autism is defined as:

56846.2 (a) For purposes of this chapter, a "pupil with autism" is a pupil who exhibits autistic-like behaviors, including, but not limited to, any of the following behaviors, or any combination thereof:

(1) An inability to use oral language for appropriate communication.

(2) A history of extreme withdrawal or of relating to people inappropriately, and continued impairment in social interaction from infancy through early childhood.

(3) An obsession to maintain sameness.

(4) Extreme preoccupation with objects, inappropriate use of objects, or both.

(5) Extreme resistance to controls.

(6) A display of peculiar motoric mannerisms and motility patterns.

(7) Self-stimulating, ritualistic behavior.

California Education Code, TITLE 2. ELEMENTARY AND SECONDARY EDUCATION [33000-64100], DIVISION 4. INSTRUCTION AND SERVICES [4600064100], PART 30. SPECIAL EDUCATION PROGRAMS [56000-56865], CHAPTER 7.5. Autism Training and Information [56846-56847] (Chapter 7.5 added by Stats. 2006, Ch. 783, Sec. 1.)

We then add to this mix the definition of special education, as that is the system through which many children with ASD receive services. The federal government defines special education as:

TITLE I - AMENDMENTS TO THE INDIVIDUALS WITH DISABILITIES EDUCATION ACT. Regulations: Part 300/A/300.39
Special education.

(a) General.

(1) Special education means specially designed instruction, at no cost to the parents, to meet the unique needs of a child with a disability, including:

(i) Instruction conducted in the classroom, in the home, in hospitals and institutions, and in other settings; and

(ii) Instruction in physical education.

(2) Special education includes each of the following, if the services otherwise meet the requirements of paragraph (a) (1) of this section:

(i) Speech-language pathology services, or any other related service, if the service is considered special education rather than a related service under State standards;

(ii) Travel training; and

(iii) Vocational education.

Such a broad definition offers little by way of specifics and mixes the terms "instruction", "services", "training", and "education". Since states are obligated to follow federal education regulations, the operational definition of special education is contained in the Individualized Education Plan (IEP), as is also required by federal regulation. However, since the specific content and breadth of the IEP is not well defined by the federal government, great variation exists from school district to school district and also state-to-state. Not surprisingly, the IEP can become a focal point for disagreement between parent and school district. While precise estimates at a national level are not available, an attempt to analyze impartial hearings (the primary method of resolution in New York) is illustrative. McMahon (2011), through a Freedom of Information Law request to the New York Impartial Hearing Reporting System (IHRS) for the period 2002-2003 to 2009-2010 school years, found that the top three reasons for requesting an impartial hearing was tuition reimbursement to parents for alternate placement/services to public school, determination of appropriate educational program (placement), and the specifics of the IEP/program.

The situation is similar for the term "medical necessity". As stated by the American Academy of Pediatrics "In particular, a much used term - "medical necessity" - is, in fact, generally ill defined." (Long 2013, p 398). Further, in the 906 pages of the 2010 Patient Protection and Affordable Care Act, Public Law 111-148 of the 111th Congress, the term "medically necessary" is not defined. The American Medical Association defines medical necessity as "Health care services or products 
that a prudent physician would provide to a patient for the purpose of preventing, diagnosing or treating an illness, injury, disease or its symptoms in a manner that is: (a) in accordance with generally accepted standards of medical practice; (b) clinically appropriate in terms of type, frequency, extent, site, and duration; and (c) not primarily for the economic benefit of the health plans and purchasers or for the convenience of the patient, treating physician, or other health care provider." (Harmon 2011, p. 3). More recently, the American Academy of Pediatrics has offered the following definition of medical necessity for children: "Hence, the pediatric definition of medical necessity should be as follows: health care interventions that are evidence-based, evidence-informed, or based on consensus advisory opinion and that are recommended by recognized health care professionals, such as the AAP, to promote optimal growth and development in a child and to prevent, detect, diagnose, treat, ameliorate, or palliate the effects of physical, genetic, congenital, developmental, behavioral, or mental conditions, injuries, or disabilities." (Long 2013, p 400). This definition's emphasis on "... promote optimal growth and development ..." would appear to be complementary to the concepts presented above concerning education services, in that it emphasizes preparing the child to benefit from the social, physical, and educational environment.

In the on-going debate about educational requirement vs. medical necessity, it often appears that intent to influence funding decisions is conflated with definition. While the desire to facilitate funding of services is understandable, this leads to ambiguity and confusion among important concepts. Overly broad definitions along the lines of "whatever is necessary" do not aid in resolving a complex societal issue. We propose that symptoms/problems that are contained in the diagnostic criteria be considered those that are medically necessary and specific knowledge/achievement/skill deficits be considered educationally necessary. Such a distinction provides clear, understandable boundaries consistent with the general concept of what is medical and what is educational. However, as in all complex issues, our definition has a degree of artificiality. As an example, insensitivity to social motivation can impede a child's ability to learn simple addition as taught by a teacher in school. One would rarely seek "medical" services to address the specific content of the classroom lessons but may indeed seek such assistance to address poor social motivation. This distinction can blur further depending on the specific professional orientation of the service provider. For example, a Board Certified Behavior Analyst trained specifically to provide services to individuals with ASD would typically have no conceptual difficulty addressing both of these issues. This reflects their training and the underlying intervention principles being utilized. But this is a very different perspective than the one facing bureaucracies - how to determine which aspects of need do schools vs. medical insurance pay for and for how long?

\section{Insurance Coverage and Reimbursement}

A study by the Harvard School of Public Health (Ganz 2007) estimated lifetime care costs of $\$ 3.2$ million for an individual with autism. Total US costs were estimated at $\$ 35$ billion each year at that time. Estimates vary, with total costs possibly several times higher currently. But, because of the size and scope of the insurance programs in the US, according to the Council for Affordable Health Insurance, covering autism increases the cost of health insurance by about only $1 \%$. Once again a caveat is needed as the federal regulations of what must be covered are changing. For example, "habilitation services" is a category of services recognized by the Department of Health and Human Services. Effective 2014, states must specify what they will cover under this category. Clearly regulation and insurance industry policies are a work in progress.

At the time of this review, 36 states in the US and Washington, D.C., have enacted autism insurance reform laws, eight states have bills under review, and one state is pursuing autism insurance reform (Autism Speaks 2014c). Given this, health insurance coverage across the country has undergone revision regarding access to services and reimbursement policies. Although a thorough review of the reimbursement rates for the US would be ideal in determining a "recommended rate" for reimbursement of autism-related services, there are several factors that limit the ability to do so. First and foremost, the three major sources of health insurance coverage (i.e., Medicaid, TRICARE, and private commercial insurance companies) offer various plans that differ with respect to access and coverage of services. Second, reimbursement rates typically vary state-to-state and differ substantially between providers. Finally, institutions can negotiate unique reimbursement rates for services rendered at their facility. For example, one hospital might receive a higher reimbursement rate than another hospital within the same city based solely on negotiation with the providing insurance company. Therefore, an accurate universal analysis of reimbursement rates for autism-related services is not feasible. Instead, we present available data representing maximum service coverage for children from birth through 5 years old for 34 states and the federal district of Washington, DC with active autism insurance reform laws.

Autism Service Coverage in the US As of December 2013, four states (CA, IN, MA, MN) and Washington, DC provided unlimited coverage for applied behavior analysis (ABA) services throughout an individual's lifetime (see Fig. 1). Alaska and Vermont also provided unlimited coverage of costs for ABA, but only to individuals under the age of 21 years old. Similarly, Texas provided unlimited coverage until the age of 10 years old, with annual dollar caps $(\$ 36,000 /$ year) applied thereafter. Other states placed age and dollar caps on ABA 
Fig. 1 State-regulated Insurance Dollar Caps for ABA Services by State for Children Ages 0-5. Adapted from a larger analysis of insurance coverage for ages $0-23$; used with permission of Lorri Unumb, Autism Speaks.

Excludes Oregon due to weekly hour caps as opposed to dollar caps. All bars that reach 75,000 represent unlimited coverage (marked as ceiling by source) for children from birth through age 5 . Gray bars indicate age caps that restrict coverage to certain ages within the range of birth to age 5

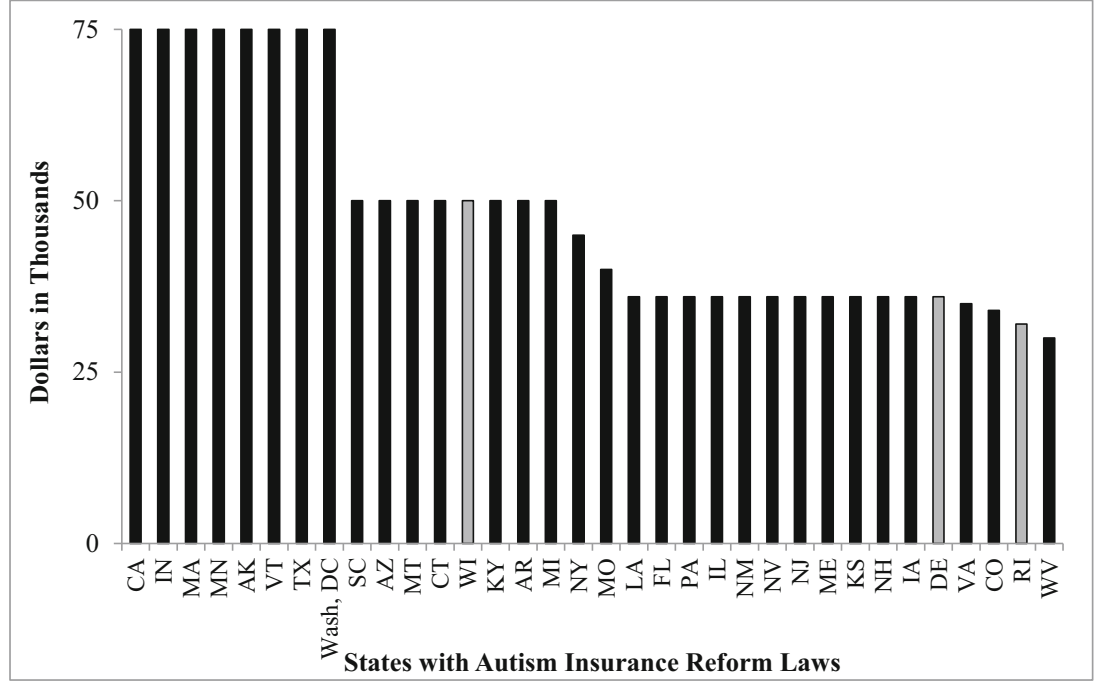

services. Virginia restricted service coverage to children between the ages of 2-6 years old and placed a \$35,000 annual dollar cap on ABA services, while Kentucky set the approved age range between 1 and 21 years old, with dollar caps varying by age $(\$ 50,000 /$ year for individuals $0-7$ years of age; $\$ 1,000$ / month for individuals 7-21 years of age). West Virginia provided $\$ 30,000$ in annual coverage for individuals between 3 and 18 years old, but required that individuals have a diagnosis before the age of 8 years old to qualify. While Oregon did not specify a dollar or age cap, individuals had to begin receiving services before the age of 9 years old and there was an hour cap of $25 \mathrm{~h}$ per week. With that said, $91 \%$ of the states and federal districts represented in this analysis were providing coverage for children from birth through 5 years.

Importantly, half of the states with active insurance reform laws set a cap on annual service coverage at or below $\$ 36,000$. Costs of evidence-based behavioral therapy for children with autism can exceed \$40,000-\$50,000 each year (Berr 2013; National Conference of State Legislatures 2012). Therefore, despite the enactment of autism insurance reform laws, instatement of full coverage for evidence-based services was only available for $30 \%$ of the nation. To provide examples of the substantial differences that existed, we present in detail data from New York and Virginia as two case examples of service reimbursement rate-setting for different regions of the country. Data from New York represent coverage of children from birth through age five with an annual dollar cap that fell within the estimated service cost range noted above. In contrast, data from Virginia represent restricted coverage by age (i.e. 2-6 years old), with an annual dollar cap that fell below the estimated service cost range.

New York State Autism Insurance Reform New York enacted autism insurance reform in November 2011, with provisions effective for state-regulated health plans issued or renewed on or after November 2012. Coverage includes screening, diagnosis, and treatment of autism spectrum disorder, specifying behavioral health treatment such as ABA (Autism Speaks 2013). Effective January 2013, New York State issued an emergency rule (11 NYCRR 440, Entitled Insurance Regulation 201, Provider Requirements for Insurance Reimbursement of Applied Behavior Analysis) to establish standards of professionalism, supervision, and experience for those who provide ABA to individuals with ASD under the new insurance law. According to the text of the rule, ABA services were only reimbursable if provided by a licensed professional who was also a Board Certified Behavior Analyst (BCBA) or an aide who met specific education or experience requirements and was supervised by a licensed professional who is a BCBA. In July 2013, the NY State Department of Financial Services redacted the requirement that a license was necessary to provide ABA services, but maintained the requirement that a licensed provider be responsible for developing the treatment plan.

New York State Early Intervention (EI) Services Rates of service reimbursement for children ages 0-2 years, 11 months are set by the New York State Department of Health Early Intervention Program (NYSEIP). These service rates are used for both Medicaid and private commercial insurance reimbursement. Services are typically reimbursed on an hour per day service delivery schedule, per type of service. However, extended and enhanced service rates are available in cases in which the need for more intensive or extended duration of services is evident. Individual service rates are provided for home/community and facility-based services, while group rates are provided for parent-child, basic and enhanced developmental, and family/caregiver support groups. There are also higher rates for services requiring a 1:1 Aide. Additionally, although rarely used by agencies at the present time, the NYSEIP has provided an hourly rate of reimbursement for ABA Aide services. Notably, reimbursement rates are set at 
the county level, so there is significant variation across the state in terms of cost per intervention. The present range and average early intervention service reimbursement rates for 58 of the 62 counties in New York State, as posted on the NYSEIP website, are displayed in Fig. 2.

Services provided within the categories displayed in Fig. 3, with the exception of ABA Aide, include special education instruction, related services (speech, occupational, physical therapy), and family training and support. Services can only be provided by licensed, certified, or registered individuals approved by New York State. Hourly direct individual service reimbursement rates range between $\$ 38$ and $\$ 75 / \mathrm{h}$, with extended services falling between $\$ 85$ and $105 / \mathrm{h}$. Direct group services are reimbursed at rates between $\$ 35$ and $\$ 71 / \mathrm{h}$, with addition of a 1:1 Aide increasing rates to $\$ 79$ and $\$ 123 / \mathrm{h}$. Direct services to the parent and child for the purposes of training and intervention are reimbursed at rates between $\$ 42$ and $\$ 57 / \mathrm{h}$. Notably, ABA Aide hourly services represent the lowest reimbursed rates (\$24-\$38/h), which are parallel only with Family/Caregiver Support group services that serve as indirect support of the targeted child by supporting parents, caregivers, or siblings.

New York State Preschool Special Education Services Children between the ages of 3 and 5 years old fall under the service umbrella of preschool services, with reimbursement rates set by the New York State Education Department (NYSED) RateSetting Unit in collaboration with the New York State Department of Health. Services are typically reimbursed on a half-hour per day service delivery schedule, per type of service. Similar to NYSEIP, reimbursement rates are set at the county level and there is significant variation across the

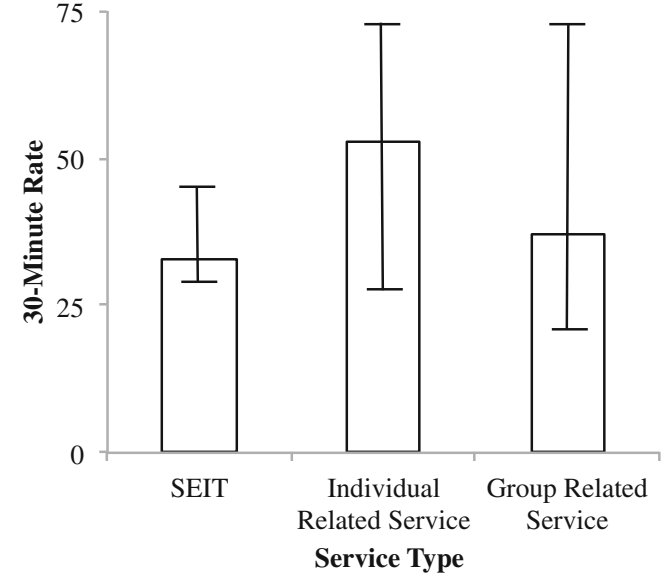

Fig. 3 Mean Half-Hour Rates for Preschool Service ReimbursementNew York State. Range of reimbursement rate across counties depicted by error bars. Data retrieved from http://www.oms.nysed.gov/rsu/Rates Methodology/Rates/NonRSURates/CountyRS201213_000.html and http://www.oms.nysed.gov/rsu/Rates_Methodology/MethodLetters/ CurrentYear/1213metholttr.html

state in terms of cost per intervention. In contrast, the type of services reimbursed may vary across counties and there is no service designation that specifies applied behavior analysis as a reimbursable service. Although there are a wide variety of types of reimbursement, we will limit our review to the services typically approved for children with an ASD. Common service types include occupational therapy, physical therapy, speech therapy, parent counseling and training, counseling services, and psychological services. Similar to EI, NYSED approves preschool programs and related service providers based on criteria related to licensing and certification within the designated professions. Services can also include
Fig. 2 Mean Hourly Rates for EI Service Reimbursement-New York State. Range of reimbursement rate across counties depicted by error bars. Data retrieved from $\mathrm{http}: / / \mathrm{www}$. health.ny.gov/community/ infants_children/early intervention/service rates.htm

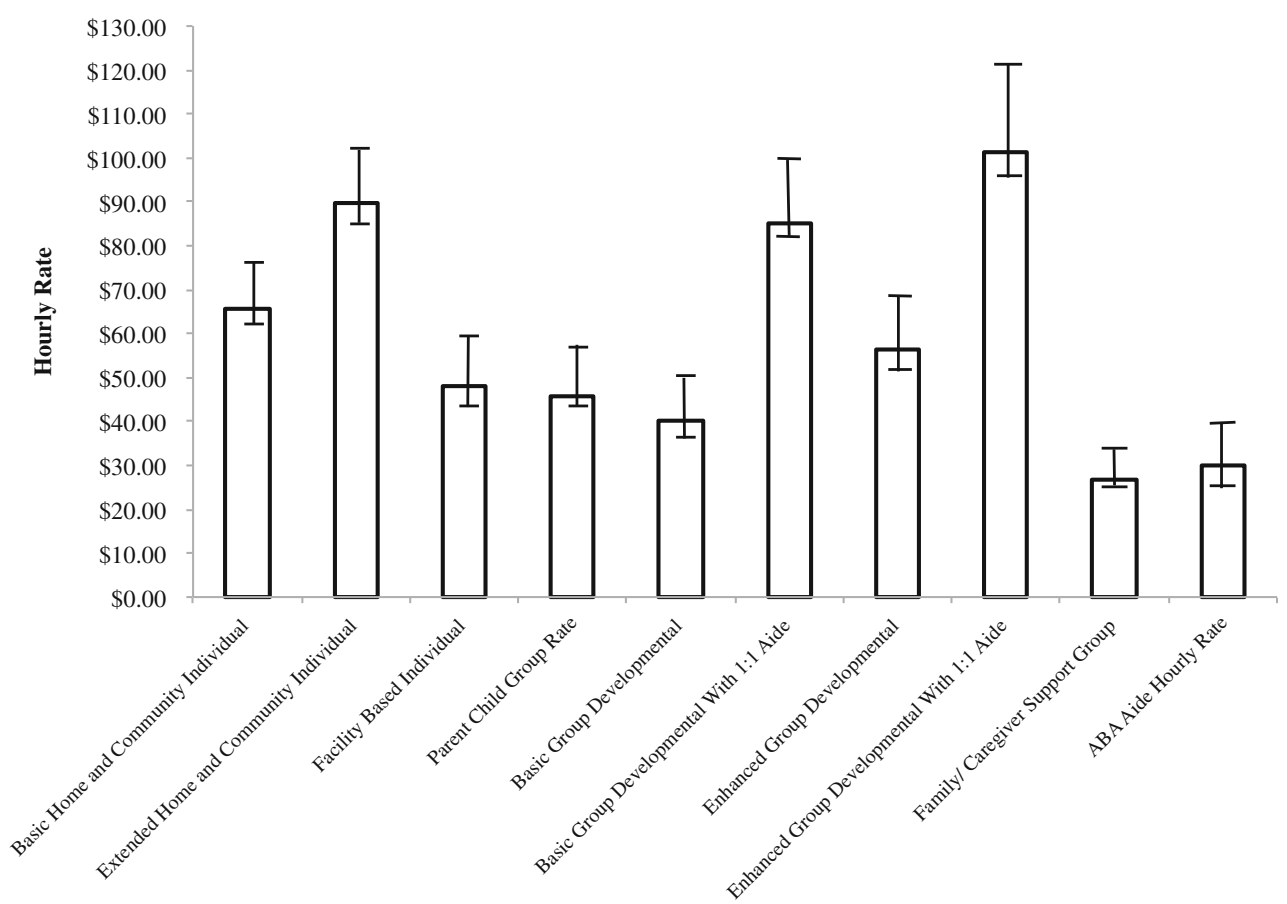


1:1 aides in 49 of the counties, but reimbursement rates are significantly more variable $(\$ 4 \$ 25, M=\$ 11.35$ per half hour) than other related service rates across counties.

The present ranges and average preschool special education service reimbursement rates for counties in New York State, as posted on the New York State Education Department website, are displayed in Fig. 3.

Data are presented separately for special education itinerant services (SEIT), individual related services, and group related services. Values presented for SEIT and individual related services represent 58 of the 62 counties in New York State. Group related service values were generated from 43 counties, since only this subset lists reimbursement for group services. Data are presented as rates per half hour of service (i.e., standard time unit for preschool special education service reimbursement). For counties with differential rates for each related service type, an average rate was computed for individual and group services within that county in order to calculate the overall average maximum reimbursement for individual and group services. As shown in Fig. 3, the range for SEIT services is between $\$ 30$ and $\$ 47 /$ half hour. Individual related services vary between $\$ 31$ and $\$ 74 /$ half hour and group related services between $\$ 22$ and \$74/half hour. To compare these values to EI reimbursement rates, doubling the average service delivery rate (i.e., full hour service duration) results in \$66 for SEIT, \$106 for individual related services, and $\$ 74$ for group related services per hour.

Virginia Autism Insurance Reform The Commonwealth of Virginia became the 26th state to enact autism insurance reform on May 6, 2011 for plans issued or renewed on or after January 1, 2012 (Virginia House Bill No. 2467 (2011), Amendment in the Nature of a Substitute). The law requires state-regulated large group health plans and the state employee health plan to provide coverage for the diagnosis and treatment of ASD for individuals between the ages of 2 and 6 years. Health insurance companies are required to provide coverage for diagnostic assessments (including neuropsychological evaluations and genetic testing), behavioral health treatments (including ABA), pharmacy care, psychiatric care, psychological care, and therapeutic care (i.e., speech, occupational, and physical therapies as well as clinical social work). Coverage for $\mathrm{ABA}$ is subject to an annual maximum of $\$ 35,000$ and $A B A$ services must be supervised by a BCBA who is licensed by the Virginia Board of Medicine.

Table 1 Virginia Early Intervention Reimbursement Rates. Range of service and reimbursement rates for Part C services in the Commonwealth of Virginia. Data retrieved from: http://infantva.org/documents/ovw-st-ProvBillingReimbursInfoSheet.pdf

\begin{tabular}{|c|c|c|c|}
\hline Service & Location & Provider & Rate (per 15 min unit) \\
\hline \multirow[t]{4}{*}{ Initial Assessment for Service Planning } & \multirow[t]{4}{*}{ Natural environment or center } & Reimbursement category 1 providers & $\$ 37.50 /$ unit \\
\hline & & $\begin{array}{l}\text { Reimbursement category } \\
2 \text { providers }+ \text { dietitians }\end{array}$ & $\$ 27.50 /$ unit \\
\hline & & Audiologists & $\$ 150 /$ assessment \\
\hline & & Physicians & $\begin{array}{l}\text { Negotiated individually } \\
\text { at local level }\end{array}$ \\
\hline \multirow[t]{2}{*}{ Initial or Annual IFSP Meeting } & \multirow[t]{2}{*}{ Natural environment or center } & $\mathrm{RC} 1+$ audiologists & $\$ 37.50 /$ unit \\
\hline & & $\mathrm{RC} 2+$ dietitians & $\$ 27.50 /$ unit \\
\hline \multirow{2}{*}{$\begin{array}{l}\text { Team Treatment activities (more } \\
\text { than one professional providing } \\
\text { services during same session) }\end{array}$} & \multirow[t]{2}{*}{ Natural environment } & $\mathrm{RC} 1+$ audiologists & $\$ 37.50 /$ unit \\
\hline & & $\mathrm{RC} 2+$ dietitians & $\$ 27.50 /$ unit \\
\hline \multirow[t]{2}{*}{ Team meetings (child or family present) } & \multirow[t]{2}{*}{ Natural environment } & $\mathrm{RC} 1+$ audiologists & $\$ 37.50 /$ unit \\
\hline & & $\mathrm{RC} 2+$ dietitians & \$27.50/unit \\
\hline \multirow{4}{*}{$\begin{array}{l}\text { Assessments that are done after the } \\
\text { initial Assessment for Service Planning }\end{array}$} & \multirow[t]{4}{*}{ Natural environment } & $\mathrm{RC} 1$ & $\$ 37.50 /$ unit \\
\hline & & $\mathrm{RC} 2+$ dietitians & $\$ 27.50 /$ unit \\
\hline & & Audiologists & \$150/assessment \\
\hline & & Physicians & $\begin{array}{l}\text { Negotiated individually } \\
\text { at local level }\end{array}$ \\
\hline \multirow{2}{*}{$\begin{array}{l}\text { Group (congregate) early } \\
\text { intervention services }\end{array}$} & \multirow[t]{2}{*}{ Natural environment } & RC $1+$ audiologists & $\$ 25.13 /$ unit \\
\hline & & $\mathrm{RC} 2+$ dietitians & $\$ 18.43 /$ unit \\
\hline \multirow[t]{2}{*}{ Individual early intervention services } & \multirow[t]{2}{*}{ Natural environment } & $\mathrm{RC} 1+$ audiologists & $\$ 37.50 /$ unit \\
\hline & & $\mathrm{RC} 2+$ dietitians & $\$ 27.50 /$ unit \\
\hline \multirow[t]{2}{*}{ Center-based group (congregate) services } & \multirow[t]{2}{*}{ Center } & $\mathrm{RC} 1+$ audiologists & $\$ 7.43 /$ unit \\
\hline & & $\mathrm{RC} 2+$ dietitians & $\$ 5.44 /$ unit \\
\hline \multirow[t]{2}{*}{ Center-based individual services } & \multirow[t]{2}{*}{ Center } & RC $1+$ audiologists & $\$ 22.50 /$ unit \\
\hline & & $\mathrm{RC} 2+$ dietitians & \$16.49/unit \\
\hline
\end{tabular}


Services must be prescribed, provided, or ordered by a licensed physician or psychologist who deems the interventions to be medically necessary. The law does not affect the provision of services to an individual under an individualized family service plan (IFSP), an IEP, or an individualized services plan (ISP).

Virginia Early Intervention Services In the Commonwealth of Virginia, early intervention (EI) services are overseen by the lead state agency, Infant and Toddler Connection. EI service reimbursement rates are set by Infant and Toddler Connection and Medicaid. A range of service providers are reimbursed through the program including physical therapists, occupational therapists, speech therapists, therapeutic recreation specialists, family therapists, music therapists, medical professionals (e.g., nurses and physicians, educators and psychologists). Rates for reimbursement are dependent upon the type of service being provided and the individual providing the service. Reimbursement rates range from $\$ 21.76$ to $\$ 150 / \mathrm{h}$.

Table 1 presents a summary of the services covered and the reimbursement rates. ABA services are not listed as a service covered through EI in Virginia. In fact, the practice manual for EI providers in Virginia states that ABA is not an entitled early intervention service, rather it is a treatment modality and that only entitled services are listed on an IFSP. While an EI provider may be trained in behavior analysis, those services would not be listed as ABA on an IFSP and would not be reimbursed under a separate rate.

Reimbursement category 1 (RC 1) providers are physical therapists, occupational therapists, speech-language pathologists, nurses (registered nurses or nurse practitioners), physical therapy assistants, and occupational therapy assistants. Reimbursement category 2 ( $\mathrm{RC} 2$ ) providers are certified therapeutic recreation specialists, counselors, educators, family and consumer science professionals, family therapists, music therapists, orientation and mobility specialists, psychologists, social workers, early intervention assistants, certified nurse aides, and licensed practical nurses.

While ABA services are not reimbursed through the Virginia EI program, individuals and families can gain access to ABA services through another Medicaid program, the Early Periodic Screening Diagnosis and Treatment (EPSDT) program. Individuals under the age of 21 years, who are enrolled in Medicaid (through a waiver or due financial status), are eligible to receive services through the EPSDT program. The program covers a range of "medically necessary" services (as determined by physician recommendation and file review) including hearing aids, assistive technology, personal care, nutrition, and behavioral therapy. ABA services provided through the EPSDT program must be supervised by a BCBA or a licensed mental health professional (LMHP). Services must focus on increasing adaptive behaviors and communication and teaching parents and caregivers to implement behavioral techniques.
Interventions that focus on educational skills are excluded from coverage through this program. All EPSDT Behavioral Therapy services are reimbursed at a rate of $\$ 60 / \mathrm{h}$ and cover direct service, parent training, case management, and supervision. Group and center-based services are not covered through the EPSDT program. Services are generally authorized for a duration of 6 months, at which point the service provider would need to send a request to continue services including an updated treatment plan and progress summary. While the EPSDT program allows a number of families to access ABA services, gaining access to them is often difficult. Getting an individual onto a Medicaid waiver can be a long and arduous process. And once an individual is on a waiver, finding a provider with the expertise and license to provide the services can be difficult.

The Affordable Care Act Based on generally accepted research-based estimate of the number of hours identified as necessary for significant clinical impact (addressed later in this review), the approved service duration and reimbursement rates detailed above are clearly not sufficient to meet evidence-based service requirements. Further, only a third of the country had autism insurance reform laws that provided coverage for ABA services within the estimated range for annual service costs through 2013. The Patient Protection and Affordable Care Act (PPACA), signed into law in March 2010, set January 2014 as a major turning point in healthcare reform for children with autism and their families. While some variability is dependent upon a family's circumstances, there are several provisions that have changed the definition of covered services. First and foremost, Autism Spectrum Disorder, often classified as a pre-existing condition, can no longer be grounds for exclusion or denial of coverage for treatment (Autism Speaks 2014b). Coverage for young children with autism and their families now also includes a set of "essential health benefits," including behavioral health treatment, habilitative services, prescription medication, and pediatric services (Autism Speaks 2014a). Additionally, coverage now has no lifetime or annual dollar caps, there are annual limits on out-of-pocket costs for families, and preventive services, including early childhood screening, are now covered without copays or deductibles (Autism Speaks 2014a). However, there are now visit caps on services (Autism Speaks 2014a). Given the evolving nature of healthcare and importance of addressing the significant public health burden of ASD, specific definitions of appropriate services are necessary to provide insurance companies, service agencies, individual practitioners, and community stakeholders with a starting point for establishing criteria for coverage. Central to this effort is the need to establish the boundaries of evidence-based services that warrant coverage due to demonstrated impact through controlled research. As indicated earlier in this manuscript, thus far, data overwhelmingly support the use of behaviorally oriented treatments in establishing best outcomes for individuals with ASD. 


\section{Part 2-The Evidence Base and Cost-Benefit}

Basic Principles of Behavioral Interventions

Before discussing the data collection procedures and analysis, it is important to establish a definition of what behavioral interventions are. "Behavioral" refers to an approach to therapy and education that draw upon core scientific principles of how people learn and adapt. These interventions are derived from research on basic principles of learning, retention, and generalization of learned skills. Behavioral interventions draw upon extensive research on learning principles that emphasize the antecedents and precursors of behavior, the topography of behavior, and its adaptability to the social and physical environment. The social and physical environment in turn provides simple and complex stimuli and simple and complex reactions to behavior. Additionally, behavioral interventions focus on the function of behavior in order to understand how it is acquired, maintained, and sometimes lost. Further, the teaching of new skills typically involves an analysis of the many component parts of complex behaviors involving communication, emotional development, social development, independence, physical status, and knowledge.

Within the family of behavioral interventions, terms describing specific, well-established disciplines include ABA, behavioral medicine, behavior therapy, and cognitive behavior therapy. The emphasis in these areas rests upon an evidence-based approach and focus on:

- An understanding of the individual's skill assets and deficits, as well as their physical/developmental/medical status

- Teaching skills that promote independence

- An emphasis on developing adaptive behavior and skills

- Sensitivity to the social and physical environment of the individual

- Thorough assessment prior to intervention to identify the relationship between a behavior and the environment in which it occurs

- An individualized treatment plan that is linked to the results of the assessment

- Clear identification of treatment goals

- Objective quantification of outcomes

Behavioral interventions are highly individualized and incorporate developmental, medical, and situational factors, and also caregiver (and when appropriate, client) perspectives and needs in goal selection and treatment planning.

\section{Data Collection Procedures}

For this review, articles describing the use of behavioral interventions with individuals with ASD under the age of five that were published between January 2000 and June 2013 were selected. Similar to the process employed by the New York State Department of Health in 1999, the collection and review of articles was a three-step process involving an extensive literature search, a screening, and an in-depth review. Figure 4 presents a schematic of the process.

\section{Literature Search}

A search strategy was developed to identify relevant scientific research on behavioral interventions for children with ASD. For the purposes of this review, ASD was defined as Autistic Disorder, Pervasive Developmental Disorder-Not Otherwise Specified (PDD-NOS) and Asperger's Disorder. Electronic searches were conducted using relevant computer bibliographic databases, which included MEDLINE (a database containing most of the medical literature and much of the psychological literature), PsycINFO (a database covering psychology and social science literature), and ERIC (a database of literature on education). These were the same electronic databases used to collect literature for the Clinical Practice Guideline published in 1999 by the NYSDOH. The following search terms and search criteria were used in obtaining the articles:

- Search Terms: Autism, ASD, PDD-NOS, Behavioral Intervention, Behavior Modification, Behavior Therapy, Applied Behavior Analysis

- Date Range: January 2000-June 2013

- Publication Type: Peer-reviewed journal

- Publication Language: English

- Age: Infancy to 5 years

Additionally, references lists of articles and reports reviewing the efficacy of behavioral interventions for

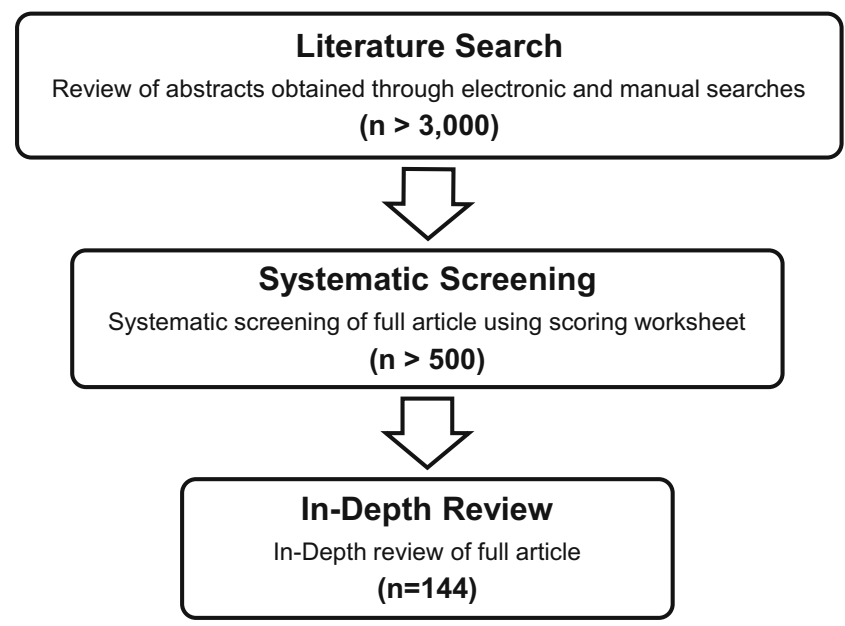

Fig. 4 The three-step process used in the current literature review 
Table 2 Definitions of research focus categories

\begin{tabular}{|c|c|c|}
\hline Research focus & $\begin{array}{l}\text { Research focus definitions } \\
\text { Definition }\end{array}$ & Source(s) \\
\hline Academic & $\begin{array}{l}\text { Interventions focusing on teaching or improving performance } \\
\text { on tasks that are precursors or required for success with school activities. } \\
\text { Dependent variables associated with these tasks include but are not } \\
\text { restricted to preschool activities (e.g., sequencing, color, letter, number } \\
\text { identification, etc.), fluency, latency, reading, writing, mathematics, science, } \\
\text { history, or skills required to study or to improve performance on }\end{array}$ & NAC Standards Report (pg. 34) \\
\hline Behavior reduction & $\begin{array}{l}\text { Assessments and intervention strategies designed to decrease inappropriate } \\
\text { behaviors. This may include functional analyses to determine the function } \\
\text { of the behaviors, the use of differential reinforcement of appropriate behaviors } \\
\text { and/or punishment of inappropriate behaviors. }\end{array}$ & $\begin{array}{l}\text { DOH Technical Guidelines } \\
\text { Report (pg. IV-35) }\end{array}$ \\
\hline Cognitive & $\begin{array}{l}\text { Interventions focusing on improving tasks that require complex problem-solving } \\
\text { skills outside of the social domain. Dependent variables associated } \\
\text { with these tasks include but are not limited to critical thinking, IQ, problem } \\
\text { solving, working memory, executive functions, organizational skills, and } \\
\text { theory of mind tasks. }\end{array}$ & NAC Standards Report (pg. 36) \\
\hline Communication & $\begin{array}{l}\text { Interventions focusing on the functional use of language (such as the use of } \\
\text { language in context, including implicit and explicit communicative intent; } \\
\text { nonverbal communication such as intonation, communicative gestures, } \\
\text { and facial expressions; and social aspects of communication such as } \\
\text { turn-taking). The systematic means of communication may involve the } \\
\text { use of sounds, symbols, signs, or a combination of the three. Dependent } \\
\text { variables associated with these tasks include but are not restricted to requesting, } \\
\text { labeling, receptive, conversation, greetings, nonverbal, expressive, syntax, } \\
\text { speech, articulation, discourse, vocabulary, and pragmatics. }\end{array}$ & $\begin{array}{l}\text { DOH Technical Guideline } \\
\text { Report } \\
\text { (pg. IV-41) NAC Standards } \\
\text { Report (pg. 36) }\end{array}$ \\
\hline Comprehensive & $\begin{array}{l}\text { Comprehensive programs involve a combination of applied behavior analytic procedures } \\
\text { (e.g., discrete trial, incidental teaching, etc.). These interventions may be delivered in a } \\
\text { variety of settings (e.g., home, self-contained classroom, inclusive classroom, community) } \\
\text { and involve a low student-to-teacher ratio (e.g., } 1: 1) \text {. These treatments generally have } \\
\text { the following characteristics }\{\text { a }\} \text { target the defining symptoms of ASD }\{b\} \text { have treatment } \\
\text { manuals, }\{c\} \text { providing treatment with a high degree of intensity, and }\{d\} \text { measure the } \\
\text { overall effectiveness of the program. }\end{array}$ & NAC Standards Report (pg. 46) \\
\hline Daily living & $\begin{array}{l}\text { Interventions focusing on tasks that involve teaching or improving performance on } \\
\text { activities that are embedded in everyday routines. Dependent variables associated with these } \\
\text { tasks include but are not restricted to dressing, cleaning, family and/or community activities, } \\
\text { health and fitness, phone skills, time and money management, and self-advocacy. }\end{array}$ & NAC Standard Report (pg. 37) \\
\hline Feeding & $\begin{array}{l}\text { Interventions focusing on teaching skills associated with appropriate food intake. Dependent } \\
\text { variables associated with feeding interventions include but are not limited to appropriate } \\
\text { use of utensils, acceptance and ingestion of food, and expansion of variety of foods ingested. }\end{array}$ & \\
\hline Play & $\begin{array}{l}\text { Play tasks involve non-academic and non-work related activities that do not involve } \\
\text { self-stimulatory behavior or require interaction with other persons. Dependent variables } \\
\text { associated with these tasks may include but are not limited to functional independent play } \\
\text { (i.e., manipulation of toys to determine how the "work" or appropriate use of toys, games). } \\
\text { Whenever social play was targeted (independently or in conjunction with make-believe play), } \\
\text { it should be included in the "social" category. }\end{array}$ & NAC Standards Report (pg. 37) \\
\hline Sleep & $\begin{array}{l}\text { Interventions focusing on improving difficulties associated with sleep including disordered } \\
\text { sleep patterns, night waking, and difficulty falling asleep common among children with } \\
\text { ASDs. Behavioral interventions include sleep workshops which may provide training to } \\
\text { parents in dealing with difficult sleep behaviors and establishing sleep routines. }\end{array}$ & Vanderbilt Report (pg. 5) \\
\hline Social & $\begin{array}{l}\text { Interventions focusing on improving interactions between two or more individuals. Dependent } \\
\text { variables associated with these tasks include but are not limited to joint attention, friendship, } \\
\text { social and pretend play, social skills, social engagement, social problem solving, and } \\
\text { appropriate participation in group activities. }\end{array}$ & NAC Standards Report (pg. 36) \\
\hline Toileting & $\begin{array}{l}\text { Interventions targeting improving skills associated with toilet training. Dependent variables } \\
\text { associated with these interventions include but are not limited to indicating need to use the } \\
\text { bathroom, keeping dry underwear, using the toilet to urinate, using the toilet to defecate, } \\
\text { and wiping. }\end{array}$ & \\
\hline
\end{tabular}

individuals with ASD (AHRQ 2011; Eikeseth 2008; Eldevik et al. 2009; Howlin et al. 2009; NAC 2009) were manually searched in an attempt to identify studies that might have been missed in the electronic search. 
Over 3,000 articles were found through the electronic and manual searches. Abstracts for all articles were reviewed on the following criteria:

- Focused on a behavioral intervention

- Primary participants have an ASD

- Primary participants 5 years of age or younger

If an article met the above criteria it was obtained and included for screening. If it was unclear whether an article met criteria for screening based on the abstract, it was obtained and included for screening. Of the articles reviewed, over 500 met criteria for formal screening.

\section{Systematic Screening}

The articles identified during the literature search were systematically screened to determine if they met criteria for indepth review. A worksheet outlining the inclusion criteria for in-depth review was completed for each article. This worksheet and the in-depth review criteria were based on the criteria used for the 1999 NYSDOH Clinical Practice Guidelines.

During the screening process, articles were also categorized by "Focus" to evaluate the types of skills the intervention being used in the studies were targeting. A list of the focus categories and their definitions are presented in Table 2.

Articles were divided among three independent raters, with professional training and education in psychology and ASD, for screening. Training on the operational definitions for each of the screening questions and focus categories was conducted and reliability was established prior to the start of screening. In addition, reliability checks were completed for $10 \%$ of all of the articles that were screened in order to maintain calibration between raters.

Following screening, 144 articles met criteria for in-depth review. Table 3 provides a breakdown of those articles by study design and focus category.

\section{In-Depth Review}

The 144 articles identified during the screening process were reviewed further to obtain information about the specific interventions being conducted and the outcomes for participants. A worksheet outlining all of the variables being collected for in-depth review was completed for each article. The variables collected during in-depth review were based on the criteria used for the 1999 NYSDOH Clinical Practice Guidelines and other published reports on evidence-based practices for individuals with ASD (NAC 2009; AHRQ 2011; Reichow 2011). Sixty-five variables were recorded and were divided into two categories, article level and group level. Article level variables were those that pertained to the
Table 3 Articles meeting criteria for in-depth review by focus category and design

\begin{tabular}{lcc}
\hline Intervention focus & Group & Single subject \\
\hline Communication & 8 & 36 \\
Social & 3 & 32 \\
Behavior reduction & 0 & 21 \\
Academic & 0 & 9 \\
Daily living & 0 & 4 \\
Play & 0 & 4 \\
Feeding & 0 & 3 \\
Toileting & 0 & 3 \\
Comprehensive & 17 & 2 \\
Sleep & 0 & 2 \\
Anxiety & 0 & 0 \\
Cognitive & 0 & 0 \\
Total articles by research design & 28 & 116 \\
Grand total of articles for in-depth review & 144 & \\
\hline
\end{tabular}

article as a whole (e.g., design, group assignment method). Group level variables were specific to the focal treatment group $^{1}$ (e.g., number of hours of intervention per week, number of participants per group, outcome). Definitions for the variables were based on the 1999 NYSDOH Clinical Practice Guidelines and other published reports on evidence-based practices for individuals with ASD (NAC 2009; AHRQ 2011; Reichow 2011). Additional variables included the qualifications of the individuals providing direct intervention, the qualifications of the individuals providing either direct supervision or functioning as a "lead" or consulting supervisor, and the length and frequency of the supervision provided.

Outcome strengths were determined by the percentage of children reaching statistical or positive clinical levels of change relative to each study's design methodology. For comprehensive behavioral interventions, meaningful positive clinical changes resulted from, for example, inclusion in a regular education setting, increases in at least a standard deviation on standardized assessments, normative learning rates, or a reduction in ASD symptoms. If data were not available at an individual level, outcome strengths were based on the size of the change relative to reported effect sizes or the quality of the experimental design.

Articles were divided among four independent raters, with professional training in education and psychology and ASD, for review. Training on the operational definitions for each of the in-depth review variables was conducted and reliability was established prior to the start of the review. In addition,

\footnotetext{
${ }^{1}$ To provide consistency in reporting results, for studies using group methodology, only the primary treatment group of interest was reported. That is, control groups or comparison groups were not reported in the following summary tables.
} 
reliability checks were completed for $15 \%$ of all of the articles that were reviewed in order to maintain calibration between raters.

Each of the 144 reviewed studies was evaluated with respect to more than 70 variables of interest. A subset is presented for this review. They are:

1. Hours of intervention received per participant

2. Impact of intervention

3. Efficiency of intervention

4. Type of intervention

5. Intervention setting

6. Type of direct intervention staff

7. Type of supervisor staff

8. Type of lead supervisor staff

9. Group size for intervention sessions

10. Age range of participants

11. Duration (in months) of intervention

12. Intensity of intervention (hours per week)

13. Number of study participants receiving behavioral intervention

The studies are grouped under research design methodology, group design or single-subject methodology design, and then by the specific focus of intervention, comprehensive or specific skill/behavior.

Two variables require further description. Impact was first evaluated by reviewing each study as to the degree to which behavior change occurred as a result of intervention. This was then refined to include an estimation of the clinical impact that would accrue to the participants - that is, the significance of the behavior change as it would affect their overall functioning in concert with the proportion of participants who achieved success. Explicitly, this was a high bar to set, required significant clinical judgment of the imprecise and differing data reporting methods across studies, but was necessary in the context of this review. Thus, it is important to note that a low impact score does not imply a lack of significant or meaningful findings from a research perspective, but rather simply that impact was judged low for the purposes of this specific review. Impact was segmented into ranges. This was an estimate as to the percent of participants that received clinical impact using the following scale:

- Excellent $90 \%$ and above

- Very High 80 to $89 \%$

- High 70 to $79 \%$

- Medium 60 to $69 \%$

- Fair 50 to $59 \%$

- Poor 40 to $49 \%$

- Very Poor 30 to $39 \%$

- Unacceptable less than $30 \%$
This variable, Impact, and intervention session group size was in turn used to calculate Efficiency for intervention using the same scale. This variable was intended to capture an element of "cost-benefit", in that while meaningful clinical change for an individual is the most important outcome variable, doing so with relatively fewer resources per individual outcome is highly valued. Thus, group size during intervention session was factored in with a group size greater than 1 receiving a one step higher tier ranking than if based on Impact alone with 1:1 session group size, and in turn a group size of greater than 3 receiving a two step higher ranking. The same categories as for Impact were used. Ideally, the factor of average total hours of intervention per participant per study would have been utilized in this formulation. However, there was too much inconsistency in reporting to allow this calculation across all studies.

\section{Section 1-Comprehensive Intervention}

There is much support for the effectiveness of comprehensive behavioral interventions for children with ASD (Eikeseth et al. 2002, 2007; Howard et al. 2005; Lovaas 1987; Remington et al. 2007; Sallows and Graupner 2005; Sheinkopf and Siegel 1998). In comparison to skill-based behavioral interventions, the essential elements of a comprehensive behavioral intervention include a wide range of individualized treatment target behaviors across multiple developmental domains and specific areas of deficit (BACB 2012; Howlin et al. 2009). Comprehensive behavioral interventions involve a combination of specific intervention procedures that may be delivered in a variety of settings (e.g., home, self-contained classroom, inclusive classroom, community) and involve a low child-toservice provider ratio (e.g., 1:1). All of the studies falling into this category met the strict criteria of (a) targeting the defining symptoms of ASD, (b) having treatment manuals, (c) providing treatment with a high degree of intensity, and (d) measuring the overall effectiveness of the intervention program.

There are also many different treatment providers and supervisory models, intervention contexts, and intervention intensities utilized when delivering comprehensive behavioral interventions to children with ASD. As indicated by the recent BACB Guidelines for Health Plan Coverage of ABA Treatment for ASD (BACB 2012), a key variable in the effective delivery of comprehensive behavioral interventions is the intensity and duration of the intervention. In general, research has suggested that high intensity (e.g., at least $30 \mathrm{~h}$ per week) interventions are more beneficial than low-intensity interventions (approximately $10 \mathrm{~h}$ per week) (Eldevik et al. 2006). Another key variable is the amount and frequency of individual case supervision as well as the qualifications and experiences of the supervisor. Research has indicated that the intensity of supervision in comprehensive behavioral 
interventions is positively correlated with improvement in children's IQ scores (Eldevik et al. 2009). Comprehensive behavioral programs typically function within a tiered service delivery and supervisory model, with differential insurance reimbursement rates for various service providers. It is therefore important to assess the supervisory resources needed to achieve positive outcomes.

Combining these variables, as well as others such as intervention context and parent involvement, make the large-scale analysis of the effectiveness of comprehensive behavioral interventions very complex. As such, the purpose of this section is to provide a systematic analysis of these variables in relation to impact. Such analysis is essential for the generation of intervention guidelines for comprehensive behavioral intervention with respect to key variables such as service provider characteristics, dosage, and cost-benefit.

Results-Comprehensive Studies Nineteen comprehensive studies met inclusion criteria for this review. Studies were grouped by the type of behavioral intervention provided, and included the Lovaas model (63\%, $n=12)$, Early Start Denver Model $(5 \% ; n=1)$, and the TEACCH model $(11 \% ; n=2)$. Twenty-one percent $(n=4)$ of authors identified their behavioral interventions as "comprehensive". Seventeen of the 19 studies utilized group designs, and two studies utilized singlesubject designs to determine intervention effectiveness. The average number of participants in the group comparison studies was 21.4 (range 12-45), while the single-subject design studies had six participants each. Children ranged in age from 17 to 81 months. Notably, studies in which children began receiving comprehensive behavioral intervention prior to age five were included in this review, even if children were older than age five at the time of the outcome assessment. Forty-two percent $(n=8)$ of studies were conducted across multiple settings. Services were primarily delivered in school settings $(68 \% ; n=13)$ and/or children's homes $(63 \% ; n=12)$. Additional settings included university-based centers $(5 \% ; n=1)$, the community $(5 \% ; n=1)$, and private agencies $(5 \% ; n=1)$.

Table 4 presents the 13 review variables for the 19 studies. Of note is the very high variability of hours of intervention and the clinical impact factor. Inspection of these two variables indicates no significant relationship. Perhaps more striking is that only 2 of the 19 could be classified as having excellent clinical impact. Interestingly, both these studies demonstrated a very high efficiency as well.

Group Size A 1:1 child-to-provider ratio was implemented for at least some proportion of the intervention for nearly all studies, consistent with the recent review by Matson and Jang (2014). In one study, behavioral intervention was provided to children in large groups only and, notably, one study did not indicate group size. However, as can be seen in
Table 4 , it is clearly the case that a 1:1 child-to-provider ratio is the standard in the reviewed literature.

Duration and Dosage The duration of services averaged 21 months, with a range from 3 to 52 months. The intensity of services averaged $24 \mathrm{~h} /$ week with a range from 1.5 to $39 \mathrm{~h} /$ week. Such a range precludes simple summary statements using mean values.

Direct Service Delivery Sixty-three percent $(n=12)$ of studies included more than one type of direct service provider. The majority of direct intervention hours were provided by paraprofessionals $(68 \% ; n=13)$ and/or parents $(68 \% ; n=13)$, with some direct intervention provided by teachers/educators (11 $\% ; n=2)$, and university students $(16 \% ; n=3)$. Two studies did not provide details on the individuals providing direct intervention.

Supervision Specific information regarding the professional qualifications of supervisors was reported in $79 \%(n=15)$ of the comprehensive studies. Most comprehensive studies utilized a hierarchical supervision model in which there was a "direct" and "lead" supervisor. The direct supervisor provided frequent supervision to those directly providing behavioral intervention and was supervised by, or consulted with, the lead supervisor. Figure 5 displays the professional qualifications of both direct and lead supervisors. Between both the direct and lead supervisors, the most frequent professional qualification of the supervisors was a BCBA $(21 \% ; n=8)$, followed by Psychologists $(18 \% ; n=7)$, other Master's level professionals $(16 \% ; n=6)$, and teachers/ educators $(16 \% ; n=6)$. Doctoral level BCBA (BCBA-D) were reported to provide supervision in $8 \%(n=3)$ of comprehensive studies.

Figure 6 displays the professional qualifications of direct supervisors only. BCBAs, teachers/educators, and other masters level professionals ( $24 \%$ each; $n=4$ each) provided the most frequent direct supervision, closely followed by graduate students $(18 \% ; n=3)$.

Psychologists were only reported as direct supervisors in one comprehensive study (6\%); however, psychologists were the most likely type of professional to provide lead supervision (29 \%; $n=6$; see Fig. 7). BCBAs $(19 \% ; n=4)$ and BCBA-Ds $(14 \% ; n=3)$ were the next most likely type of lead supervisor.

Although method sections often included information about who was providing the supervision, information regarding the amount of supervision was not consistently included. Only $42 \%$ reported the amount of supervision provided by direct supervisors, and $26 \%$ reported the amount of supervision provided by lead supervisors. Utilizing the information from these studies, on average, direct supervisors provided $6.25 \mathrm{~h} /$ week of supervision (range 1-20 h/week) and lead 


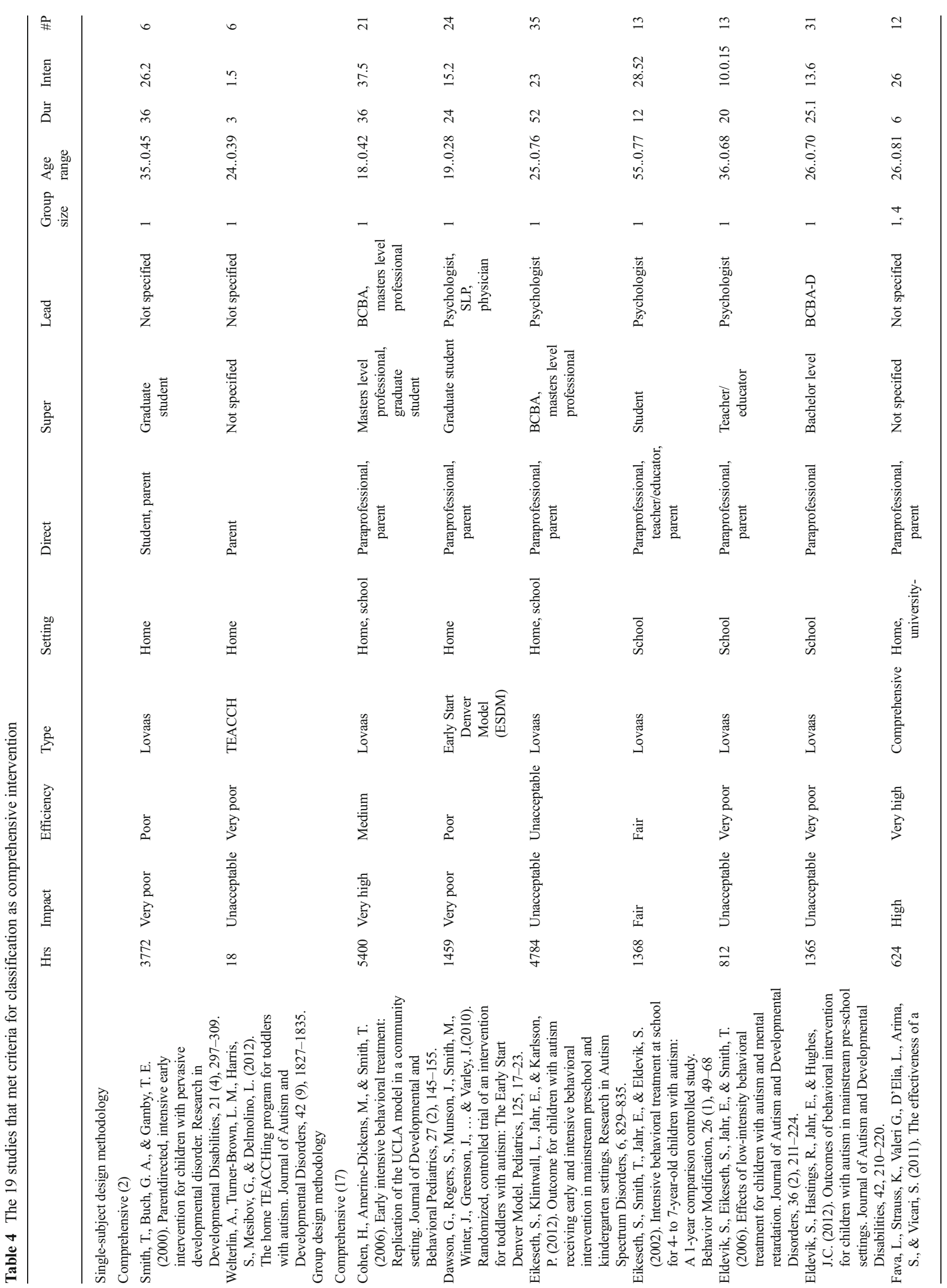




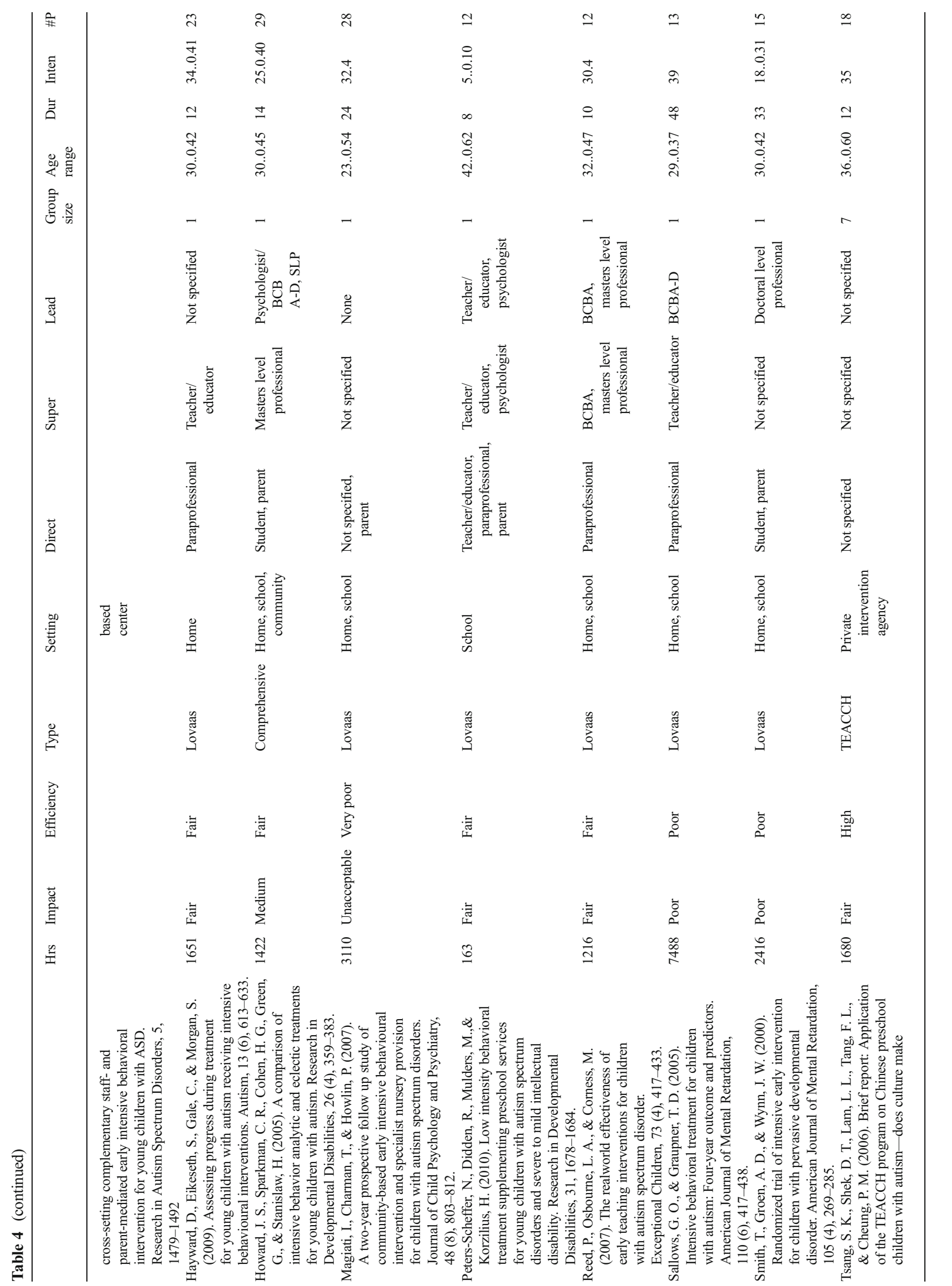


supervisors provided $1.6 \mathrm{~h} /$ week of supervision (range 1-3 h/ week).

\section{Section 2-Skill-Based Interventions}

While comprehensive behavioral interventions have shown to be the most impactful for improving skills and addressing core symptoms of ASD, the large majority of published research has addressed the development of individual skills or skill sets. The information gleaned from such research is critical to identifying the components and intervention strategies that should be included as a part of a comprehensive intervention program. Within this large body of available research, studies were categorized into primary areas of skill development for more directed evaluation. For the purposes of this review, skill-based interventions (i.e., not comprehensive treatments) were grouped into the categories shown in Table 2.

As was done for the comprehensive studies included in this review, information about dosage, intensity, duration, group size, setting, qualifications of interventionists, and qualifications of supervisors was obtained. This section provides an analysis of the information obtained from the skill-based studies and will assist in developing recommendations for intervention guidelines. In addition, these analyses will provide guidance for researchers on key variables to include in written communication about their research methods.

Results-Skill-Based Interventions A total of 125 skill-based studies met the inclusion criteria for this review. The use of single-case methodology dominated the skill-based intervention research. Ninety-one percent of the studies $(n=114)$ utilized a single-case design, and $9 \%(n=11)$ used a group design to evaluate intervention effectiveness. The average number of participants in the single-subject studies was 3.2 (range 1-8). For the group designs, the average number of participants receiving skill-based interventions was 24.5 (range 10-56). Participants ranged in age from 10 months to 144 months. Twenty-eight percent $(n=36)$ were conducted across multiple settings. The majority of the studies had at least some portion of the intervention delivered in a school setting $(58 \% ; n=72)$. At least a third of the studies also had a component of the intervention that took place in the home environment ( $34 \% ; n=43$ ). Additional service settings included hospitals $(2 \% ; n=3)$, research labs $(10 \% ; n=13)$, outpatient clinics $(6 \% ; n=7)$, university-based centers (13\%;n=16), and the community $(4 \% ; n=5)$; see Fig. 8 . As shown in Table 3, communication $(29 \% ; n=36)$, social skills $(26 \% ; n=32)$, and behavior reduction $(17 \% ; n=21)$ were the focus areas with the highest number of published articles meeting the review criteria. Given that these are the three core areas in which many individuals with autism spectrum disorders experience deficits, this result is not surprising. 
Fig. 5 Frequency of direct and lead supervisors reported in comprehensive behavioral intervention studies

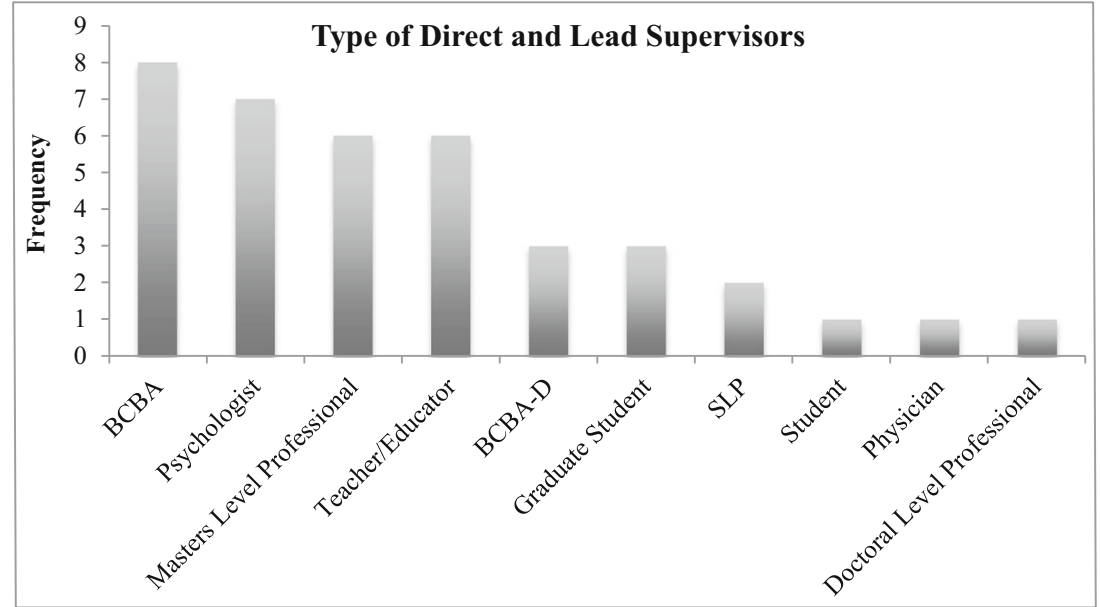

Group Size A 1:1 child-to-provider ratio was implemented for the majority of the skill-based studies reviewed ( $92 \% ; n=$ 115). Of the studies not utilizing a 1:1 ratio, the child-toprovider ratio ranged from 2:1 to 6:1. These results are consistent with the results from the comprehensive studies included in this review.

Duration and Dosage The duration of treatment and intensity (sessions per week) were not consistently specified. The duration of treatment was not reported for $46 \%(n=57)$ and the intensity of treatment was not reported for $38 \%(n=47)$, of the articles reviewed. Of the studies that reported duration of treatment, the average was 2.3 months with a range of less than a week to 12.5 months. For treatment intensity, the average was $2.5 \mathrm{~h} /$ week with a range of less than $15 \mathrm{~min}$ to $27.5 \mathrm{~h} /$ week

Direct Service Delivery In $35 \%(n=44)$ of articles reviewed, the individual providing the treatment was not identified by professional role or attained credentials. Instead, generic terms like "experimenter" and "instructor" were frequently used. When more specific information was provided, $27 \%$ $(n=34)$ of the studies included more than one type of direct service provider. Teachers/educators $(18 \%$; $n=$ $23)$, parents (22\%; $n=28)$ and paraprofessionals $(20 \% ; n=25)$ were most likely to be implementing intervention procedures.

Supervision Specific information about regarding the professional qualifications of supervisors was only provided in $22 \%$ $(n=28)$ of the skills-based articles meeting review criteria. Of the articles that did provide information about supervision, doctoral level professionals $(11 \% ; n=14)$, teachers/educators $(7.2 \% ; n=9)$, and master's level professionals $(6.4 \% ; n=8)$ were most often reported to be providing supervision over the implementation of treatment. Of note and quite puzzling, the lowest frequency of reported supervisors is for BCBA's (see Fig. 9). Even less often than identifying who was providing
Fig. 6 Frequency of direct supervisors reported in comprehensive behavioral intervention studies

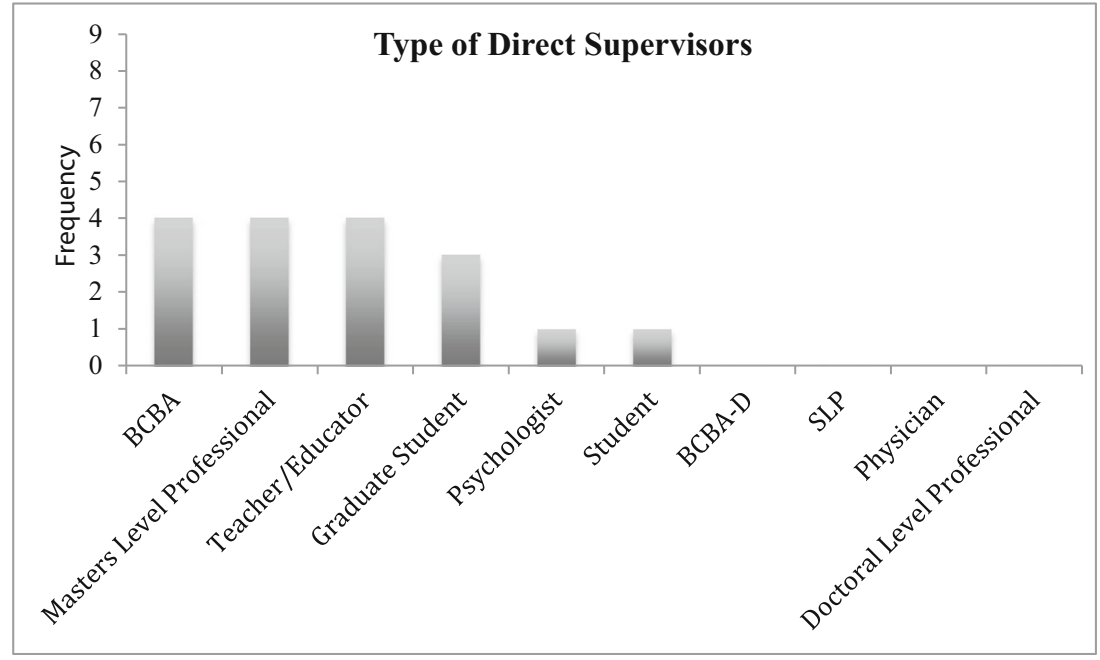


Fig. 7 Frequency of lead supervisors reported in comprehensive behavioral intervention studies

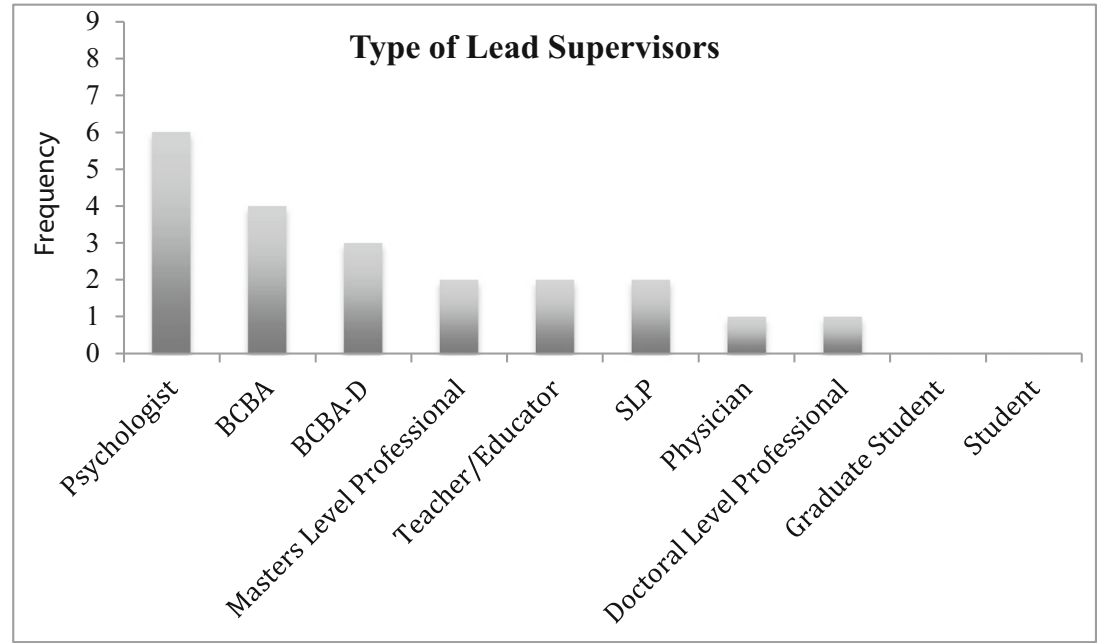

supervision was any information provided about the amount of supervision that occurred. Only five articles of the 125 reviewed provided any information about the duration and frequency of supervision.

\section{Section 3-Evaluation of Impact and Efficiency}

Table 5 presents the studies that were rated as having "Excellent" Impact and "Excellent", "Very High", or "High" Efficiency. Of note, only 1 of the 51 studies was rated as "Excellent" Impact and "Excellent" Efficiency, with 4 rated "Very High", and the remaining 46 rated "High" Efficiency. Given this "high bar" for impact and efficiency, the results are impressive. It is unfortunate, however, that due to lack of detailed reporting in individual studies, total intervention hours per participant could only be estimated for 18 of the 51 studies.
In this select group of 18 studies that allowed estimation of total intervention hours per participant, presented in Table 6, the range was from 1 to $1,366 \mathrm{~h}$. Of particular note is that this very large range was seen for both single-subject methodology as well as group design methodology studies. But, with just one exception, the very high number of hours per participant was associated with comprehensive intervention studies, independent of design methodology.

Even given the limitations because of inconsistent information reporting in published research studies, Table 6 does illustrate the point that with proper development of standards of reporting, compilation of specific intervention procedures that can be evaluated for impact as well as cost-benefit can be achieved. This will allow for more and more fine-grained analyses that incorporate child characteristics, procedural components, level of training/expertise of service provider, and specific levels of impact.
Fig. 8 Frequency of intervention setting for skill-based interventions

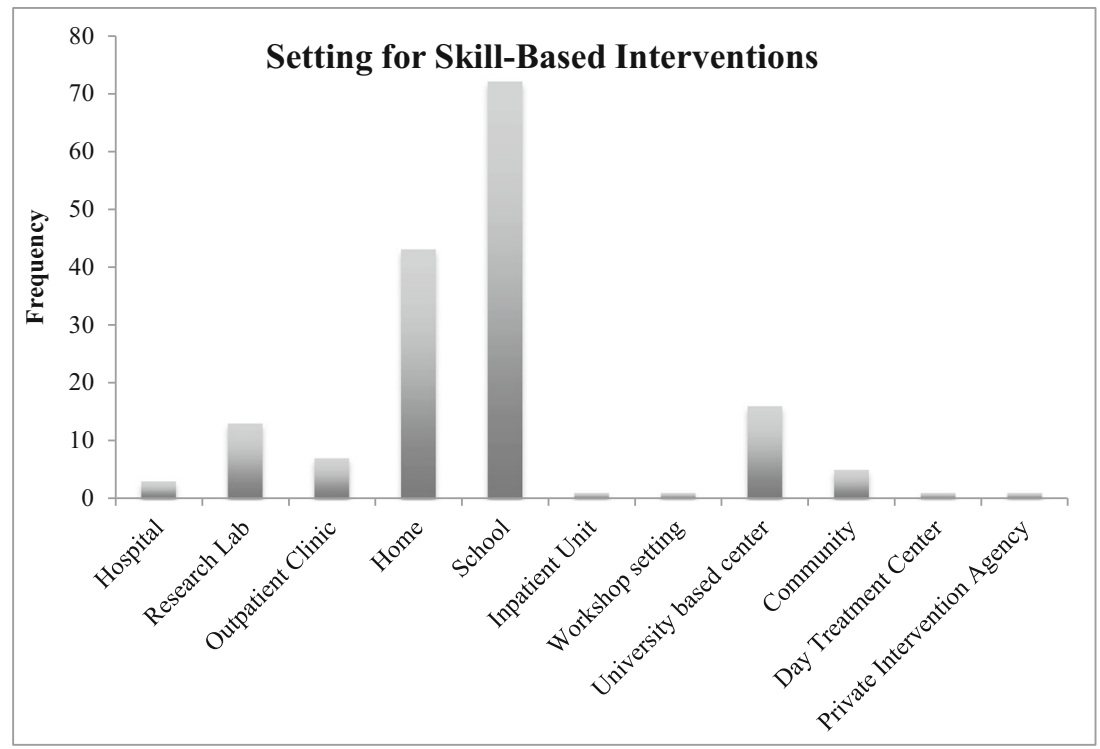




\section{Summary}

Limitations of Published Research

It is clear from both our review and a more general reading of the literature that there is no consensus as to what participant characteristics or intervention parameters should be specified. A previous review and critique of the extant outcome research literature formed the impetus for the current review (Romanczyk 2011). Because of this lack of consensus, reviews, such as the present attempt, must of necessity be "creative" in culling information from research that comes from diverse investigators, intervention approaches, and publication journals, in order to approximate estimates of impact and efficiency. This serious limitation of lack of consensus for reporting variables in the field represents an enormous waste of resources because of inefficiency in aggregating research studies, and in turn squanders valuable time in understanding important variables in effective and efficient intervention. The result of this lack of consensus is that specific and focused analyses across studies are highly limited. Thus, progress in comprehensive analysis across research studies is being made in a slow and disjointed fashion. There are two noteworthy studies, however, that exemplify the approach we propose. Eldevik et al. (2006), (2012), in addition to reporting group outcomes, presented data on the proportion of children making significant vs. clinical gains. This type of data presentation, over time, will enable additional analyses of the impact of behavioral interventions.

The use of generic, or in contrast sub-field idiosyncratic descriptors, in publications is problematic in several ways.
Vague descriptors for treatment providers, such as "experimenter" or "instructor," and use of split descriptors such as "undergraduates/paraprofessionals" limit using the evidence base to establish a level of experience or credential necessary for effective treatment delivery. Additionally, descriptors such as "sessions" or "trials" provide minimal treatment parameters due to the absence of quantitative time duration information regarding intensity and treatment duration. Specifying provider credentials and duration specification are central to furthering research to understand appropriate choice of intervention parameters in applied settings, and would greatly serve the debate as to school districts' and insurance providers' determination of covered services, including the methodology, providers, and dosage required for meaningful impact.

Research has also indicated that certain child characteristics, such as IQ and language level, may be the best predictor of outcome (e.g., Magiati et al. 2007). Unfortunately, given the breadth of the content area, the disappointing lack of standardization, and general low rate of reporting detailed child characteristics, meaningful analyses of such child characteristics in relation to behavioral intervention outcomes could not be conducted in the present review.

\section{Impact Versus Efficiency}

As is apparent in Table 7, the complete listing of all 144 studies, by a very substantial margin, even within comprehensive intervention articles, the most common group size reported is a 1:1 child-to-provider ratio. This places severe constraints on efficiency as defined by utilizing an intervention procedure that does not rely on a $1: 1$ ratio. This pattern of results would seem to confirm the general clinical opinion that
Fig. 9 Frequency of supervisor type for skill-based intervention studies

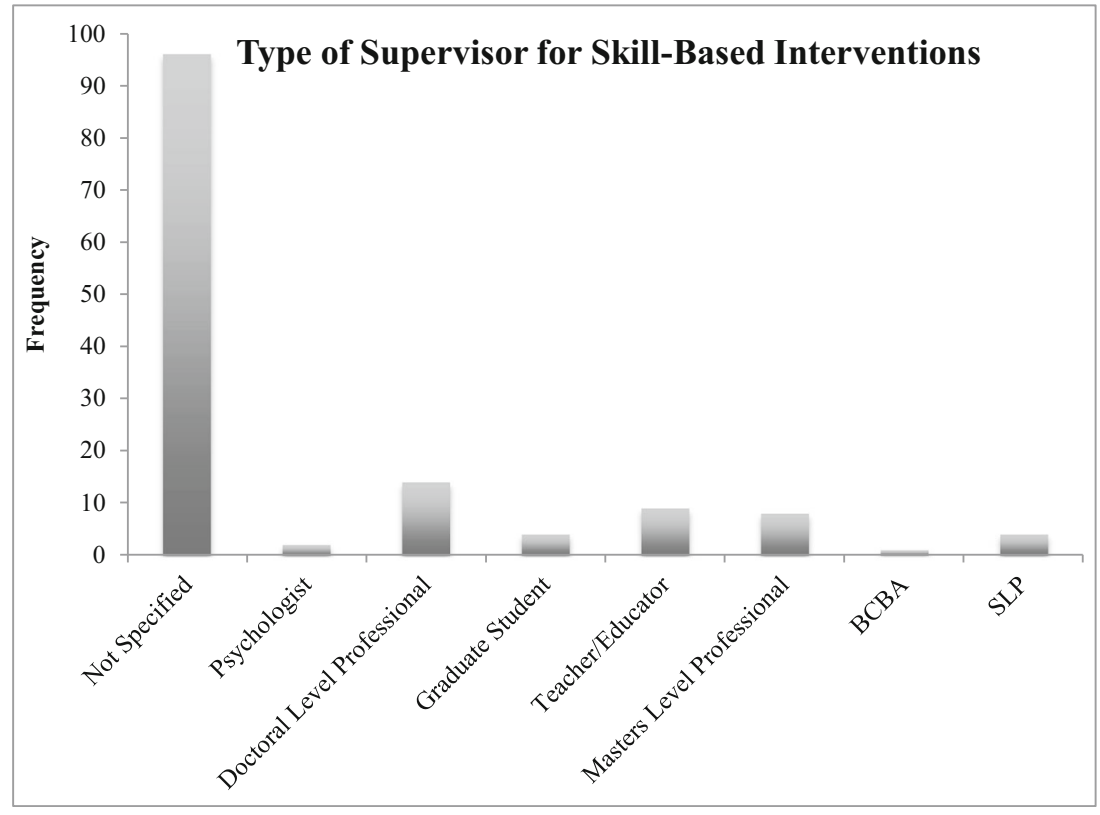




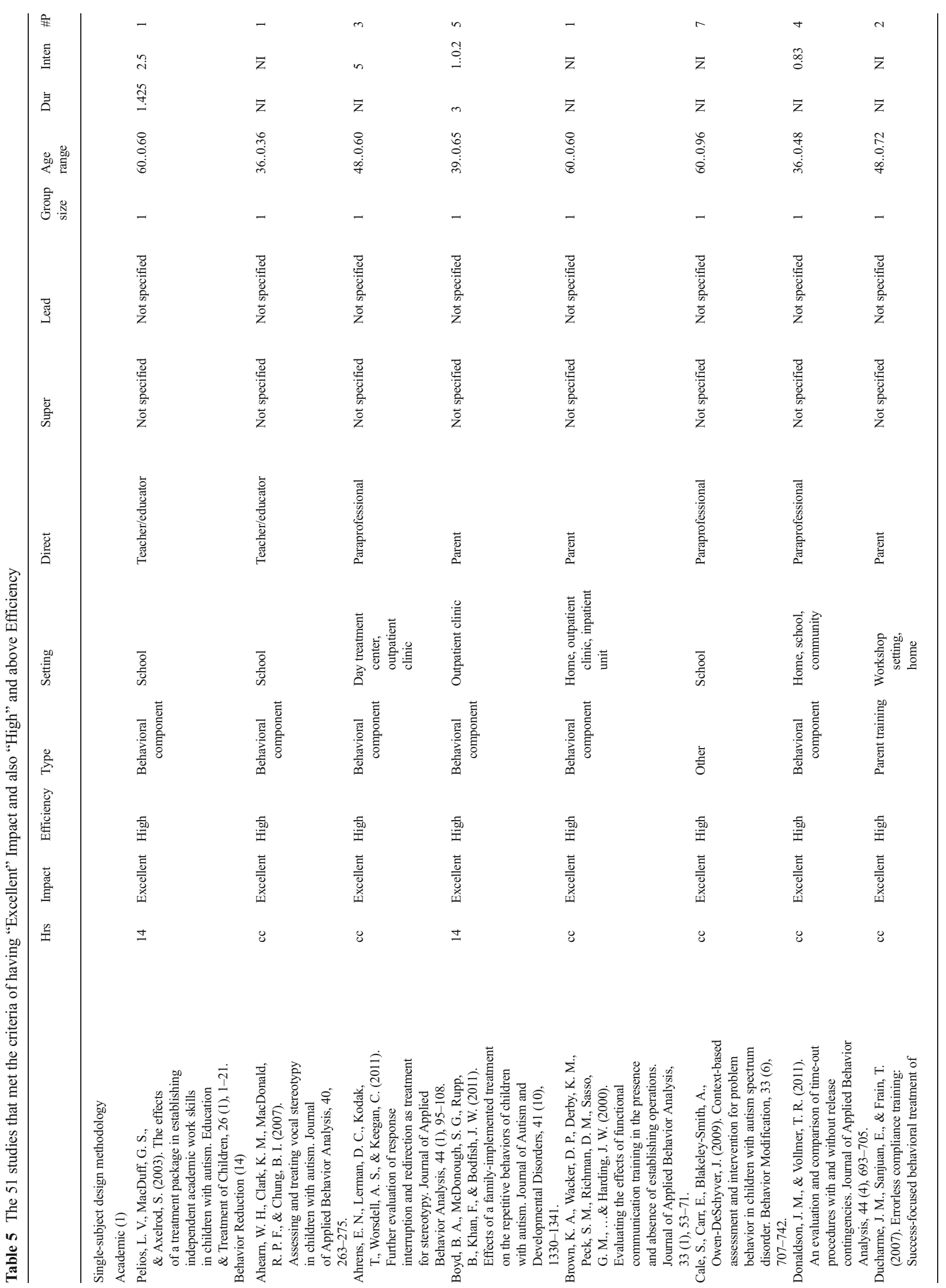




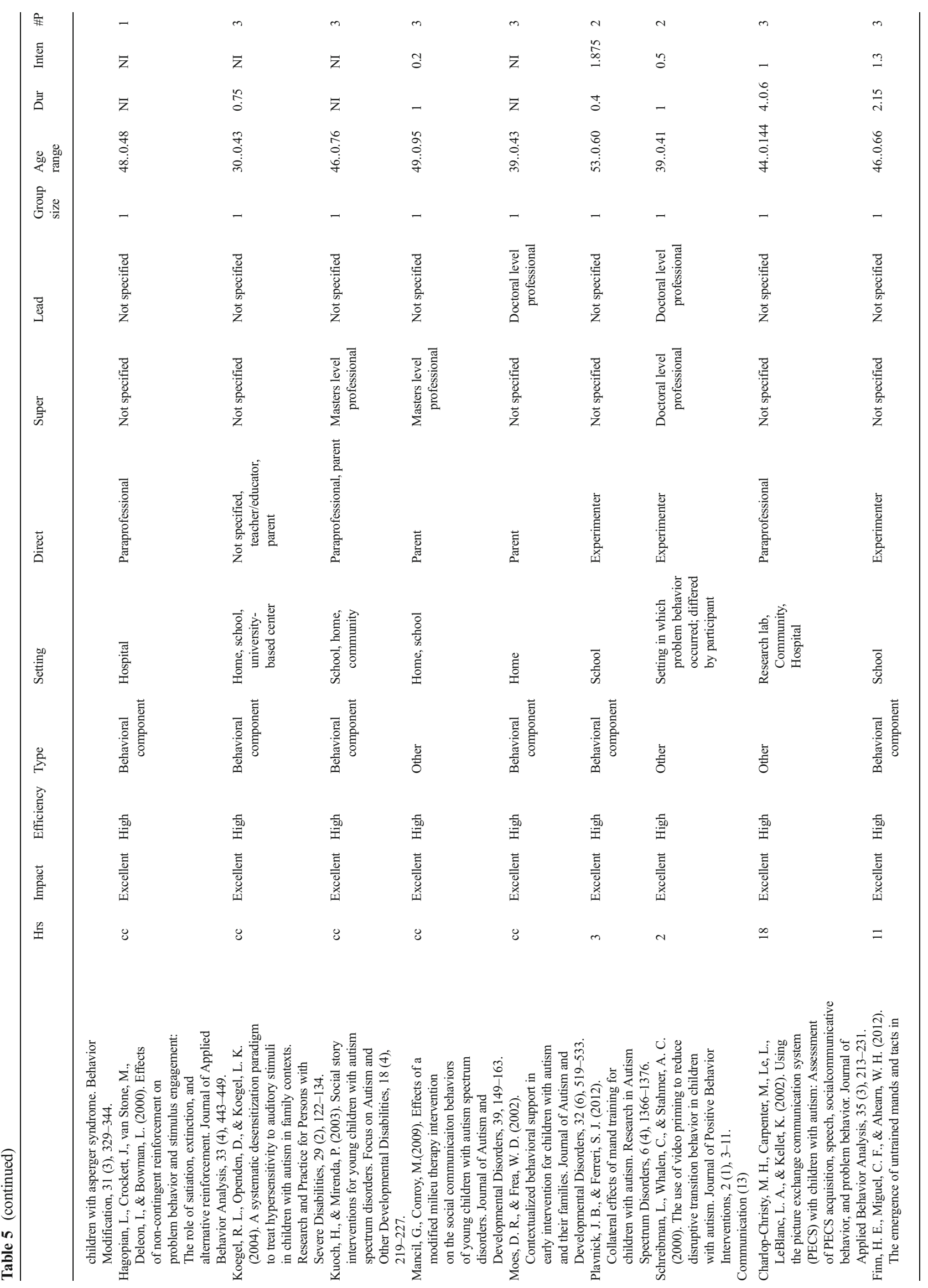




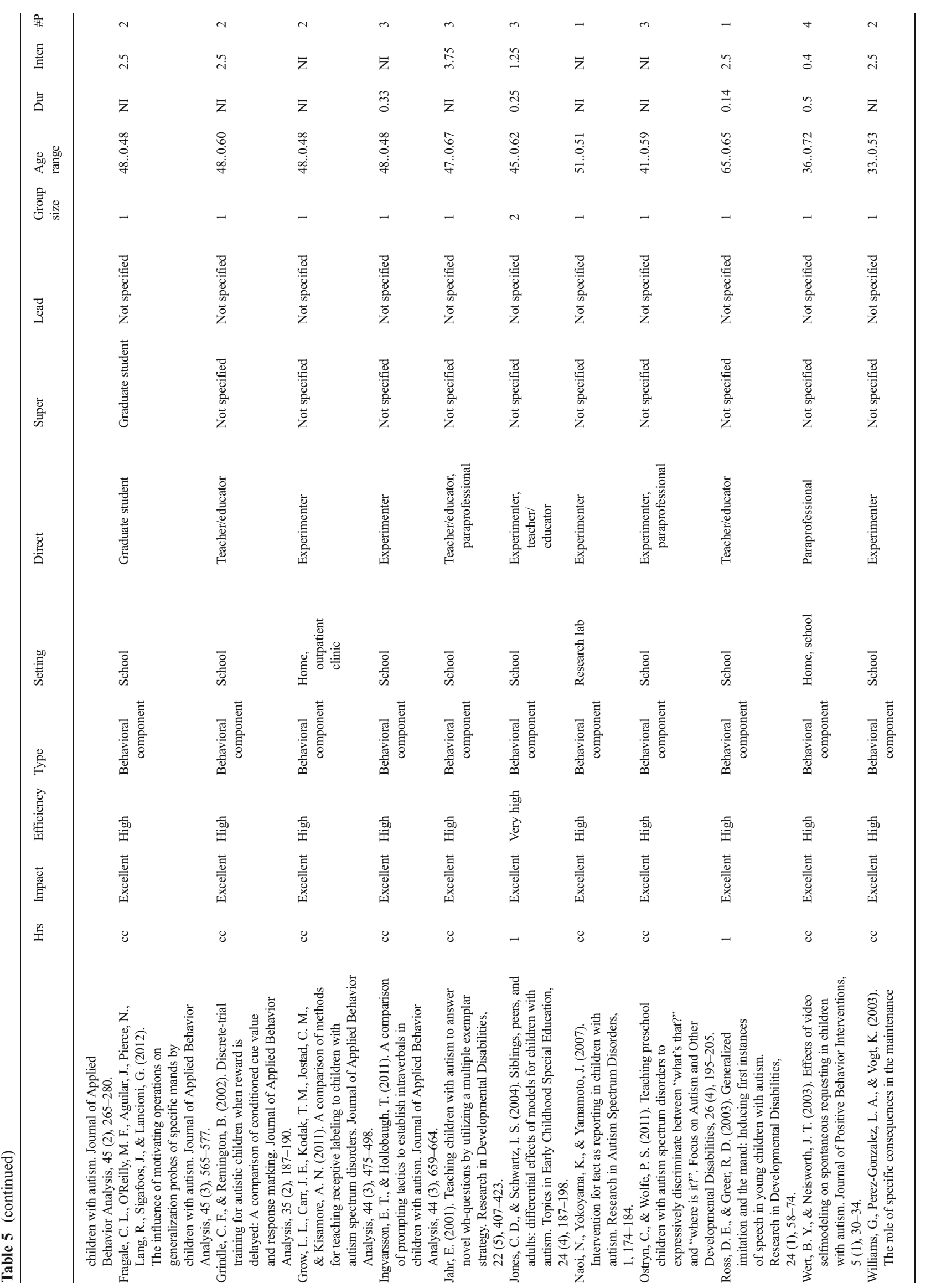




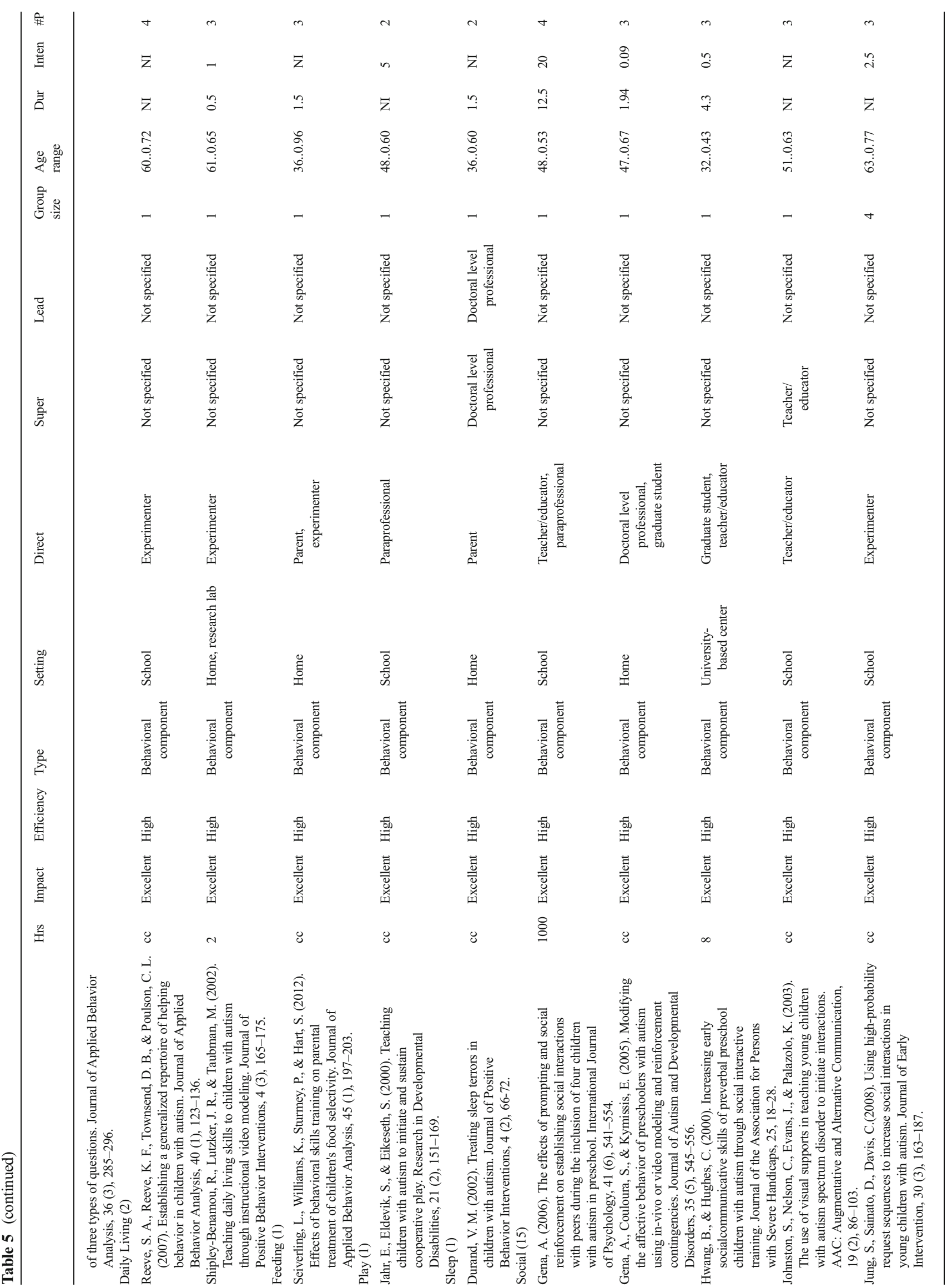




\begin{tabular}{|c|c|c|c|c|c|c|c|c|c|c|c|}
\hline 茟 & $m$ & $\nabla$ & m & m & m & m & 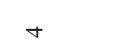 & $m$ & - & $\infty$ & $\stackrel{2}{2}$ \\
\hline 苞 & $\alpha$ & $\because$ & $\stackrel{n}{\hat{o}}$ & $\stackrel{t}{0}$ & $\bar{z}$ & $\stackrel{n}{\stackrel{n}{=}}$ & $\stackrel{\text { તે }}{\text { ㄱ. }}$ & $\bar{z}$ & $\bar{z}$ & - & - \\
\hline 音 & $\bar{z}$ & $\stackrel{n}{i}$ & $\overrightarrow{\vec{i}}$ & $\sim$ & $\bar{z}$ & $\bar{z}$ & $\bar{z}$ & $\bar{z}$ & $\bar{z}$ & $n$ & 0 \\
\hline 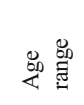 & 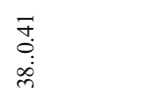 & $\begin{array}{l}n \\
\vdots \\
\vdots \\
\dot{g}\end{array}$ & $\begin{array}{l}\infty \\
n \\
0 \\
\dot{+}\end{array}$ & $\begin{array}{l}\text { Ju } \\
\stackrel{\vdots}{0} \\
\text { in }\end{array}$ & $\begin{array}{l}+ \\
0 \\
0 \\
0 \\
\infty \\
⿱ 亠 乂 \\
+\end{array}$ & $\begin{array}{l}1 \\
\hat{0} \\
\dot{0} \\
m\end{array}$ & $\begin{array}{l}\stackrel{n}{0} \\
0 \\
\vdots \\
i\end{array}$ & $\begin{array}{l}\stackrel{0}{n} \\
0 \\
\dot{j} \\
\dot{7}\end{array}$ & $\begin{array}{l}\infty \\
+ \\
0 \\
\dot{0} \\
\dot{q}\end{array}$ & $\begin{array}{l}0 \\
0 \\
\vdots \\
0\end{array}$ & 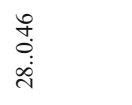 \\
\hline 总. & - & - & - & $m$ & - & - & - & $\sim$ & $N$ & - & - \\
\hline 芯 & 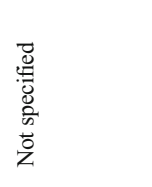 & 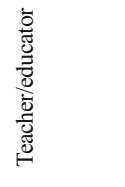 & 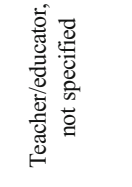 & 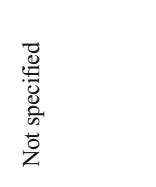 & 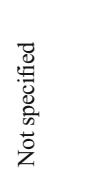 & 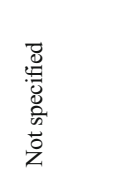 & 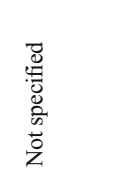 & 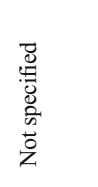 & 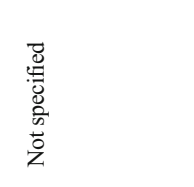 & 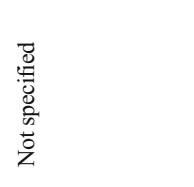 & 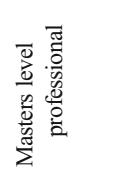 \\
\hline 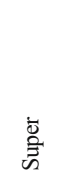 & 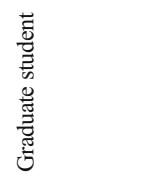 & 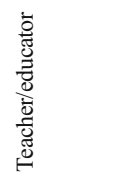 & 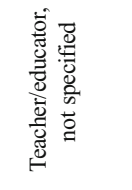 & 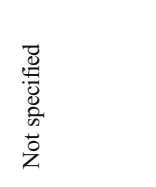 & 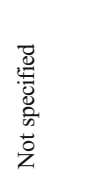 & 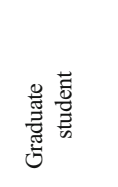 & 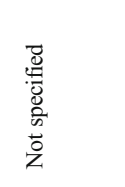 & 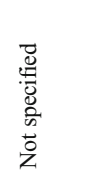 & 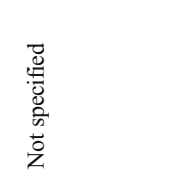 & 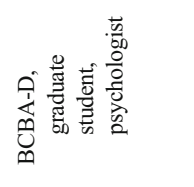 & 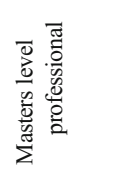 \\
\hline 蒿 & 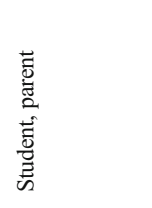 & 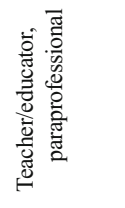 & 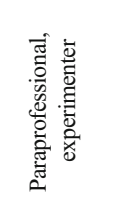 & 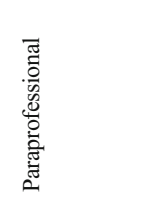 & 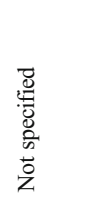 & $\begin{array}{l}\text { 言 } \\
\text { 离 }\end{array}$ & $\begin{array}{l}\bar{\Xi} \\
\frac{\mathscr{0}}{0} \\
\overline{0} \\
\overline{0} \\
\bar{\Delta}\end{array}$ & 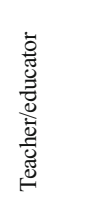 & 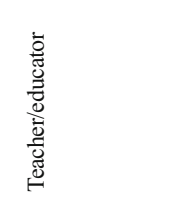 & $\begin{array}{l}\text { 言 } \\
\text { 离 }\end{array}$ & 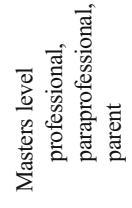 \\
\hline $\begin{array}{l}\text { 总 } \\
\text { 意 } \\
\text { 出 }\end{array}$ & 芯 & $\begin{array}{l}\bar{o} \\
\bar{o} \\
\tilde{c}\end{array}$ & 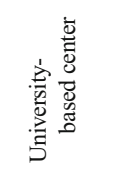 & 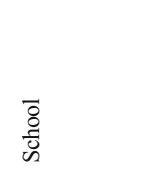 & 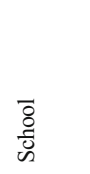 & 苇 & $\begin{array}{l}\overline{0} \\
\frac{8}{d} \\
i n\end{array}$ & 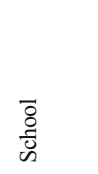 & $\begin{array}{l}\overline{\bar{o}} \\
\overline{0} \\
\bar{n}\end{array}$ & 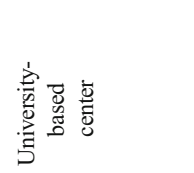 & 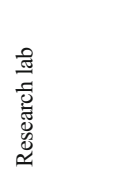 \\
\hline 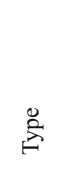 & 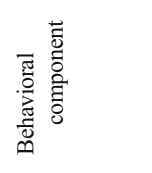 & 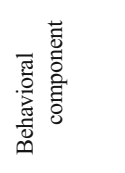 & 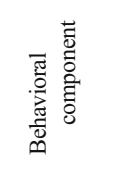 & 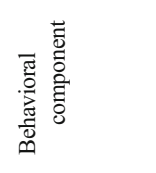 & 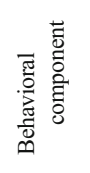 & 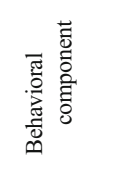 & 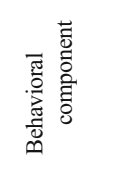 & 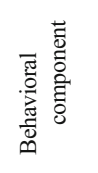 & 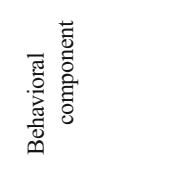 & 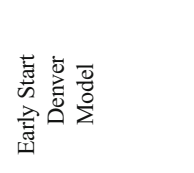 & $\begin{array}{l}\overline{\mathrm{g}} \\
\overline{\tilde{\sigma}}\end{array}$ \\
\hline 总 & 离 & 它 & 咅 & 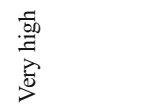 & 总 & 总 & 总 & 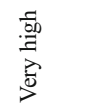 & 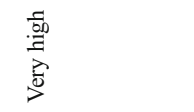 & 駕 & 总 \\
\hline $\begin{array}{l}\overrightarrow{\tilde{\Xi}} \\
\text { 节 }\end{array}$ & $\begin{array}{l}\text { 䓂 } \\
\frac{\overline{0}}{\overline{8}} \\
\text { 离 }\end{array}$ & $\begin{array}{l}\text { 䓂 } \\
\text { 离 } \\
\text { 离 }\end{array}$ & $\begin{array}{l}\text { 言 } \\
\text { 离 } \\
\text { 离 }\end{array}$ & $\begin{array}{l}\text { 言 } \\
\text { 离 } \\
\text { 畜 }\end{array}$ & 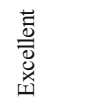 & $\begin{array}{l}\text { 䓂 } \\
\text { 离 } \\
\text { 畜 }\end{array}$ & $\begin{array}{l}\text { 言 } \\
\frac{\overline{\bar{g}}}{\bar{y}} \\
\text { 离 }\end{array}$ & $\begin{array}{l}\text { 䓂 } \\
\text { 离 } \\
\text { 离 }\end{array}$ & 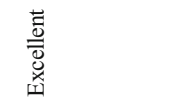 & 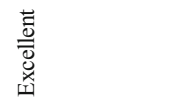 & $\begin{array}{l}\text { 䓂 } \\
\text { 苛 } \\
\text { 离 }\end{array}$ \\
\hline 番 & 8 & in & $r$ & n & 8 & 8 & 8 & 8 & 8 & $\simeq$ & $\stackrel{+}{\sim}$ \\
\hline & 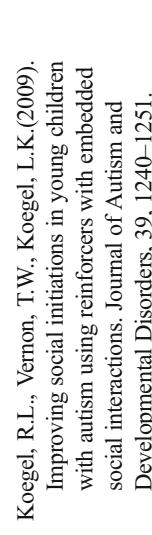 & 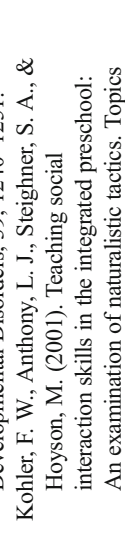 & 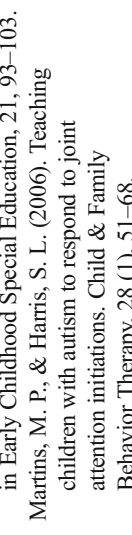 & 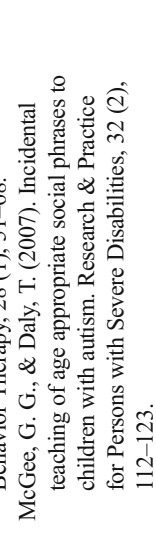 & 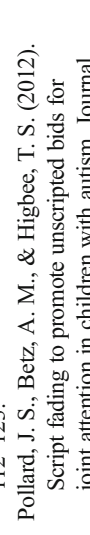 & 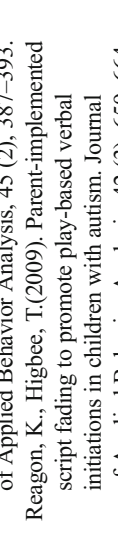 & 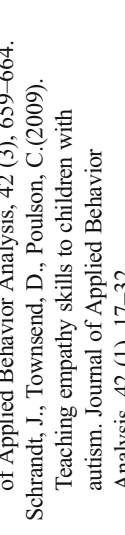 & 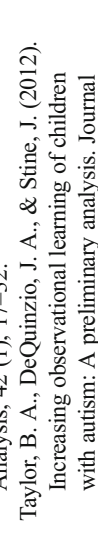 & 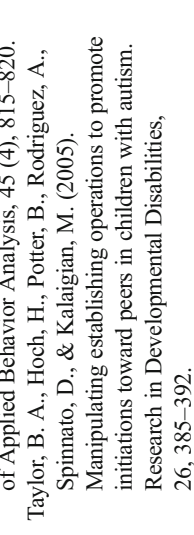 & 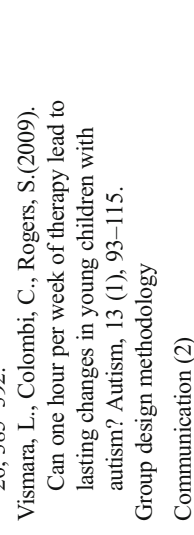 & 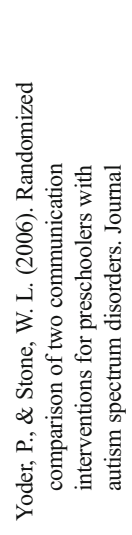 \\
\hline
\end{tabular}


intensive, effective intervention, even for specific skills, requires a strong one-to-one component as a significant aspect of the intervention program.

Given this, attention should perhaps focus on the degree of consistent impact achieved relative to the cost of the intervention program. This is the first comprehensive review we are aware of that attempted to calculate the actual hours of intervention per participant. Ideally, this variable would be used in concert with child characteristic variables to determine potential cost-benefit patterns and factors that limit impact. As described above, unfortunately the inconsistency in reporting such characteristics severely restricts such analyses.

\section{Perspective}

As we have acknowledged, there are limitations to our attempt to bring clarity of definition and perspective to limited resource allocation and to our review of intervention studies. Unlike generally accepted standards with respect to evaluating time-series experimental designs or the type of statistical analyses appropriate for various group designs, there are no generally accepted standards for the type of analyses we attempted in this review - the policies and costs of clinically significant impact across various intervention foci. Critique will be welcomed if it can lead to a consensus on how to evaluate clinical impact as can be used in the context of limited resource allocation.

The first part of this review examined the complex issues involved in public policy and resource allocation. Given resources are constrained, it appears valuable to determine intervention procedures that result in substantial and consistent impact for young children with ASD and also to ascertain their "costs". The unit of analysis we used, total hours of intervention per participant, was not our original goal. Had the articles reviewed more consistently specified the characteristics of the individuals implementing the intervention procedures, then calculations could have been performed as to actual monetary cost using geographical average cost for various types of service providers (e.g., special education teacher vs. undergraduate student, vs. Ph. D. vs. BCBA, etc.).

However, even given the disappointing limitations in the extant literature, this review brings attention to important issues of desired standardization in reporting intervention parameters and child characteristics. Further, it represents a first step in aggregating information in a manner that allows for discussion between researchers, caregivers, policy makers, and those that are in the role of resource allocation. References to statements such as "The XYZ approach yields the best outcomes" are simply too broad to be of continuing use in the complex process of service delivery on a large scale and refinement of efficiency in achieving meaningful clinical and educational impact. 


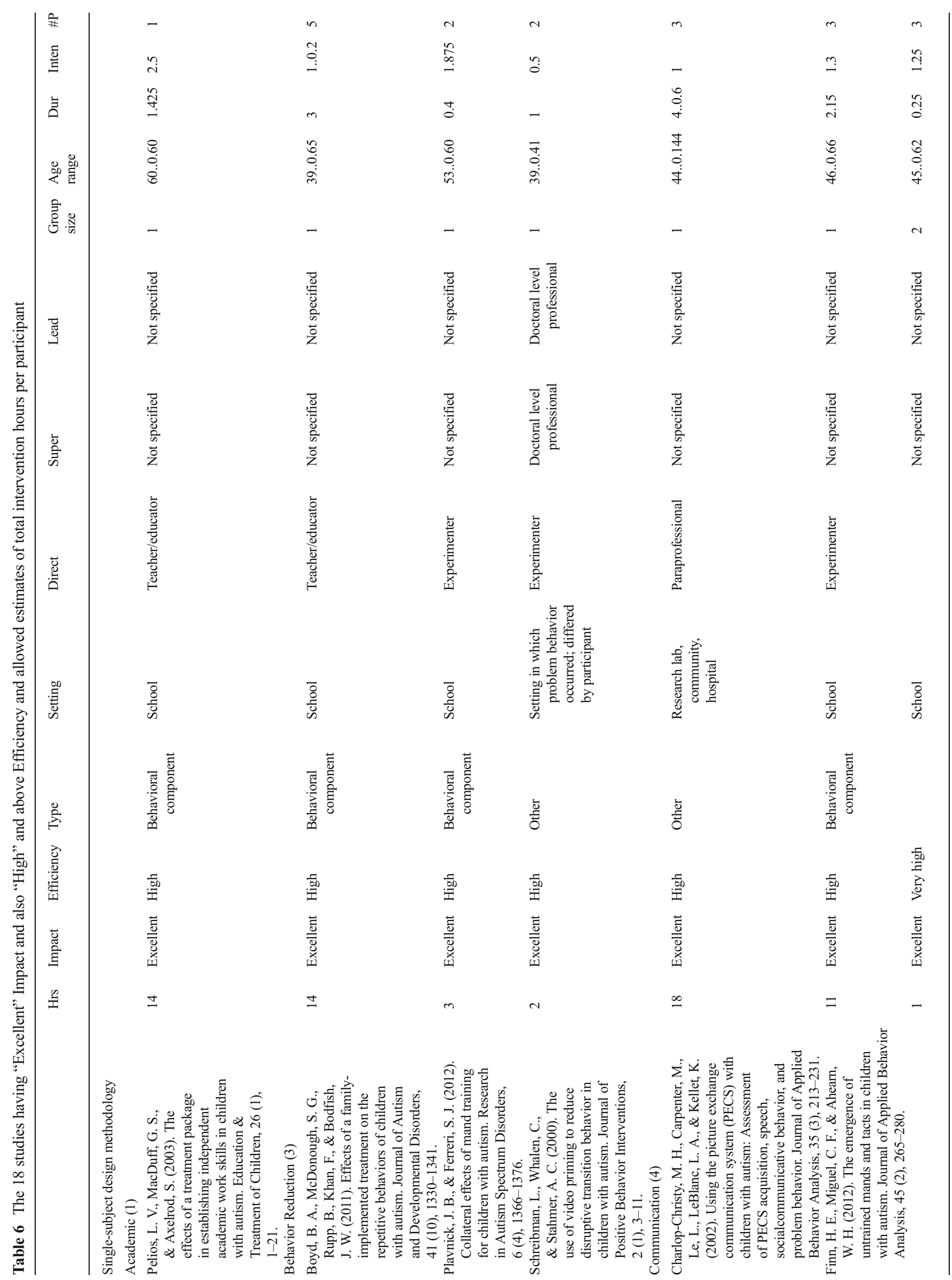




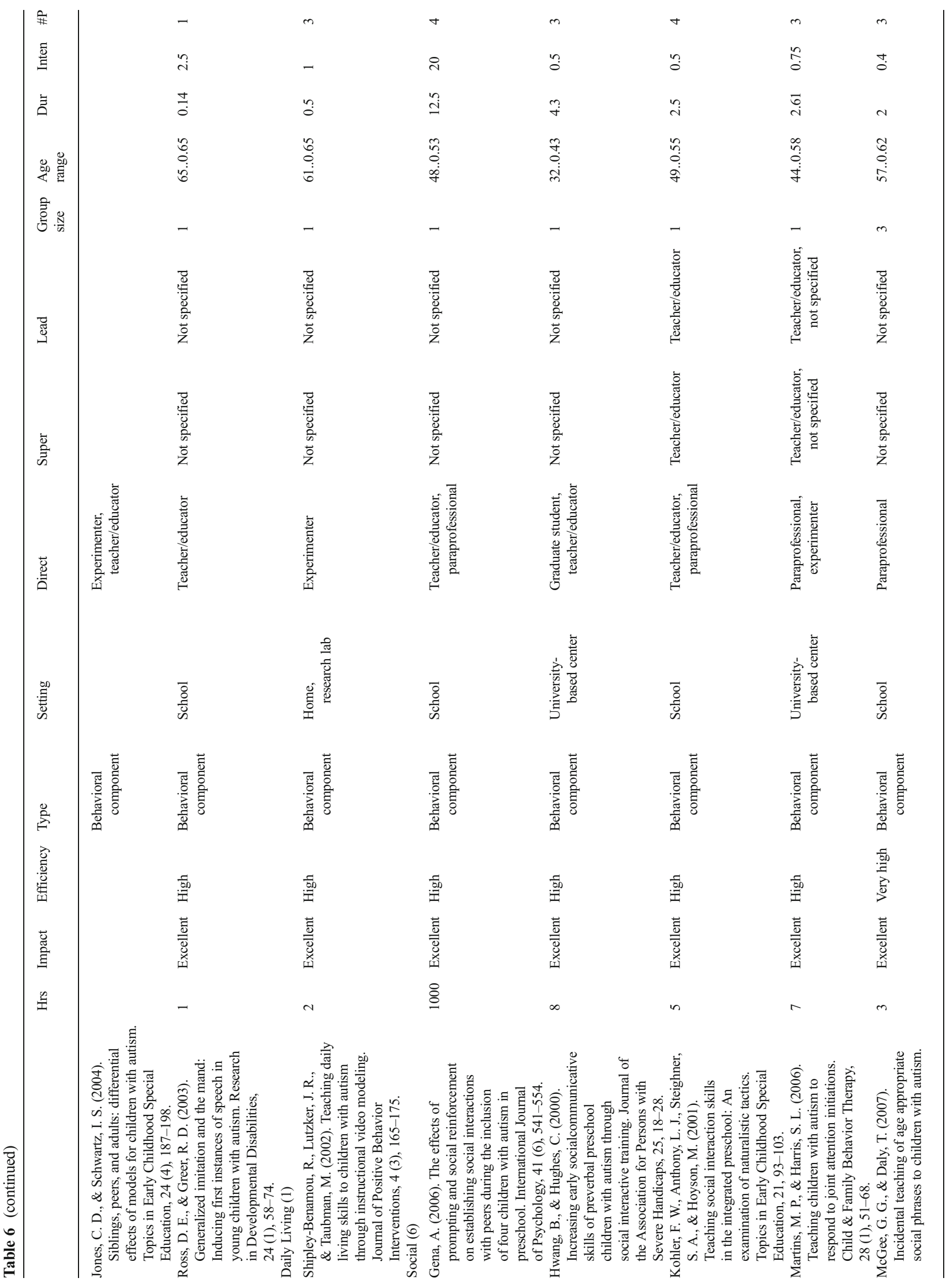




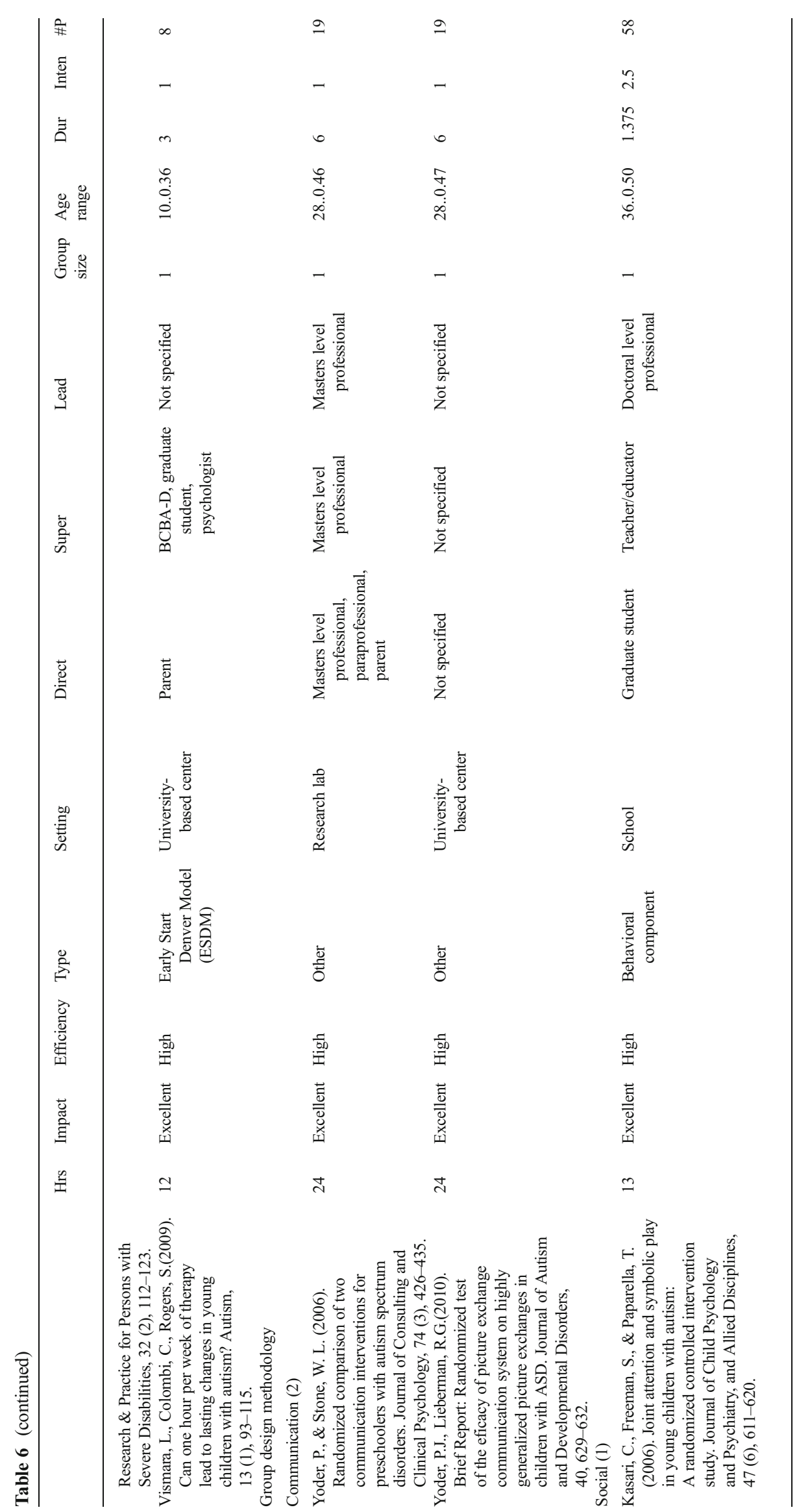




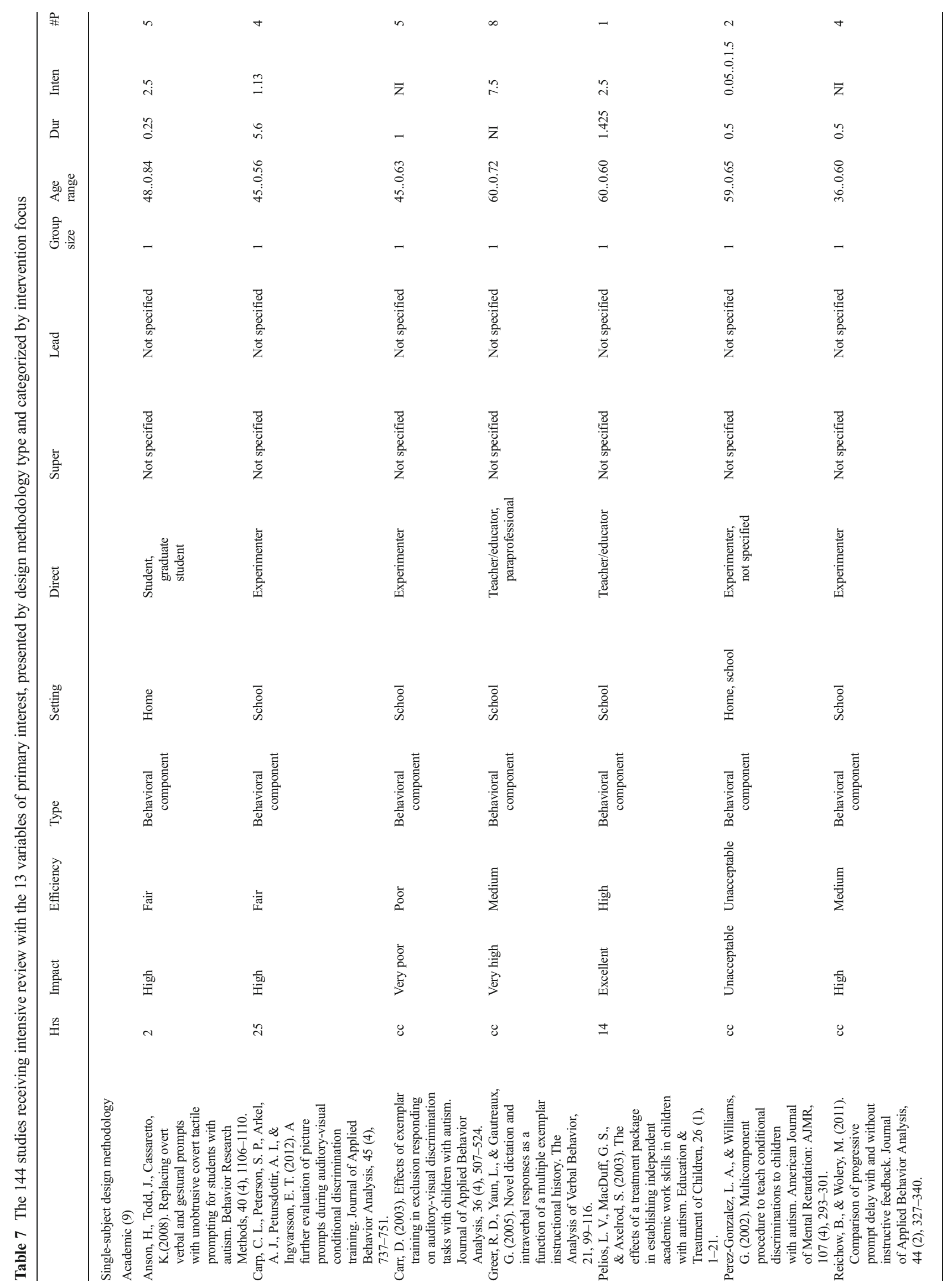




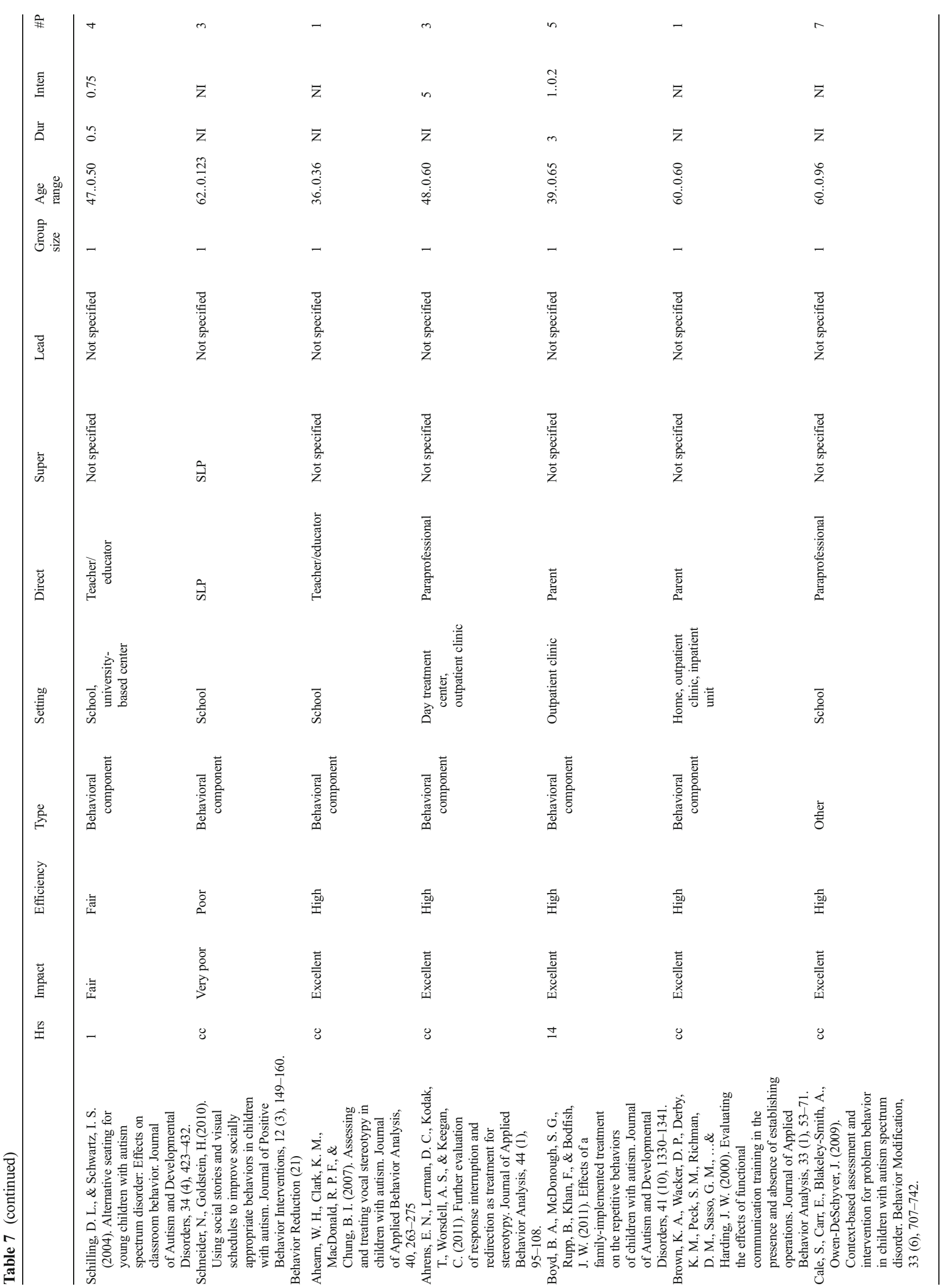




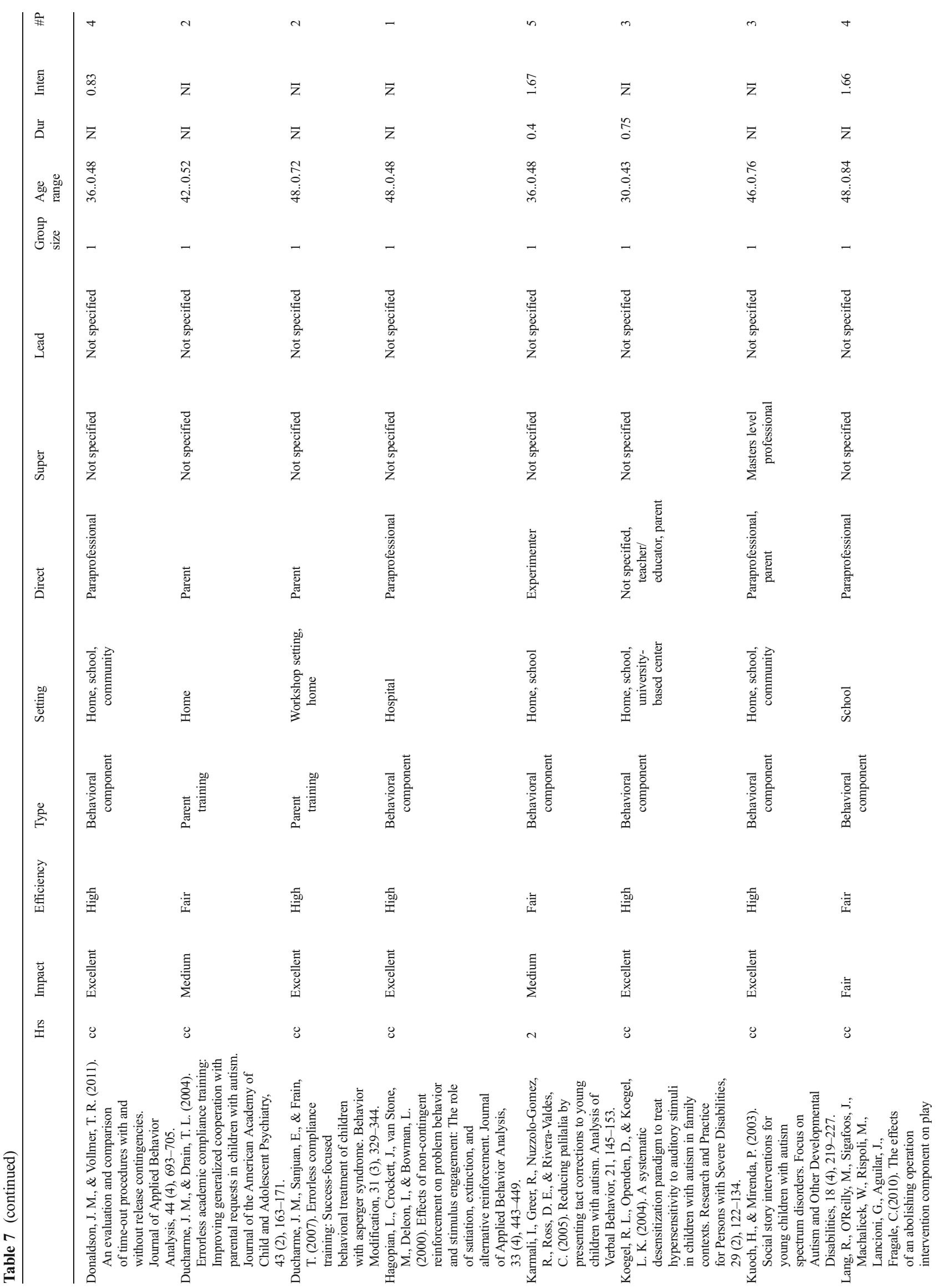




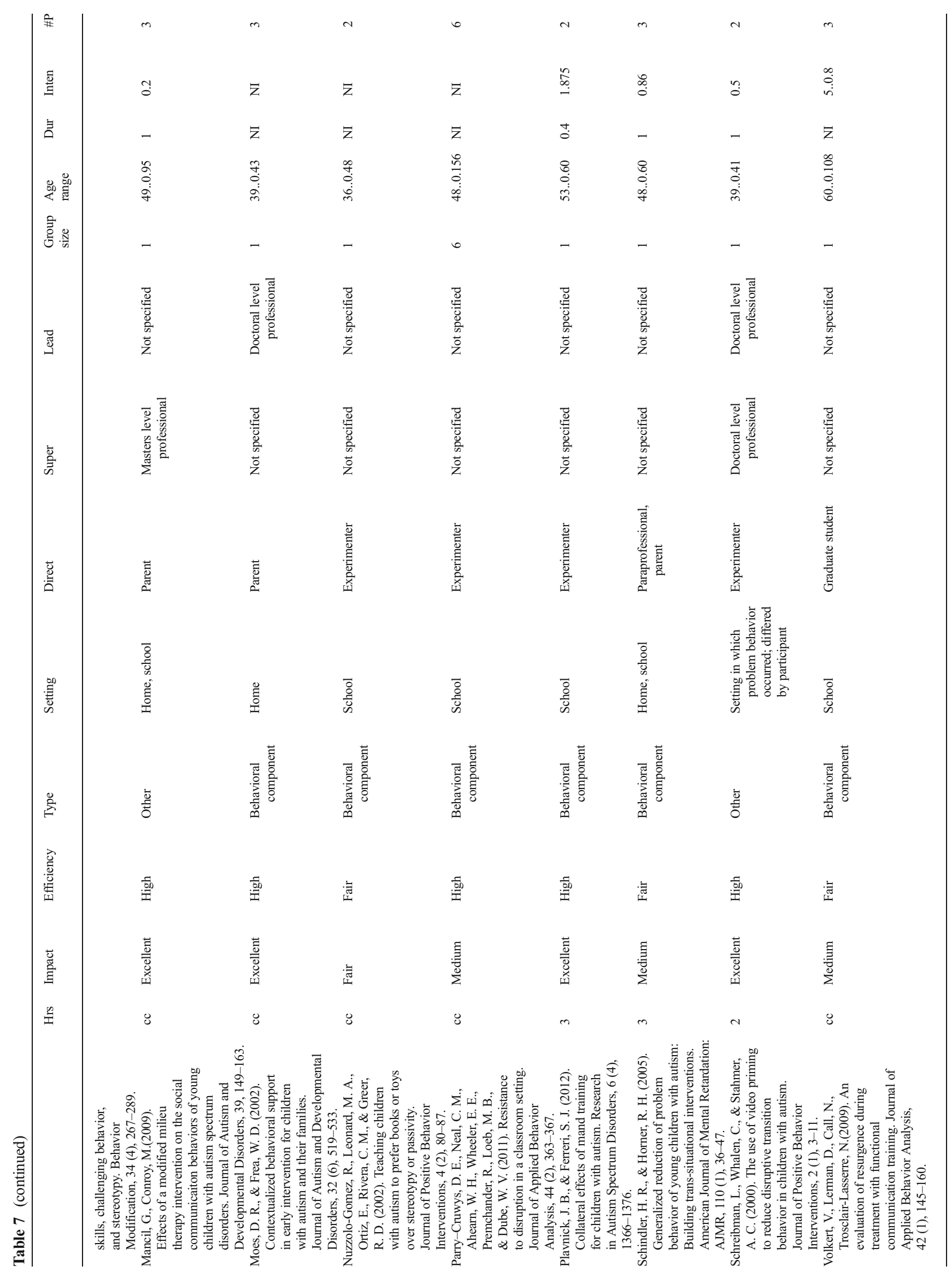




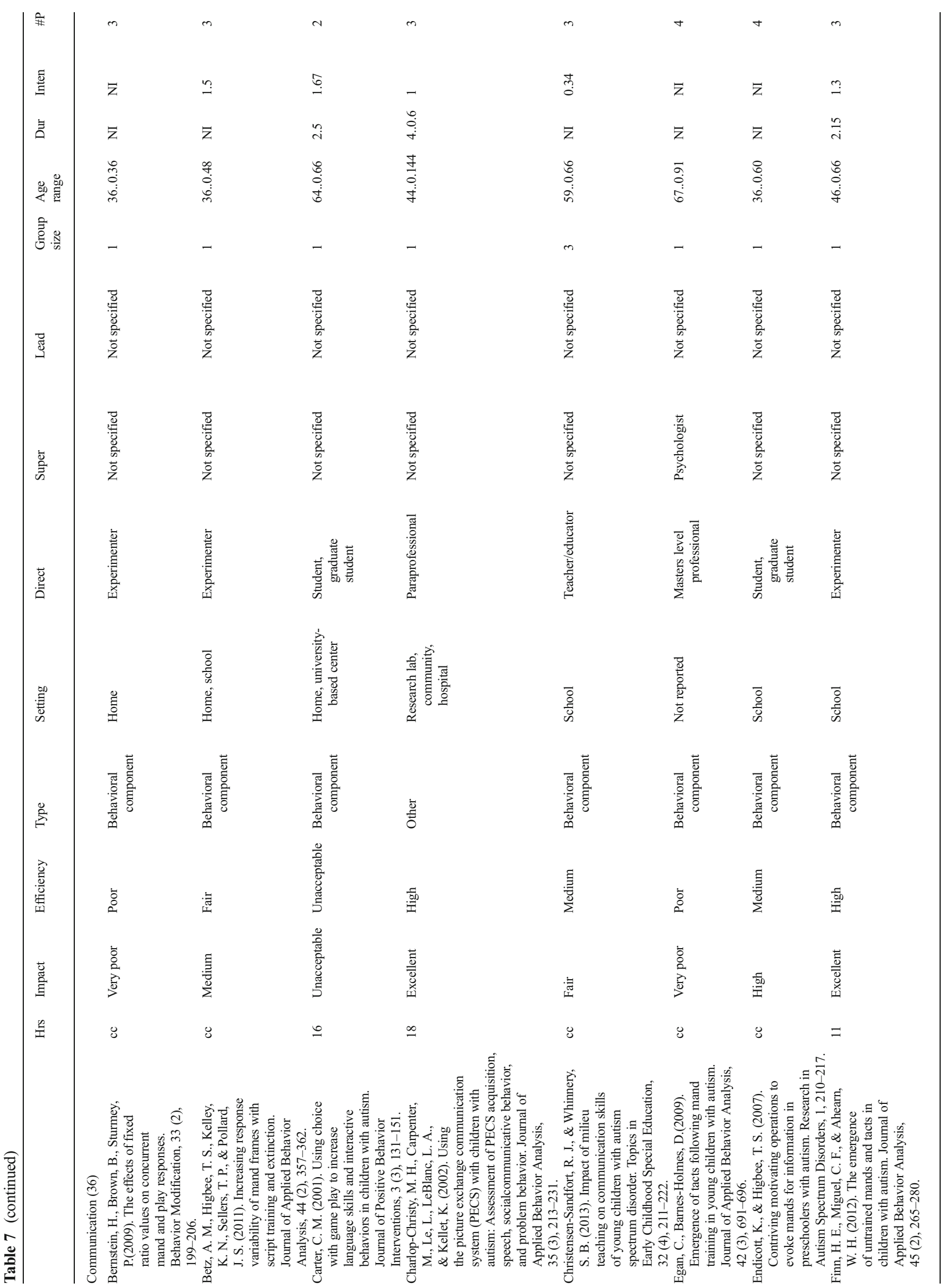




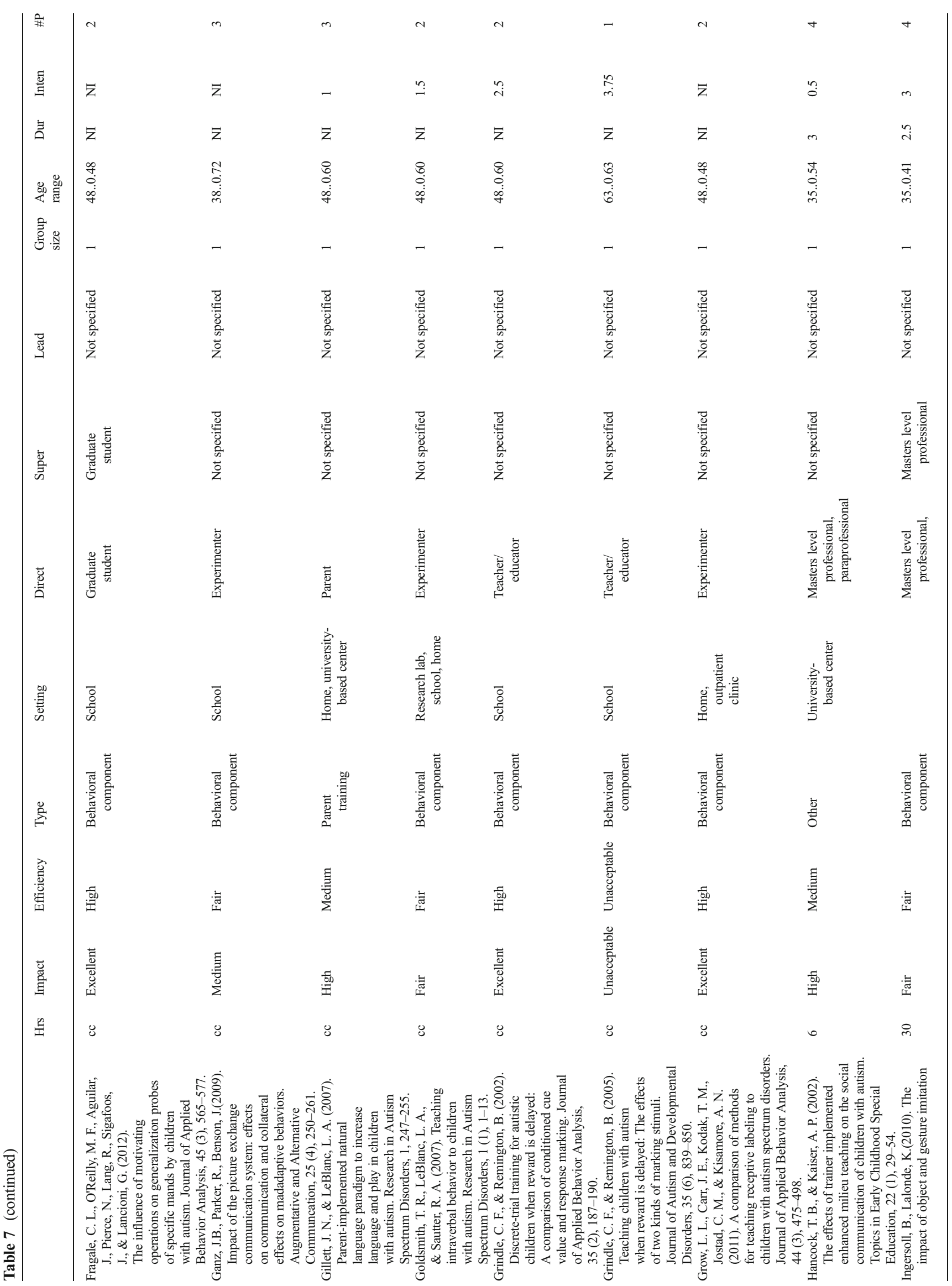




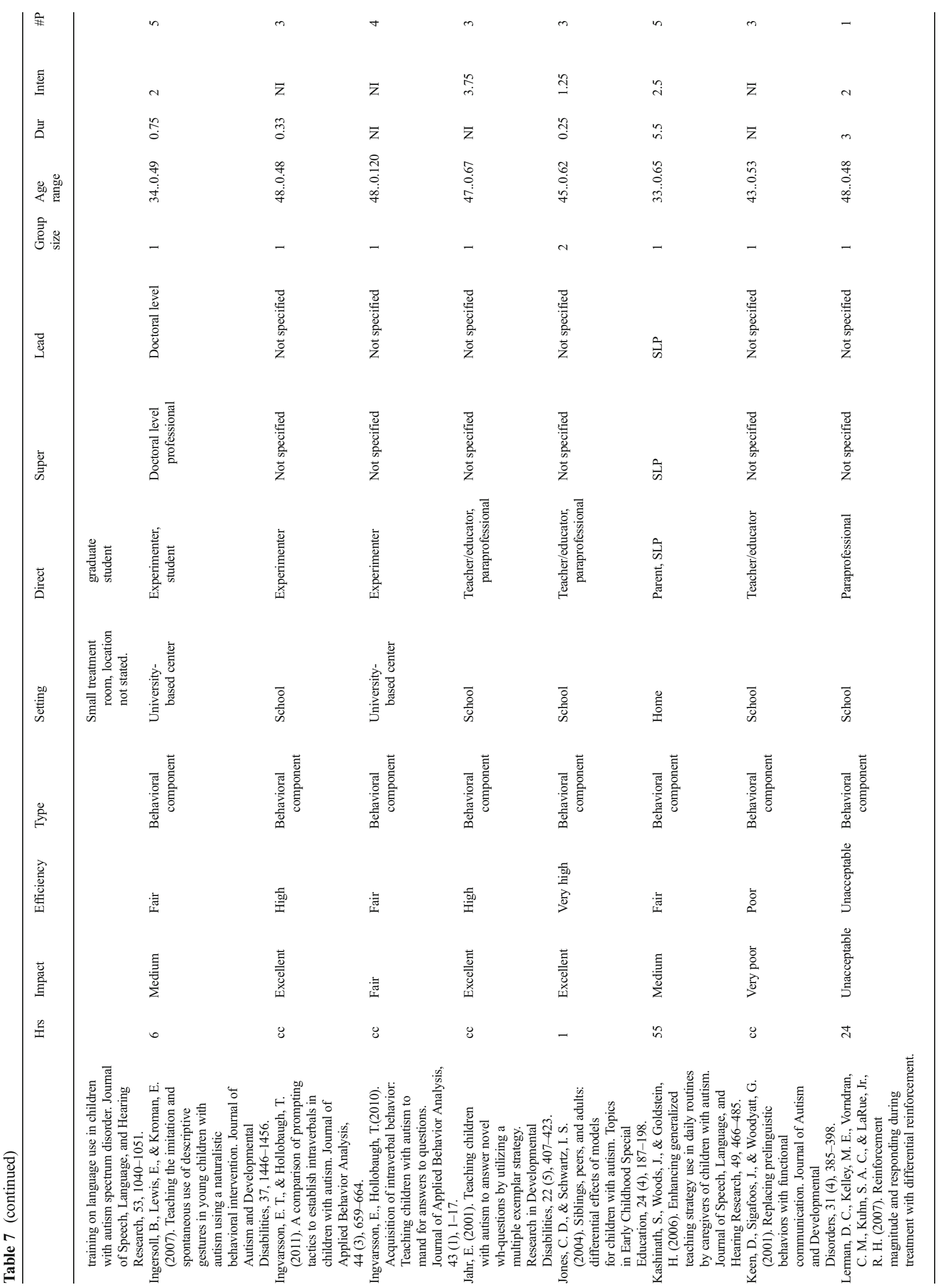




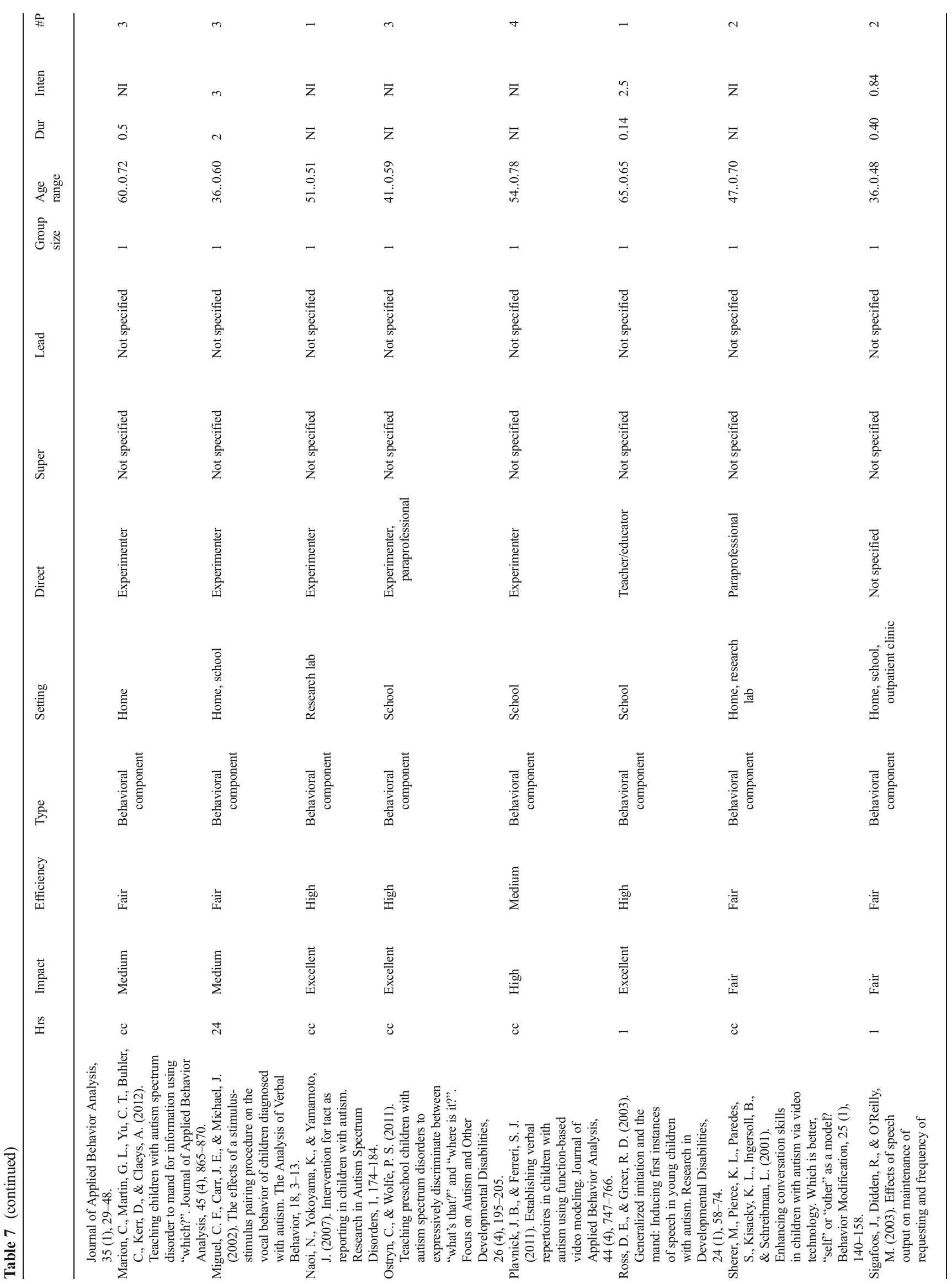




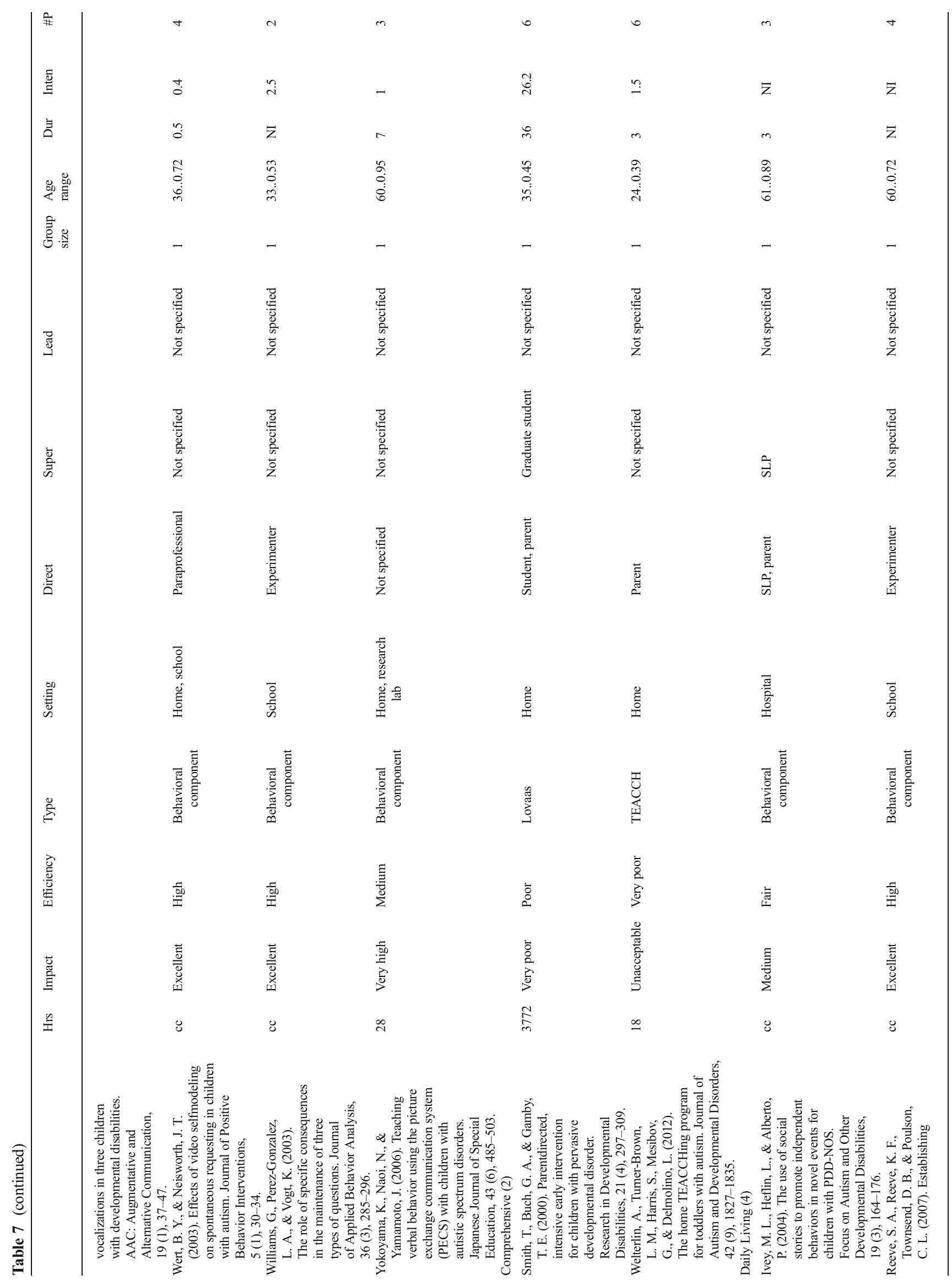




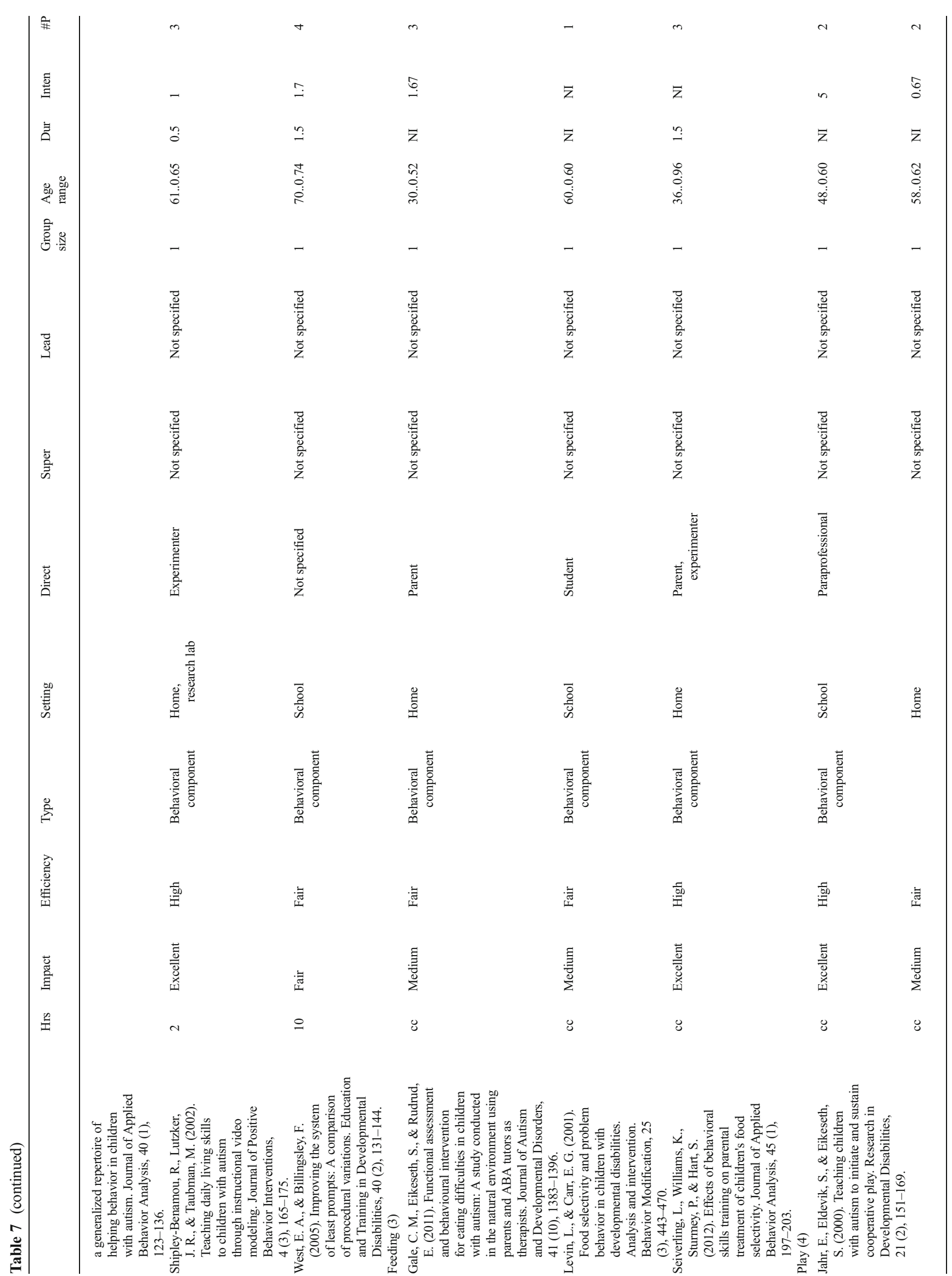




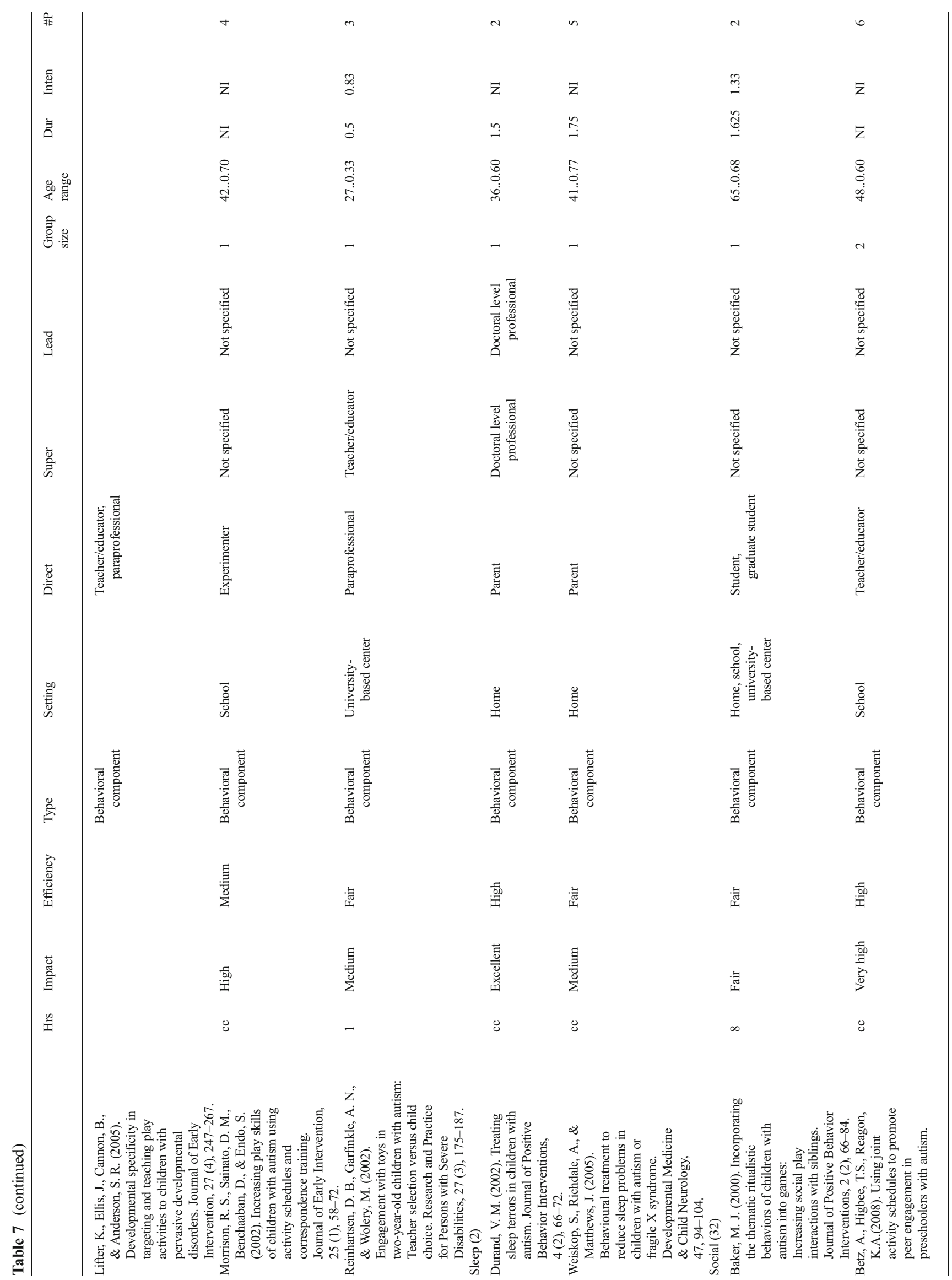




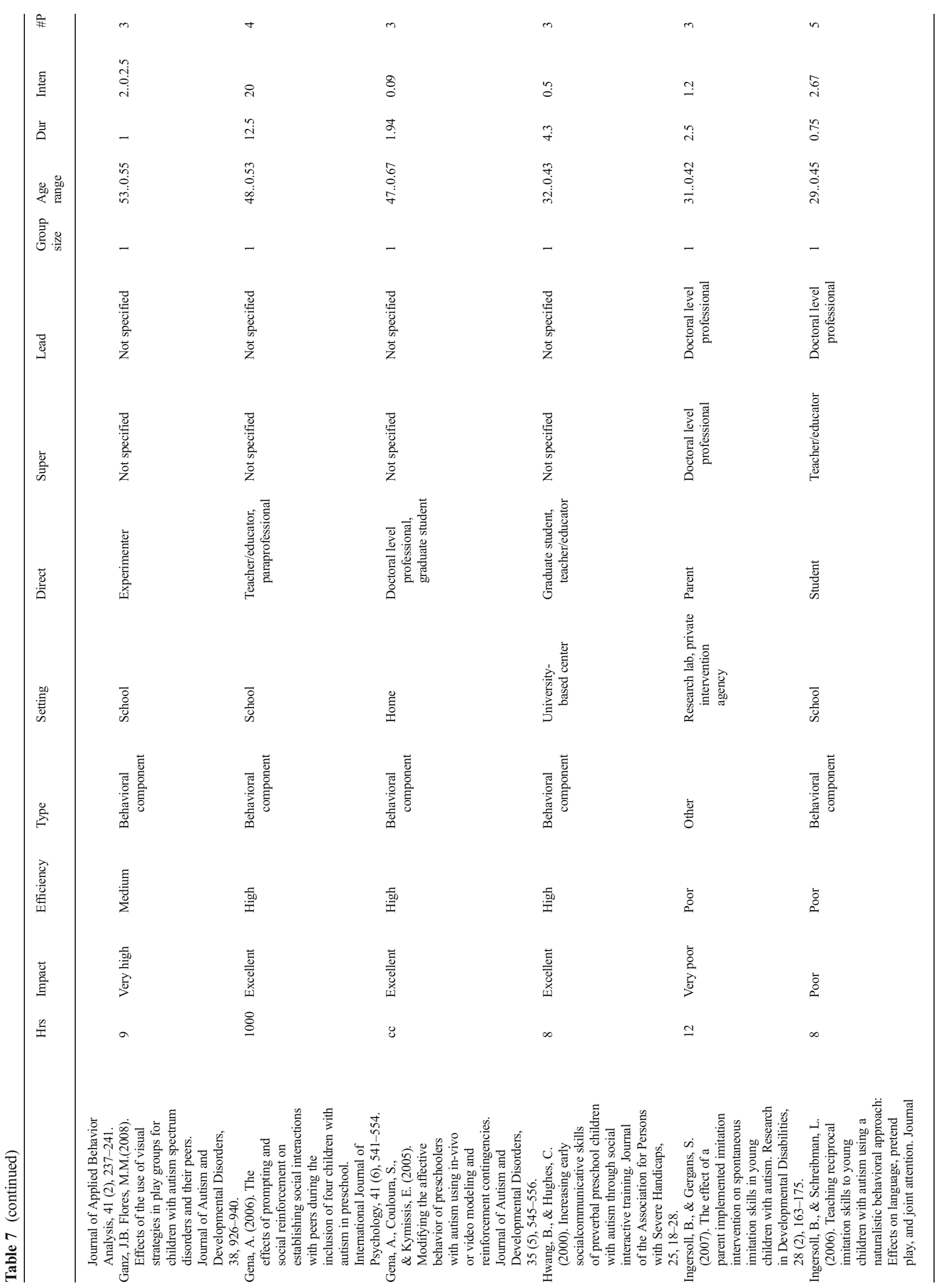




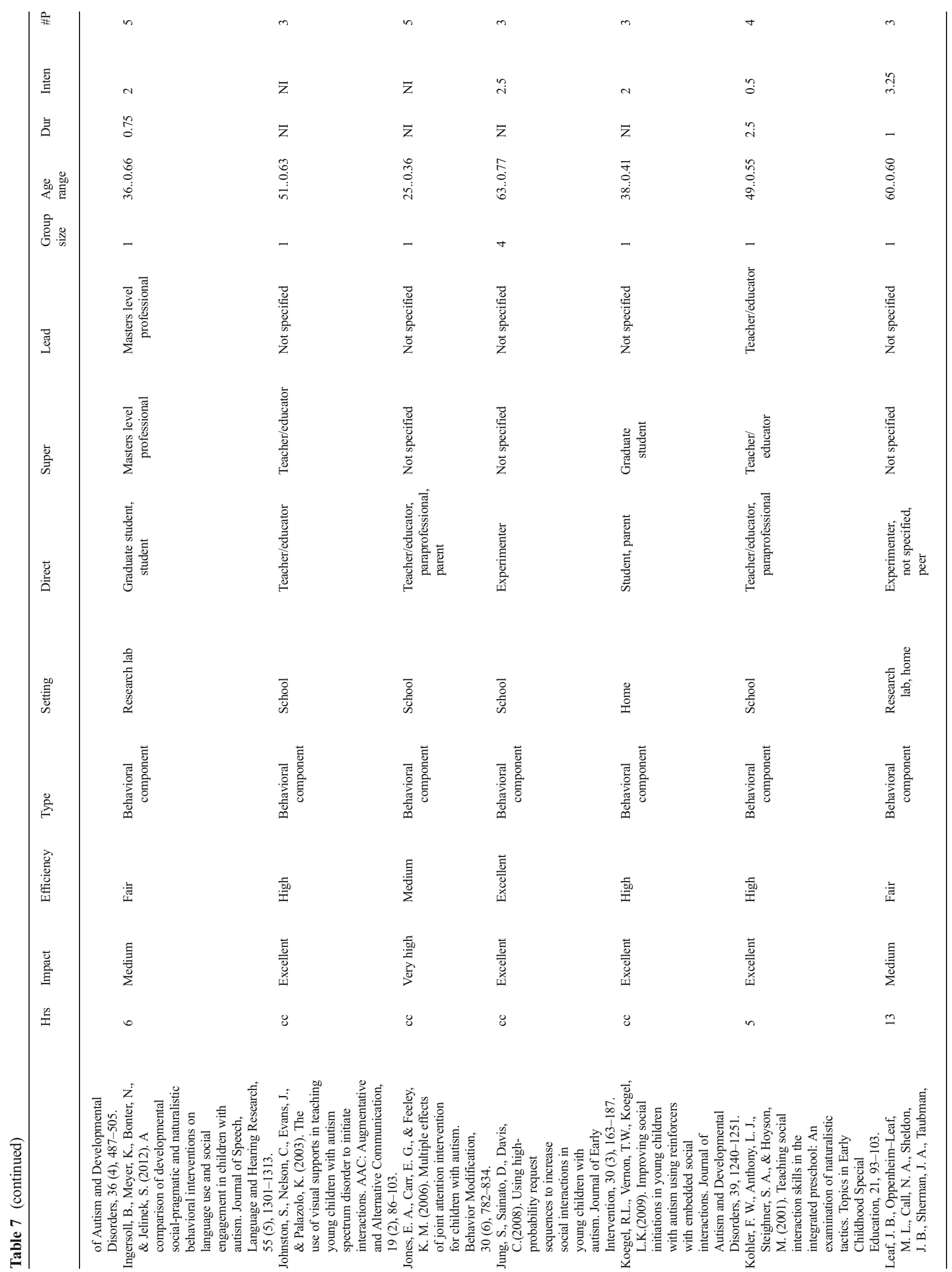




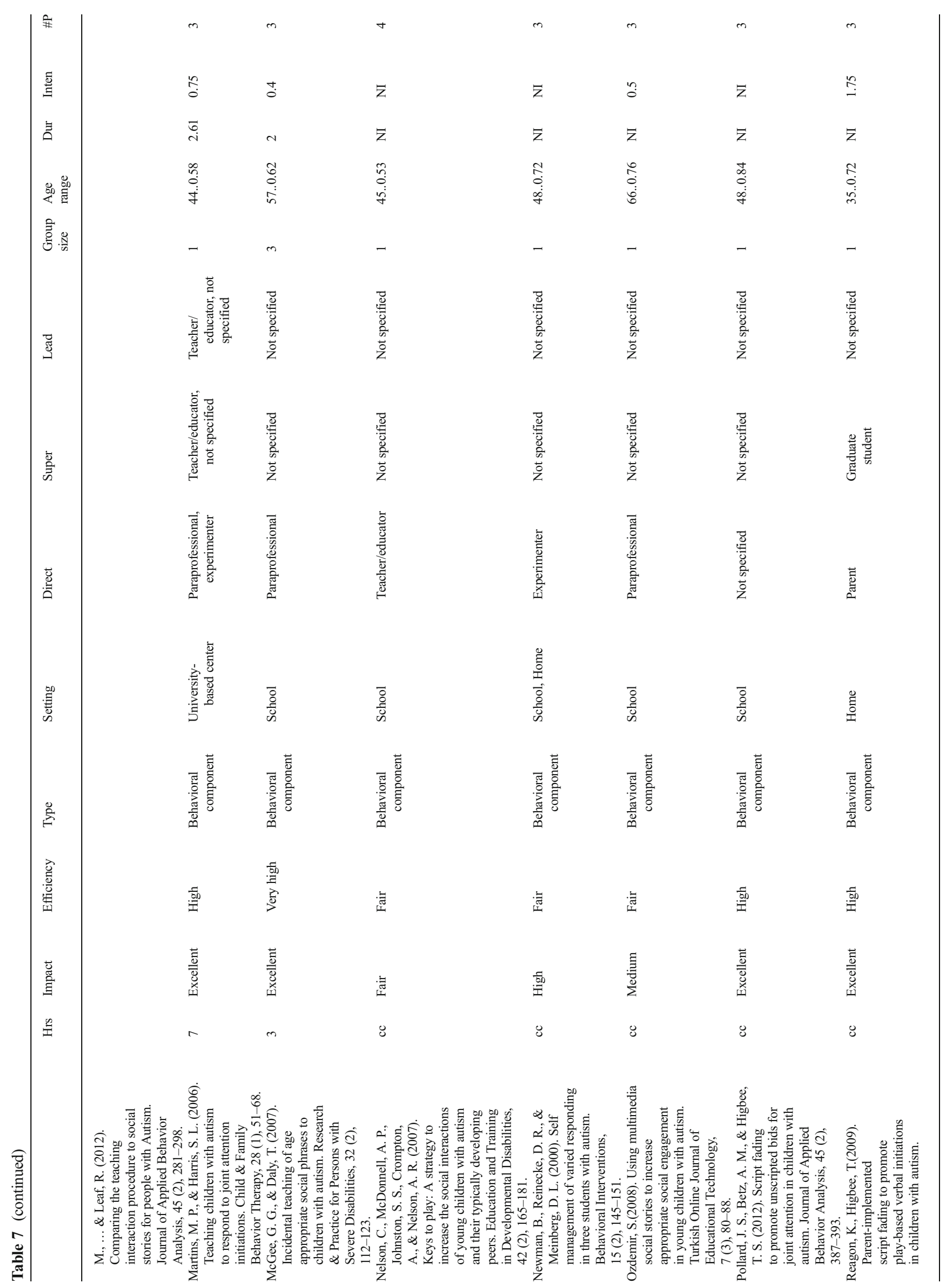




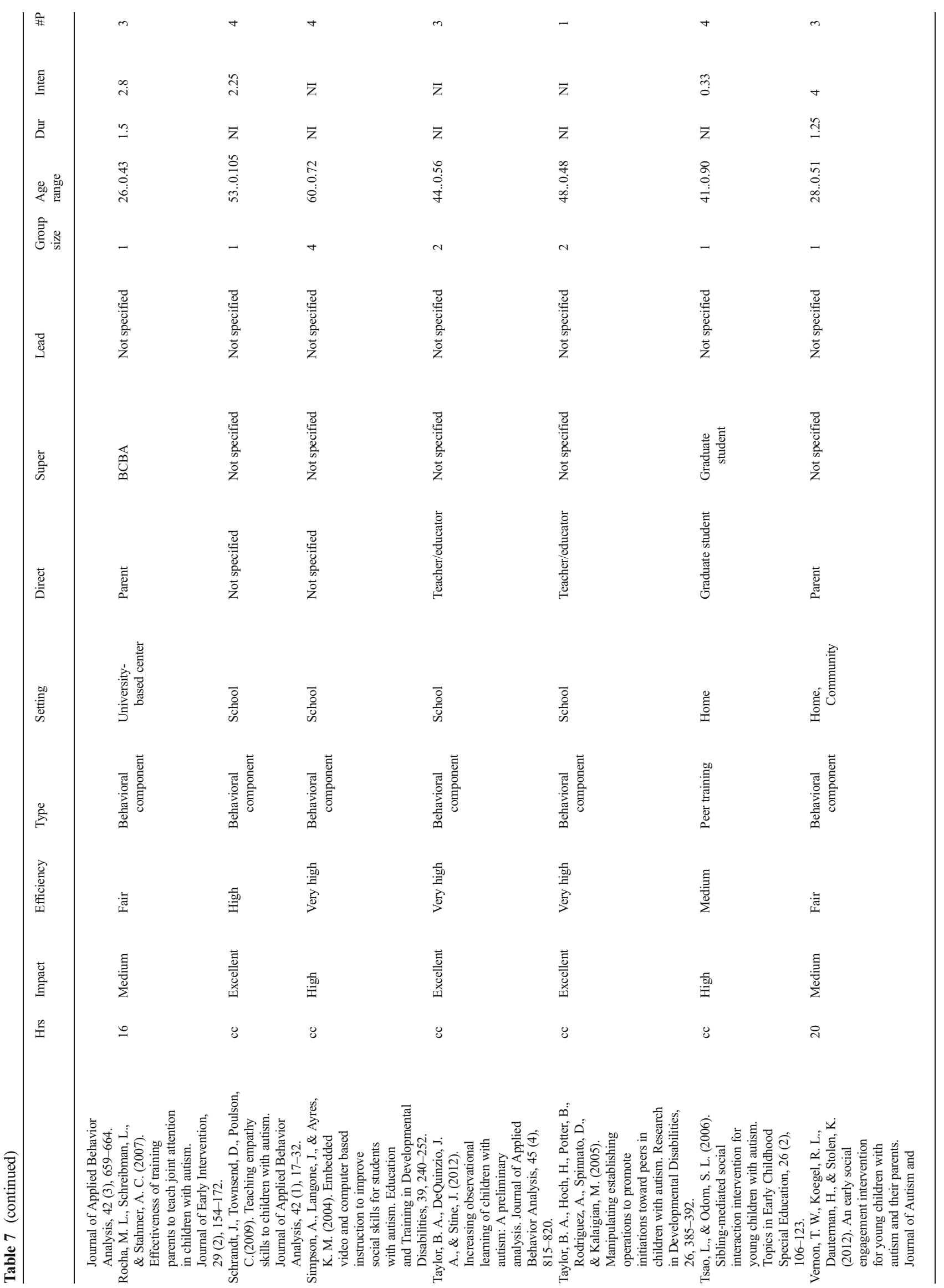




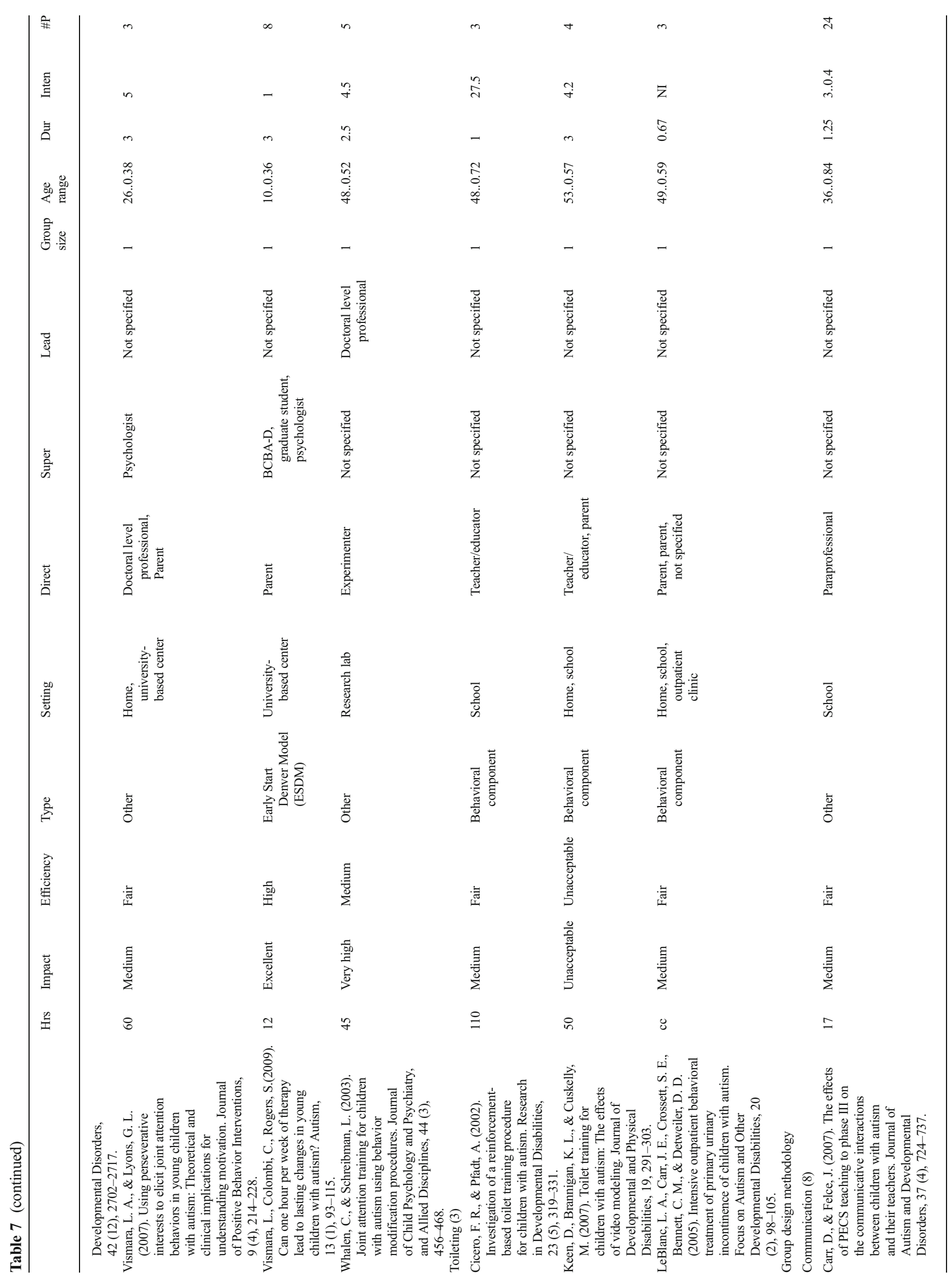




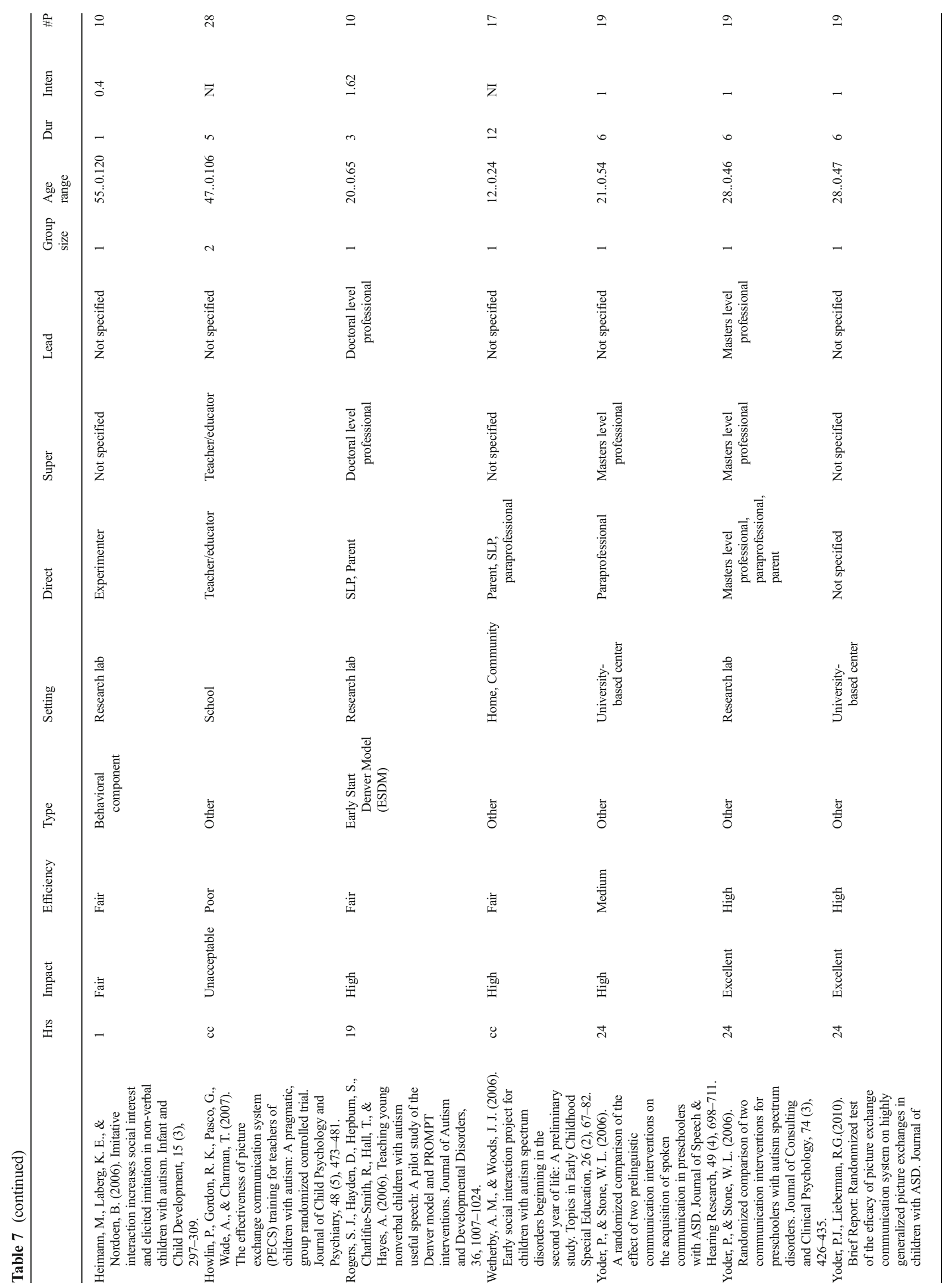




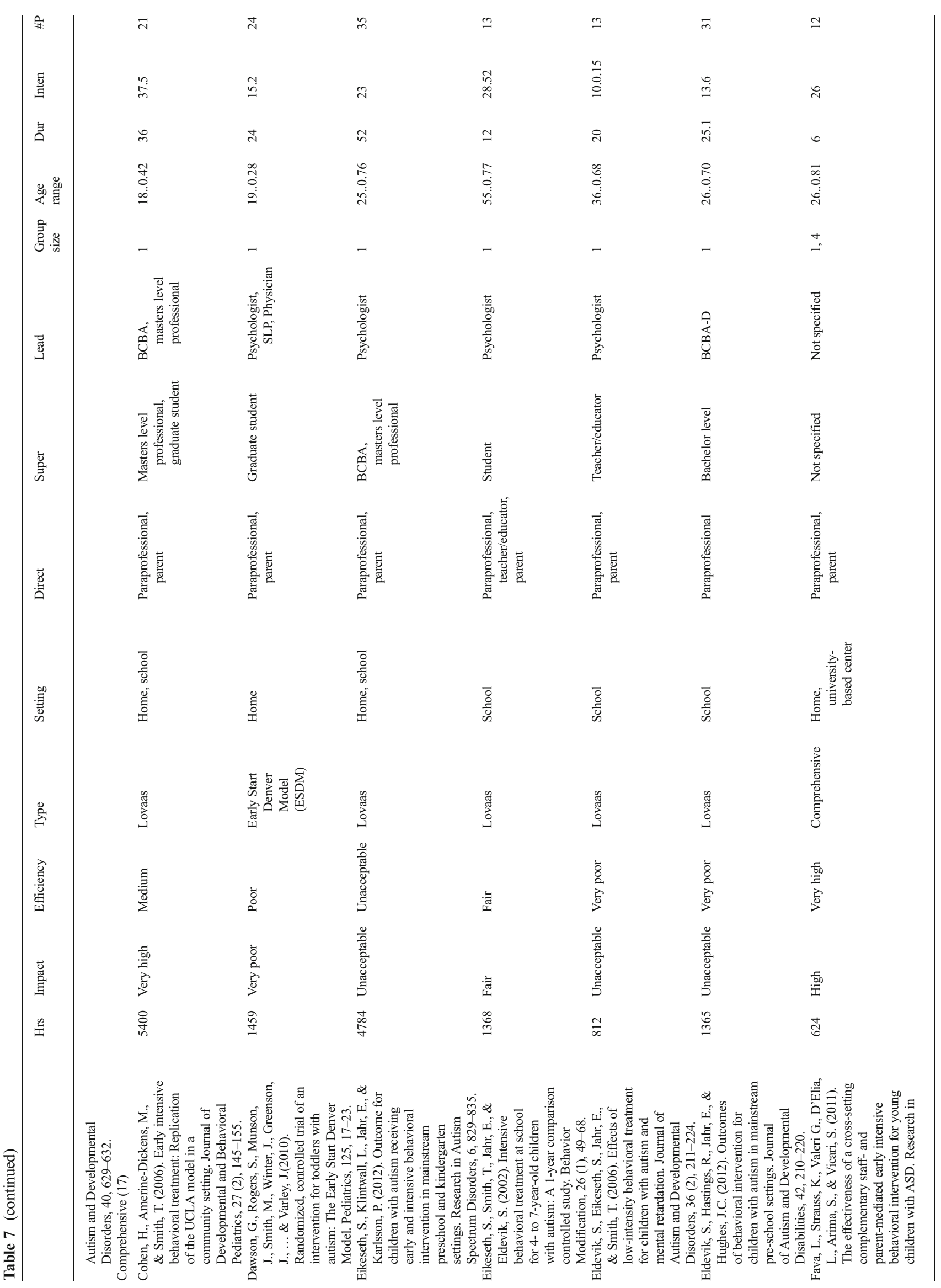




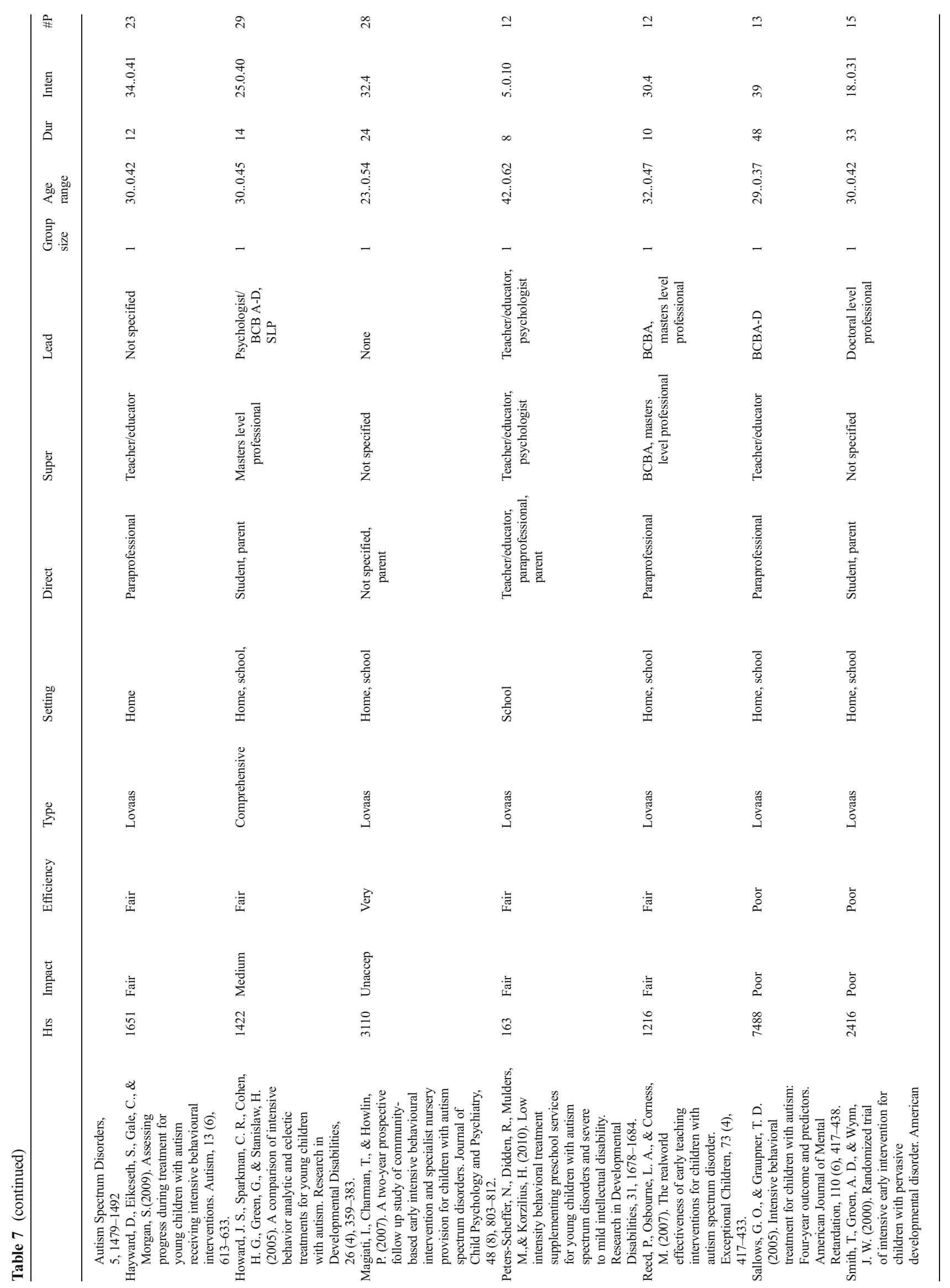




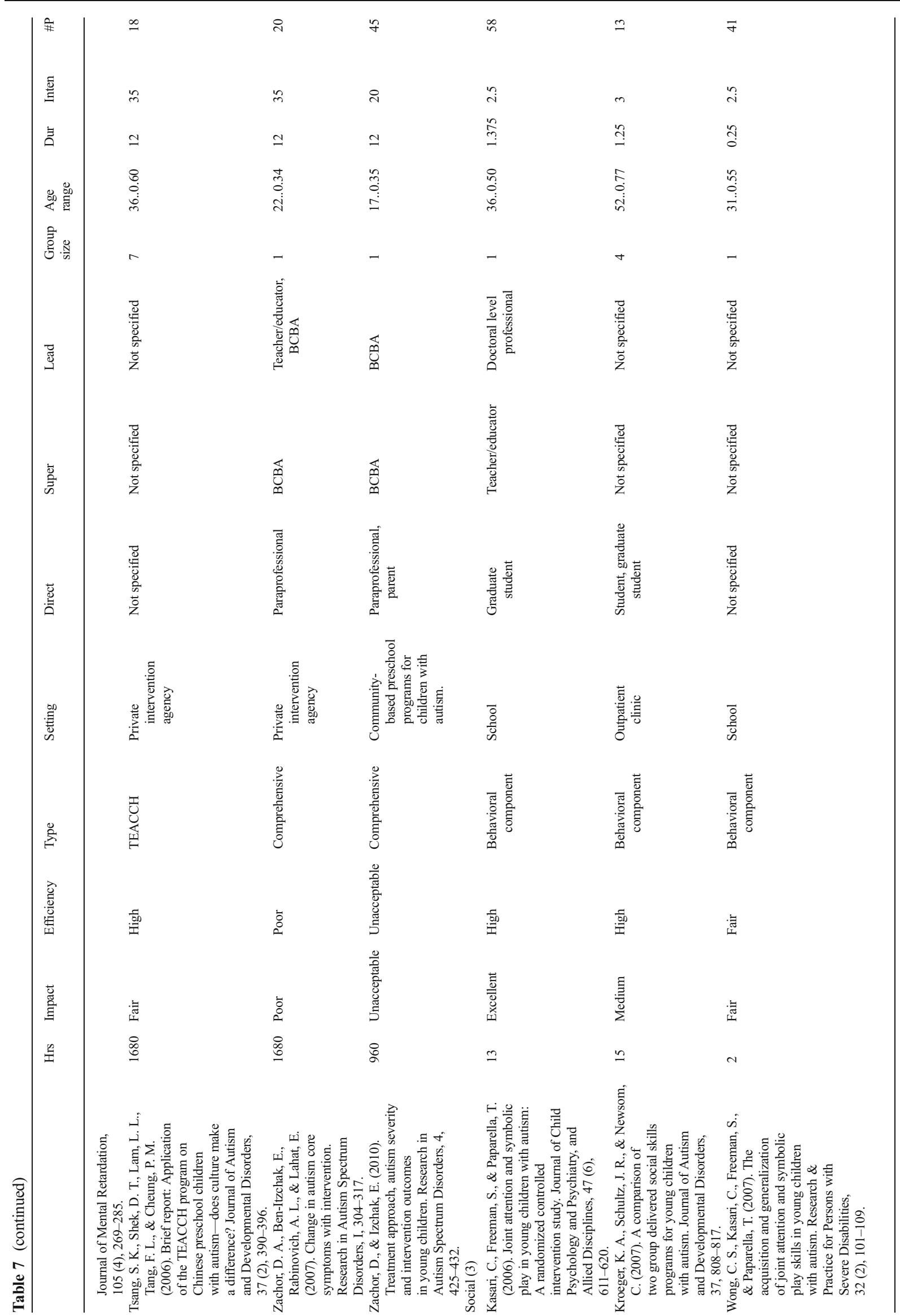




\section{References}

Agency for Healthcare Research and Quality, Effective Health Care Program. (2011). Therapies for children with autism spectrum disorders. Retrieved from: http://www.effectivehealthcare.ahrq.gov/ index.cfm/search-for-guides-reviews-and-reports/?pageaction= displayproduct\&productid $=651$.

American Psychiatric Association. (1980). Diagnostic and statistical manual of mental disorders: DSM-III (3rd ed.). Washington: American Psychiatric Association.

American Psychiatric Association. (2013). Diagnostic and statistical manual of mental disorders: DSM-5 (5th ed.). Washington: American Psychiatric Association.

Autism Speaks (2013). [Tables and map to show autism insurance initiatives across U.S.]. Autism Speaks 2013 State Initiative Map. Retrieved from http://www.autismspeaks.org/sites/default/files/ docs/gr/states 6.24.2013.pdf

Autism Speaks (2014a). The ACA and the autism community. Retrieved from http://www.autismspeaks.org/advocacy/insurance/affordablecare-act/aca-and-autism-community.

Autism Speaks (2014b). The affordable care act and autism: pre-existing conditions. Retrieved from http://www.autismspeaks.org/sites/ default/files/docs/gr/aca.pre-existing.pdf.

Autism Speaks (2014c). The affordable care act and autism: pre-existing conditions. Retrieved from http://www.autismspeaks.org/advocacy/ advocacy-news/nebraska-becomes-36th-state-require-autismcoverage.

Behavior Analyst Certification Board (2012). Health plan coverage of applied behavior analysis treatment for autism spectrum disorder. Tallahassee, Fl.

Berr, J. (2013). How autism can cost families millions. MSN Money. Retrieved from http://money.msn.com/now/post.aspx?post= 00d9751b-dad1-4d2a-b3ea-01287216ce21.

Centers for Disease Control and Prevention. Morbidity and Mortality Weekly Report, March 28th, 2014, 63(SS02);1-21.

Eddy, D. M., \& Hasselblad, V. (1994). Analyzing evidence by the confidence and profile method. In K. A. McCormick, S. R. Moore, \& R. A. Siegel (Eds.), Clinical practice guideline development: methodology perspectives. Rockville: Agency for Health Care Policy and Research, Public Health Service, US Department of Health and Human Services (AHCPR Publication No. 95-0009).

Eikeseth, S. (2008). Outcome of comprehensive psycho-educational interventions for young children with autism. Research in Developmental Disabilities, 30, 158-178.

Eikeseth, S., Smith, T., Jahr, E., \& Eldevik, S. (2002). Intensive behavioral treatment at school for 4- to 7-year-old children with autism: a 1-year comparison controlled study. Behavior Modification, 26(1), 49-68.

Eikeseth, S., Smith, T., Jahr, E., \& Eldevik, S. (2007). Outcome for children with autism who began intensive behavioral treatment between ages 4 and 7. Behavior Modification, 31, 264-278.

Eldevik, S., Eikeseth, S., Jahr, E., \& Smith, T. (2006). Effects of lowintensity behavioral treatment for children with autism and mental retardation. Journal of Autism and Developmental Disorders, 36(2), 211-224.

Eldevik, S., Hastings, R. P., Hughes, J. C., Jahr, E., Eikeseth, S., \& Cross, S. (2009). Meta-analysis of early intensive behavioral intervention for children with autism. Journal of Clinical Child and Adolescent Psychology, 38, 439-450.

Eldevik, S., Hastings, R., Jahr, E., \& Hughes, J. C. (2012). Outcomes of behavioral intervention for children with autism in mainstream preschool settings. Journal of Autism and Developmental Disabilities, 42, 210-220.

Field, M.J. \& Lohr, K.N. (1992). Guidelines for clinical practice: from development to use. Institute of Medicine, Washington, D.C.; National Academy Press.
Ganz, M. L. (2007). The lifetime distribution of the incremental societal costs of autism. Archives of Pediatric and Adolescent Medicine, 161(4), 343-349. doi:10.1001/archpedi.161.4.343.

Harmon, G. (2011). Statement of the American Medical Association to the Institute of Medicine's Committee on Determination of Essential Health Benefits. Division of Legislative Counsel, 25 Massachusetts Avenue NW, Suite 600 Washington, DC.

Holland, J. P. (1995). Development of a clinical practice guideline for acute low back pain. Current Opinion in Orthopedics, 6, 63-69.

Howard, J. S., Sparkman, C. R., Cohen, H. G., Green, G., \& Stanislaw, H. (2005). A comparison of intensive behavior analytic and eclectic treatments for young children with autism. Research in Developmental Disabilities, 26(4), 359-383.

Howlin, P., Magiati, I., \& Charman, T. (2009). A systematic review of early intensive behavioural interventions (EIBI) for children with autism. American Journal on Intellectual and Developmental Disabilities, 114, 23-41.

Long, T. F. (2013). Essential contractual language for medical necessity in children, committee on child health financing. Pediatrics, 132, 39. doi:10.1542/peds.2013-1637.

Lord, C., \& Jones, R. M. (2012). Annual research review: re-thinking the classification of autism spectrum disorders. The Journal of Child Psychology and Psychiatry, 53(5), 490-509. doi:10.1111/j.14697610.2012.02547.x.

Lord, C., Petkova, E., Hus, V., Gan, W., Lu, F., Martin, D., et al. (2011). A multisite study of the clinical diagnosis of different autism spectrum disorders. Archives of General Psychiatry, 69(3), 306-313.

Lovaas, O. L. (1987). Behavioral treatment and normal educational and intellectual functioning in young autistic children. Journal of Consulting and Clinical Psychology, 55, 3-9.

Magiati, I., Charman, T., and Howlin, P. (2007). A two-year prospective follow-up study of community-based early intensive behavioural intervention and specialist nursery provision for children with autism spectrum disorders. Journal of Child Psychology and Psychiatry, 48(8), 803-812.

Matson, J. L., \& Jang, J. (2014). The most commonly reported behavior analytic methods in early intensive autism treatments. Review Journal of Autism and Developmental Disorders, 1(1), 80-86.

McMahon, G.K. (2011). NYS Special Education Impartial Hearing Outcomes. Mahopac, New York: McMahon Advocacy Group. Retrieved from http://www.specialedlawadvocacy.com/NYS\% 20Special\%20Education\%20Impartial\%20Hearing\%20Outcomes. pdf.

Missouri Department of Mental Health (2012). Autism spectrum disorders: guide to evidence-based interventions. http://www. autismguidelines.dmh.mo.gov/.

Myers S., \& Johnson, C.P. (2007). Management of children with autism spectrum disorders. Pediatrics, 120(5), 1162-1182.

National Autism Center. (2009). National standards report: national standards project - addressing the need for evidence-based practice guidelines for autism spectrum disorders. Randolph: National Autism Center, Inc.

National Conference of State Legislatures (2012, August). Insurance coverage for autism. Retrieved from http://www. ncsl.org/issues-research/health/autism-and-insurance-coveragestate-laws.aspx.

National Research Council. (2001). In C. Lord \& J. P. McGee (Eds.), Educating Children with Autism. Washington: National Academy Press.

New York State Department of Health, Early Intervention Program. (1999). Clinical practice guideline: guideline technical report. Autism/Pervasive Developmental Disorders, Assessment and Intervention for Young Children (Ages 0-3 Years), no. 4217. Albany: NYS Department of Health. 
Noyes-Grosser, D. M., Holland, J. P., Lyons, D., Holland, C. L., Romanczyk, R. G., \& Gillis, J. M. (2005). Rationale and methodology for developing guidelines for early intervention services for young children with developmental disabilities. Infants \& Young Children, 18(2), 119-135.

Patient Protection and Affordable Care Act (2010). http://www.gpo.gov/ fdsys/pkg/PLAW-111publ148/html/PLAW-111publ148.htm.

Reichow, B. (2011). Development, procedures, and application of the evaluative method for determining evidence-based practices in autism. In B. Reichow et al. (Eds.), Evidence-based practices and treatments for children with autism (pp. 25-39). New York: Springer.

Remington, B., Hastings, R. P., Kovshoff, H., degli Espinosa, F., Jahr, E., Brown, T., et al. (2007). Early intensive behavioral intervention: Outcomes for children with autism and their parents after two years. American Journal on Mental Retardation, 112, 418-438.

Romanczyk, R. G. (2011). Keynote address. The current state of practice and research in $A B A$ intervention for autism spectrum disorders: context, status, and future directions. Association for Professional Behavior Analysts Annual Conference, Boston, MA.

Romanczyk, R. G., \& Callahan, E. H. (2012). Autism and Pervasive Developmental Disorders. In Vilanayur Ramachandran (Editor in Chief), The Encyclopedia of Human Behavior. Waltham, MA: Academic Press.

Romanczyk, R. G., \& Gillis, J. M. (2004). Treatment approaches for autism: evaluating options and making informed choices. In $\mathrm{Z}$. Dianne (Ed.), Autism: identification, education and treatment (3rd ed.). Hillsdale: Erlbaum.

Romanczyk, R. G., \& Gillis, J. M. (2008). Practice guidelines for autism education and intervention: historical perspective and recent developments. In J. Luiselli, D. C. Russo, \& W. P. Christian (Eds.), Effective practices for children with autism: educational and behavior support interventions that work. UK: Oxford University Press.
Romanczyk, R. G., Turner, L. B., Sevlever, M., \& Gillis, J. (2014). The status of treatment for autism spectrum disorders: the weak relationship of science to interventions. In Lilienfeld, Lohr, \& Lynn (Eds.), Science and pseudoscience in contemporary clinical psychology. NY: Guilford.

Sallows, G. O., \& Graupner, T. D. (2005). Intensive behavioral treatment for children with autism: four-year outcome and predictors. American Journal of Mental Retardation, 110(6), $417-438$.

Schriger, D. L. (1995). Training panels in methodology. In K. A. McCormick, S. R. Moore, \& R. A. Siegel (Eds.), Clinical practice guideline development: methodology perspectives. Rockville: Agency for Health Care Policy and Research, Public Health Service, US Department of Health and Human Services (AHCPR Publication No. 95-0009).

Sheinkopf, S. J., \& Siegel, B. (1998). Home based behavioral treatment of young children with autism. Journal of Autism and Developmental Disorders, 28(1), 15-23.

Virginia House Bill No. 2467, Amendment in the Nature of a Substitute. (2011, May 6).

Woolf, S. H. (1991). AHCPR Interim manual for clinical practice guideline development. Rockville: Agency for Health Care Policy and Research, Public Health Service, US Department of Health and Human Services. (AHCPR Publication No. 91-0018).

Woolf, S. H. (1994). An organized analytic framework for practice guideline development: using the analytic logic as a guide for reviewing evidence, developing recommendations, and explaining the rationale. In K. A. McCormick, S. R. Moore, \& R. A. Siegel (Eds.), Clinical practice guideline development: methodology perspectives. Rockville: Agency for Health Care Policy and Research, Public Health Service, US Department of Health and Human Services (AHCPR Publication No. 95-0009). 